Aus der chirurgischen Ḱlinik zu Basel (Chef: Prof. Dr. W i $1 \mathrm{~m} \mathrm{~s}$ ).

\title{
Zur experimentellen Erzeugung der Struma, zugleich ein Beitrag zu deren Histogenese.
}

\author{
Von Dr. Eugen Bircher, \\ ehemal. Assistenzarzt der chirurg. Klinik zu Basel, zurzeit I. Assistenzarzt der \\ chirurg. Abteilung (Dir. Dr. Bircher) der Kant. Krankenanstalt Aarau.
}

(Mit 40 Abbildungen.)

Daß die Entstehung des Kropfes an das Wasser gebunden ist, kann heute als wissenschaftliche Tatsache gelten. Wir haben die darauf bezuiglichen Beweise in einer letztjährigen Arbeit zusammengetragen, und andere Forscher auf diesem Gebiete, wie Ewald und neuerdings auch $\mathrm{Koll} \mathrm{e}$, sind diesen Anschauungen beigetreten.

Um auf diesem Gebiete weitere Fortschritte zu erzielen, haben wir einer Anregung unseres Chefs, Herrn Prof. Wil ms, gerne Folge geleistet, experimentell zu versuchen, Kropf zu erzeugen und nach dessen Ursachen zu suchen.

Es ist eine speziell in Kropfgegenden bekannte Tatsache, daß nicht nur die Schilddrüsen der Menschen, sondern auch diejenigen gewisser Tierarten kropfig entarten können.

Die diesbezüglichen Iiteraturangaben sind neuerdings in erschöpfender Weise von $\mathrm{Scholz}$ zusammengetragen worden. Er kann nicht weniger als 38 Autoren zitieren, die bei Hunden Kropf konstatieren konnten. Ziemlich häufig wurde der Kropf auch bei Schweinen beobachtet (9 Autoren). Kropf bei Pferden konnte von I9 Beobachtern konstatiert werden. Seltener fand dieser bei Maultieren ( 7 Beobachtungen), Katzen (2 Beobachtungen), Rindvieh (7 Beobachtungen), Schaf (7 Beobachtungen), Antilopen (I Beobachtung), Kamele (I Beobachtung), Maus (I Beobachtung), Löwe (I Beobachtung) ${ }^{1}$ ).

1) Erdheim spricht in seinen Studien über Tetania parathynoprion auch von kropfigen Ratten und Caletti e Perusiui haben kretinöse Hunde beobachtet, $v$. Hansemann einen kropfigen Schakal. 
Wir selbst haben in den letzten Jahren unser Augenmerk auf diese Punkte gerichtet und systematisch die Hunde, die uns in die Hände kamen untersucht. Wir haben uns auch da und dort bei Tierärzten erkundigt, und das Resultat stimmt mit den obigen Forschungen überein. Unter zirka 80 in einer Kropfgegend untersuchten Hunden haben wir 2I gefunden, bei denen unzweifelhaft eine palpable Struma nachgewiesen werden konnte.

Um noch nähere Aufklärıng über das Vorkommen der Struma beim Tiere zu eruieren, habe ich mich mit einem Fragebogen an die aargauischen Tierärzte gewendet. In sehr zuvorkommender Weise ist mir auf alle meine Fragen geantwortet worden.

Daraus ergeben sich nun folgende, nicht uninteressante Tatsachen.

Wie beim Menschen, zeigt sich der Kropf auch an gewisse Gegenden gebunden. Die Tierärzte, welche im Jura praktizieren, haben fast nichts mit dem Kropf bei Tieren zu tun, während er bei den Tieren in der aargauischen Molasse und Triasgegend sehr häufig vorhanden ist.

Am häufigsten tritt er bei Hunden auf, die speziell im Jugendalter von allen möglichen Formen befallen werden, die nur selten spontan verschwinden, läufig auf Jodtherapie zurückgehen. Viele kropfige Hunde werden frühzeitig abgetan. Bei alten Hunden finden sich seltener Kröpfe, die meisten sind damn bösartiger Natur und machen reichlich Metastasen. Pathologisch-anatomisch sind Parenchymkröpfe und Adenome vorherrschend. Kolloidkröpfe und Fibrome kommen cbenfalls vor.

Ziemlich häufig findet sich in Kropfgegenden die Affektion beim Pferd und speziell auch beim Schweine ausgesprochen, die dann zu Atembeschwerden führt. Bei Pferden findet er sich nach den militarischen Schätzungsverbalen in $2-3$ Proz. in einer allerdings leichten Kropfgegend. Seltener ist er bei Katzen und Ziegen anzutreffen, am seltensten bei den Wiederkäuern, es mag dies mit den Nahrungsaufnahme zusammenhängen. Die meisten Kröpfe bei Wiederkäuern waren tuberkulöser Natur.

Bei 3 Hunden, bei denen wir bei der Sektion die Struma entfernt hatten, ergab dic histologische Untersuchung regelmäßig eine Adenombildung mit spärlichem Kolloid, von unsern spätern experimentellen Untersuchungen ein völlig abweichender Befund. 
In den letzten Monaten haben wir bei den Schweinen unserer Krankenhausökonomie ebenfalls auf Schilddrüsen geachtet und können wir bestätigen, daß der Kropf in ziemlich erheblicher Anzahl, durchschnittlich bis zu 50 Proz., vorkommt.

Daß bei Hunden so häufig Kropf beobachtet worden ist, läßt sich leicht und ungezwungen daraus erklären, daß der Hund das am weitaus meistgehaltene Haustier ist, und man am ehesten Gelegenheit nahm, diese Tiere auf die fragliche Affektion hin zu untersuchen.

Kropfige Vergrößerung der Schilddrüse konnten wir bei einem Hirsche konstatieren, während er bei aus der Lüneburger Heide importierten Heidschnucken fehlte.

Ähnlich wie über kropfige Tiere ist auch in denselben Gegenden über kretinisch degenerierte Tiere berichtet worden, so konnte A le $\mathrm{x}$ a $\mathrm{n}$ de $\mathrm{r}$ in Wien neuerdings einen vollständig zum Kretin gewordenen Hund beobachten.

Bei den von uns seit dem Frühjahr Igo8 vorgenommenen experimentellen Untersuchungen haben wir uns von folgenden Fragen leiten lassen:

r. Gelingt es, experimentell bei Tieren Kropf oder Vergrößerung der Schilddrüse zu erzeugen und am besten bei welchen Tieren?

2. Welches ist das kropferzeugende Agens in den betreffenden Kropfwässern?

Wir sind heute in der Lage, auf die I. Frage eine gewissermaßen abschließende Antwort abzugeben, während über die 2. Frage noch weitere Untersuchungen und Tierversuche im Gange sind.

Wir möchten an dieser Stelle betonen, daß unsere Untersuchungen seit dem Frühjahr I 908 völlig unabhängig vom s c h w e i zerischen Nationalkomitee $\mathrm{zum} \mathrm{Studium} \mathrm{der}$ $\mathrm{Kr}$ opffrag e vorgenommen worden sind.

Um Klarheit in einen Teil der Frage zu bringen, haben wir die früher schon ausgeführten Tränkversuche wieder aufgenommen. H. B irch or hatte seinerzeit fünf junge kropflose Hunde mit Kropfwasser, und speziell dem Bodensatz von Kropfbrunnen, in dem die von ihm und Klebs beobachteten Diatomeen und Infusorien am zahlreichsten vertreten waren, 8 Monate lang gefüttert. Als die Tiere getötet wurden, konnten nur normal groBe Schilddrüsen nachgewiesen werden. H. B i r ch e r glaubt, daB die Hunde zu jung gewesen seien, oder daß die fraglichen stäbchen- 
förmigen Organismen durch die Fäulnis des Wassers zugrunde gegangen seien. Im übrigen legt er diesen Versuchen, bei denen speziell kein histologisches Examen gemacht wurde, wenig Wert bei.

Ein ähnlicher Versuch wurde von $\mathrm{Klebs}$ unternommen, welcher Kropfwasser mit reichlichen Naviculäformen mittelst Pravazspritze in den Kropf eines Hundes einspritzte, und derartiges Wasser zugleich verfütterte. Er konnte in 23 Tagen eine Vergrößerung des Lappens konstatieren. Tränkversuche an andern Hunden mit gewöhnlichem Leitungswasser schlugen fehl, und $\mathrm{K} l \mathrm{ebs}$ ist aber geneigt anzunehmen, daB die von ihm gefundenen Mikroorganismen Ursache des Kropfes seien.

Weitere etwas ausgedehntere Versuche sind in dieser Richtung von $\mathrm{L}$ u s t i g und $\mathrm{C}$ a $\mathrm{r} l \mathrm{e}$ in Turin gemacht worden. Sie fütterten Tiere aus kropffreien Gegenden in immunen Orten mit Kropfwasser. Als Objekte dienten ihnen Pferde und Hunde, die in Turin mit Kropfwasser aus dem Aostatale getränkt wurden. Das Pferd bekam nach einigen Wochen eine progressive Vergrößerung der einen Schilddrüse; der eine Lappen wurde exstirpiert, während bei weiterer Tränkung der andere eine Vergrößerung erfuhr, die nach Weglassen des Kropfwassers wieder schwand. Von I3 Hunden konnte nur bei einem eine Vergrößerung des linken, und nachdem dieser exstirpiert worden war, auch des rechten Lappens konstatiert werden, die durch Tränkung mit filtriertem Wasser zum Schwinden gebracht werden konnte.

Bei einem kropfigen Hunde aus einer Kropfgegend konnte ebenfalls weitere Größenzunahme konstatiert werden, die durch filtriertes Wasser ebenfalls zum Schwinden gebracht wurde. Io Tiere, die filtriertes oder gekochtes Wasser erhielten, blieben kropffrei. Nur bei 3 Tieren konnte dabei von einem positiven Erfolge gesprochen werden. Dabei sind auch die mikroskopischen Befunde nicht einer genügenden Würdigung unterzogen worden.

Gerade aber diese Punkte scheinen uns von sehr wesentlicher Bedeutung zu sein und es dürfte immerhin von gröBter Wichtigkeit werden, histologisch die Anfänge der Struma nachweisen und in dieser Beziehung mit den positiven Befunden der histologischen Untersuchung der Struma, wie sie systematisch von $W$ ölf 1 e $r$, Hitzig, Michaud, Langhans, Zielinska u. a. betrieben wurde, vergleichen zu können. 
Bei unseren experimentellen Untersuchungen haben wir zur Tränkung Hunde, Ratten, Neerschweinchen und junge Affen (Rhesus) benutzt. Als Tränkmittel benutzten wir Wasser aus der bekannten Gemeinde Rupperswil. Es ist dies eine Gemeinde in der Nachbarschaft unseres Aarauer Krankenhauses, welche bis zum Jahre I883 59 Proz. Kropf unter der Schuljugend aufwies. Im Jahre I884 änderte sie ihre Wasserversorgung und entnahm das Wasser auf Rat ihres einsichtigen Pfarrers Müller auf Grund der H. B i r c h e r schen Kropfkarte aus einer in der Juraformation jenseits der Aare gelegenen Quelle. Wie wir in einer früheren Arbeit dargetan haben, ist die Kropfendemie von diesem Jahre weg bis zum Jahre I895 auf ro Proz., bis zum Jahre I907 auf 2,5 Proz gesunken. Diese 2,5 Proz. konnten nachgewiesenermaßen auf eingewanderte Kropfige und auf Personen zurückgeführt werden, welche von den alten Sodbrunnen zum Trinken das Wasser verwendeten. Seit einem Jahre ist nun auch das letzte Haus, welches derartige Kropfige beherbergte, das Kosthaus, an die Wasserleitung angeschlossen worden, und es bestehen nur noch einzelne Sodbrunnen. welche das Wasser aus der kropführenden Schicht der Meeresmolasse herbeiführen. Neben diesem Wasser wurde das aus der Meeresmolasse stammende Quellwasser der Stadt Aarau verwendet. Weitere Versuche mit Wasser aus der Triasformation (kropfführend) und der Juraformation (nicht kropfführend) sind im Gange ${ }^{1}$ ).

E w a $1 \mathrm{~d}$ verlangt bei derartigen Versuchen, daß man kropffreie Tiere in kropffreien Gegenden mit Kropfwasser füttere, und als Versuchsobjekte Tiere benütze, die nicht aus Kropfgegenden stammen. Wir halten diese Versuchsbedingungen einerseits für berechtigt, andererseits scheinen sie uns, bevor wir über die ersten Anfänge der Forschung hinaus sind, zu strenge zu sein.

Gerade der weite Transport des Wassers und das längere Stehenlassen scheint dessen Infektionskraft herabzusetzen. Im weitern können Tiere in Kropfgegenden doch sicher so gehalten werden, daß sie je nach Wunsch mit einem gewissen Mittel getränkt werden und nicht anderes erhalten dürfen.

Ganz ähnlich verhält es sich mit der Herkunft der Tiere. Es ist klar, daß man, um ein objektives Resultat zu erhalten, die

I) Nit Triaswasser konnten ebenfalls deutliche Strumen erzeugt werden, während das Jurawasser völlig immun war. (Anmerkung während der Korrektur). 
Versuche an Tieren vornehmen soll, die aus absolut immuner Gegend entstammen, andererseits sollten aber auch Tiere zur Verwendung kommen, bei denen schon bei den Aszendenten eine Struma eventuell vorhanden gewesen ist, so daß eventuell eine gewisse Disposition für die betreffenden Tiere vorhanden sein dürfte. Es kann sich auch nicht un große Zahlen von Versuchen handeln, sondern um kleinere Reihen, die aber auch hauptsächlich histologisch einer genauen Durchsicht unterzogen werden.

Wir haben nun unseren Tieren Aarauer oder Rupperswiler Wasser in roher, gekochter oder filtrierter Form verabfolgt. Das rohe Wasser wurde alle Io-I4 Tage in Rupperswil dem Sodbrunnen entnommen, in Aarau von der Quellwasserleitung und in vorher sterilisierten Fässern nach Basel überführt, wo es an einem kühlen Orte aufbewahrt oder in Aarau selbst verfüttert wurde.

Zur Verfütterung wurde es gekocht (bis 80 bis $100^{\circ}$ ) oder durch den Berkefeldschen Tonfilter durchgelassen, oder durch einen eigenen Apparat, der zirka I2 übereinander liegende Papierfilter enthielt. Der Filterrückstand, sowohl des Berkefeldfilters, wie auch die Papierfilter, welche immer sehr intensive Auflagerungen zeigten, wurden ebenfalls in Milch aufgeschwemmt verfüttert. Tas Wasser wurde immer in kleinen Mengen täglich 2 mal den Tieren verabfolgt.

Auf diese Weise wurde eine Serie von Tieren (Affen, Hunde, weiße Ratten und Meerschweinchen) in Basel gefüttert, eine zweite Reihe wurde in Aarau diescr Fütterung unterzogen. Die Versuche mit der ersten Reihe in Basel können als abgeschlossen gelten, während hier in Aarau der Abschluß nur ein vorläufiger ist und weitere Experimente mit variierenden und andern Versuchsanordnungen in Gange sind.

Dic Versuche in Aarau haben den Vorzug, daß das Wasser täglich frisch von der Leitung weggenommen werden kann, während in Basel immer erst ein Transport mit der Bahn stattzufinden hatte.

Basel selbst kann als teilweise kropfimmuner Ort gelten. Nach der Karte von B i r che r und dessen Berechnungen hatte es im Jahre 18837 Proz. Kropf bei den Rekruten. Es ist dies eine geringe Zahl. In den Jahren als die B i r c h e r sche errechnet wurde, hatte Basel noch seine alte Quellversorgung, welche das Wasser teilweise der rechtsrheinischen Trias, teilweise durch das 
Riehen-Pumpwerk dem intensiv kropfführenden Muschelkalk der Schwarzwälder Trias entnahm. Die neue Grellingerquelle, welche Großbasel versorgt, entstammt aus reinem Jura und ist nicht kropfführend. Es ist auch auffallend, daß die in den Basler Kliniken operierten Kröpfe fast ausnahmslos nicht in Großbasel entstanden, sondern sich in Großzahl aus Kleinbasel oder aus der Endemie von Oberbaden, des Elsasses und des Fricktals rekrutieren. Während unserer assistenzärztlichen Tätigkeit in Basel haben wir auf diesen Punkt geachtet, und auch gefunden, da $B$ viele der Kropfigen sich als aus Kropfgegenden eingewanderte Personen entpuppten.

Wir können daher annehmen, daß die linksrheinische Seite von Croßbasel als kropffreies Gebiet zu gelten hat. Umgekehrt in Aarau befinden wir uns mitten in dem Gebiete der Endemie der Meeresmolasse. Wie wir schon hervorgehoben haben, möchten wir jedoch diesen Punkten keine allzu große Bedeutung beimessen, solange die Tiere in Käfigen gehalten werden.

Die Versuchstiere entstammen verschiedenen Gegenden. Die Affen erhielten wir vom Tierpark Fockelmann in Hamburg-Großborstel, sie entstammen den Küstengebieten Afrikas, sind daher sicher in einer kropffreien Gegend geboren. Es waren durchweg junge Exemplare, welche das Alter von 2 Jahren noch nicht erreicht hatten.

Die Hunde sind in Basel geboren, bei ihren Aszendenten, Eltern, konnte kein Kropf nachgewiesen werden. Sie selbst zeigten bei der Geburt und im Verlauf der ersten Monate, bevor ihnen Kropfwasser zugeführt wurde, niemals palpatorisch irgendeinen Befund, der als Vergrößerung der Schilddrüse aufgefaßt werden konnte. Diese Aszendenten dieser Hunde waren, wie uns Nachforschungen ergaben, schon seit mehreren Generationen in Großbasel, das nach unsern obigen Ausführungen als immun zu gelten hat, ansässig gewesen.

Bei Meerschweinchen haben wir nur in wenigen Exemplaren Fütterungsversuche vorgenommen, die jedoch in keiner Weise irgendein positives Resultat zutage förderten, so daß die Versuche bei diesen Tieren, weil ungeeignet, nicht weitergeführt wurden. Diese Tiere nehmen außerordentlich wenig Wasser zu sich, und decken den Flüssigkeitsbedarf ihres Körpers mehr durch 
die in dem Grünfutter enthaltenen reichlichen Säfte. Wir haben überhaupt bei unsern Versuchen den Eindruck erhalten, daß die Herbivoren nicht besonders geeignet seien, experimentell zur Strumenerzeugung zu dienen, da sie sehr wenig Wasser zu sich nehmen, im Gegensatz zu den durstigen Karnivoren.

In dieser Beziehung müssen wir auch die von uns verwendeten Rhesusaffen als nicht besonders günstige Objekte bezeichnen, die es vorziehen den Durst durch frische Früchte und saftige Gemüse zu stillen und mit Vorliebe die Tränkgefäße ausleeren. Immerhin bei der Sommerhitze kann man konstatieren, daß sie recht erkleckliche Mengen Wasser zu sich nehmen. Die relative Menge ist jedoch lange nicht so groß, wie diejenige bei Hunden.

Als ganz vorzügliches Material sind hingegen die weißen Ratten zu betrachten, die aus den Tierkäfigen der Basler chirurg. Klinik entstammen und deren Aszendenten aus Norddeutschland bezogen in vielen Generationen, meistens mit Milch, niemals mit Kropfwasser, auf dem immunen Boden von Großbasel aufgewachsen sind. Diesen kann man reines Wasser mit Filterrückständen, selbst die Filterpapiere mit den Rückständen, oder die strumigenen Produkte in der Milch vorsetzen. Wir haben denn auch bei diesen Tieren neben Hunden die eklatantesten Erfolge aufzuweisen gehabt.

Wir werden unsere Versuche im nachfolgenden nach Tierarten getrennt behandeln, dazu werden wir stets auch die histologischen Befunde geben, immerhin müssen wir uns vorbehalten, auf die histologischen Befunde, soweit sie für die Histogenese der Struma von Bedeutung sind, speziell auf die feinern Unterschiede noch anderweitig zurückzukommen.

A f f e n. Rhesus, über $1 \frac{1}{2} 2$ Jahre alt. Beginn der Versuche am 2. VI. I908 in Basel.

A f f e I. Kontrolltier, hat nur gekochtes Wasser erhalten, starb am I4. VI. Igo8 infolge Durchfällen, da er sich von der Reise von Hamburg nach Basel nicht erholte. Im Vergleich zu den anderen Tieren ist keine Abmagerung zu konstatieren. Der Sektionsbefund zeigt nirgends krankhafte Prozesse.

Röntgenologisch sind die Epiphysenlinien an sämtlichen Röhrenknochen noch erhalten. Die Knochenkerne von Hand- und Fußwurzel sind überall vorhanden.

Die Schilddrüse wird zur histologischen Untersuchung mit der Trachea herausgenommen. Beide Lappen haben links und rechts die- 
selbe Größe. Die Lappen sind I links bzw. Io mm rechts lang, I Io mgr schwer, 4 bzw. $5 \mathrm{~mm}$ dick und $2 \mathrm{~mm}$ breit, I5o mgr schwer. Ihr makroskopischer Bau zeigt nichts Besonderes. Auf Schnitt haben sie granuliertes Aussehen (Fig. I).

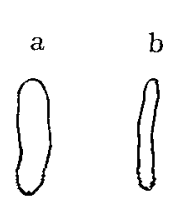

Fig. I.

a von vorn.

Histologischer Aufbau. Färbung Hämatoxylin-Eosin, v a n Gieson. Härtung Alkohol. Celloidineinbettung (Fig. 2).

Auf Schnitt sieht man bei schwacher Vergrößerung einen feinen lobulären Bau. Bindegewebige Septen trennen die Lobuli, welche $1 / 2 \mathrm{~mm}$ Durchmesser haben, voneinander $\mathrm{ab}$.

b von der Seite. Leitz, Objektiv 3, Okular 3. Follikel steht an Follikel nebeneinander angeordnet. Dieselben haben meist eine runde bis ovale Form und sind mit schön rot gefärbtem Kolloid angefüllt, welches bis an den Epithelbelag herantritt. Die Follikel stehen pfahlbauförmig angeordnet, ihre Wände können sich berühren oder sind da und dort durch eine feine Schicht Bindegewebe mit dünnen spindelförmigen Zellen voneinander getrennt.

Dieses Bindegewebe kommt am

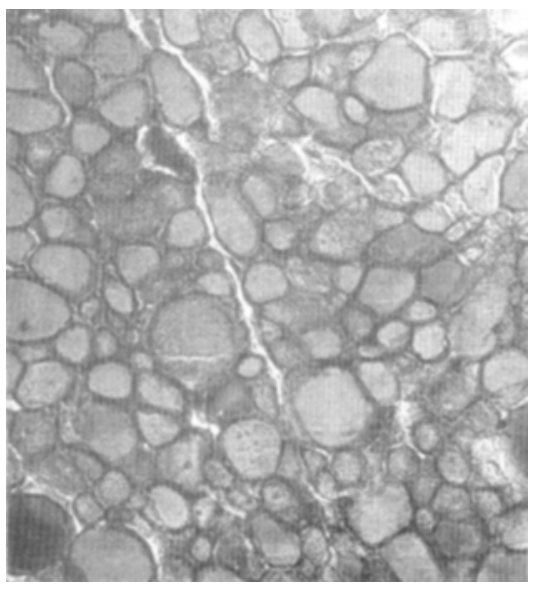

Fig. 2 . ausgesprochensten in den Randpartien vor, während die zentralen Partien gar keine bindegewebigen Stränge aufweisen. In den Randpartien kann das Bindegewebe ganze Follikel umfassen. Die Größe der Follikel variiert im Durchmesser zwischen Io-Ioo $\mu$.

Neben dem Bindegewebe finden sich perifollikulär lichte Partien und ganz vereinzelt solide Zellstränge. Ausbuchtungen oder Erhebungen des Epithelbelages kann nirgends nachgewiesen werden. Der Epithelbelag ist regelmäßig scharf begrenzt, und zeigt mit den soliden Zellpartien keinen $\mathrm{Zu}$ sammenhang. Gefäße sind in sehr beschränktem Umfange vorhanden, und finden sich da und dort zwischen den Follikeln.

Bei stärkerer Vergrößerung Obj. 7, Ok. 3, zeigt der überwiegende Teil des Epithels einen flachen Bau, der an einzelnen Partien zylindrisch werden kann, nirgends jedoch durchweg zylindrischen Charakter annimmt. Die Größe der Zellen beträgt durchschnittlich in Länge und Breite $1,6-2 \mu$. Der Zelleib ist hell, scharf konturiert am Rande. Die Kerne sind rund, nehmen jedoch hier und da eine längsovale Gestalt 
an. Sie nehmen einen großen Teil des Zelleibes ein. Ihr Durchmesser beträgt durchschnittlich I $\mu$. Sie stehen schön in Reihen angeordnet, und es beträgt ihr Abstand voneinander I, häufig jedoch auch 2 Kerndurchmesser.

Der Zellwandbelag in den Follikeln ist stets einschichtig angeordnet. Wandausstülpungen oder papilläre Erhebungen sind keine vorhanden. Verdoppelung der Wände ist nicht zu konstatieren. In den soliden Zellpartien ist eine follikuläre Anordnung der Zellen vorhanden, so daß oft ein feines zentrales Lumen zu sehen ist. Die Zellen dieser Partien sind meist kubischer Natur. In soliden undifferenzierten Partien sind die Zellen polyedrisch, Ein feines Fasernetz von Bindegewebe umgibt die Follikel, so besteht auch die Kapsel aus einer schmalen bindegewebigen Schicht.

Der Follikelinhalt ist stark lichtbrechend und steht an einzelnen Stellen etwas von der Zellwand ab; er ist von Vakuolen durchsetzt und macht da und dort den Eindruck, als ob es von einem fädigen Gerüstwerk durchsetzt wäre.

Bei OOlimmersion finden sich in den Kernen, deren Rand ziemlich scharf gefärbt ist, I-2 Nukleoli' ${ }^{1}$ ) von konstant bleibender Größe. Die Kernmembran weist vereinzelte Zacken auf. In den vereinzelten soliden Partien sind die Kerne etwas intensiver gefärbt und können keine Nukleoli nachgewiesen werden.

Das Bild entspricht dem mormalen Bau der Schilddrüse.

Affe 2, gestorben am 25. VII., nachdem er $6 \frac{1}{2}$ Wochen mit rohem Wasser der Aarauer Leitungsquelle gefüttert worden war. Exitus an Körperschwäche. Die Autopsie der wenig abgemagerten Leiche ergibt vereinzelte Knötchen von kaum Erbsengröße in der Bauchhöhle, die histologisch kein Anzeichen von Tuberkulose darbieten.

Röntgenologisch zeigt die Untersuchung keine abweichenden Befunde vom normalen Tier I.

Die Schilddrüsen, zu beiden Seiten der Trachea gelegen, sind im Vergleich zu I wesentlich vergrößert und bilden längliche, walzenförmige Gebilde. Ihr Bau ist lobulär, granuliert, auf Schnitt schön gefärbt. Die Größe beträgt links $16: 5: 4 \mathrm{~mm}$, rechts $\mathrm{I}_{7}: 6: 3$ (Fig. 3). Das Gewicht beträgt 440 und $430 \mathrm{mg}$.

$\mathrm{H}$ is to $\mathrm{log}$ is cher $\mathrm{Au} \mathrm{fb}$ a u. Hämatoxylin-Eosin. Alkoholhärtung.

Bei schwacher Vergrößerung zeigen die Randpartien einen rein follikulären Bau, aus runden und ovalen Follikeln bestehend. Die Follikel stehen dabei schön in Reihen angeordnet, mit ihren Wandungen

I) Um Mißverständnissen vorzubeugen. möchten wir bemerken, daß wir zwischen Kernkörperchen nnd Chromatinkörnern keine scharfe Unterscheidung gemacht haben, da die von uns angewandte Färbung eine durchgehende Trennung nicht zuließ. 
einander berührend. Die Größe der Follikel ist im Durchmesser eine verschiedene, die größten haben einen solchen von $90 \mu$, im Durchschnitt ist er bei der Großzahl derselben zwischen 10-50 $\mu$. Zerstreut finden sich in den Follikeln papillenartige Zellverbände und Wandvorsprünge in das Lumen, diese sind nicht besonders häufig. Der mehr normale

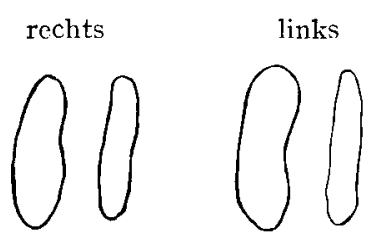

Fig. 3. follikuläre Bau ist am ausgesprochensten in den Randpartien, je mehr man gegen das Zentrum des Lappens zu kommt, desto zahlreicher werden die kleineren Follikel und papilloforme Wandvorsprünge. In diesen Partien sind das solide undifferenzierte Zellgewebe und solide Follikelpartien am reichhaltigsten vertreten, und die mit Lumen versehenen Follikel treten sehr stark zurück. Die Epithelwandungen sind nicht mehr scharf unter sich und von den soliden Zellhaufen zu scheiden.

In diesen Partien findet sich ganz selten und vereinzelt, hier und da ein schlauchförmiges, längliches Gebilde, dessen Epithelbelag durch eine intensivere Zellfärbung vor den andern, speziell den dem Rand zu gelegenen Follikeln hervortritt, welche eine schwächere Färbung haben.

Die Lumina der Rand-

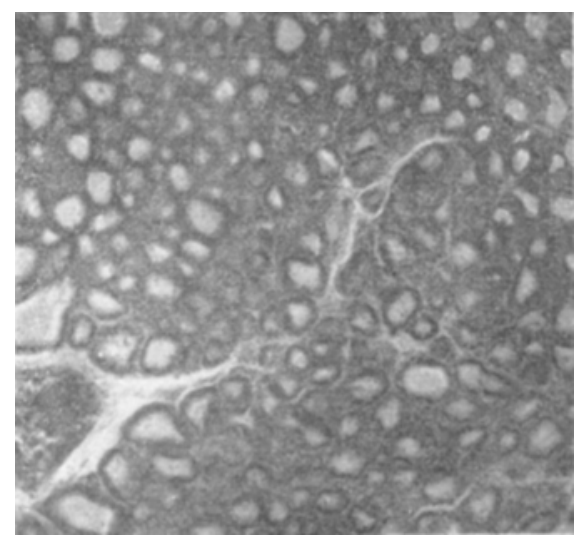

Fig. 4. follikel sind mit intensiv rot gefärbtem Kolloid gefüllt, während in den mehr zentralen Partien der Kolloidbelag ausgefallen ist, oder eine ganze helle Färbung zeigt. Die Bindegewebskapsel ist am Rande dünn und ganz feine Streifen dringen als schmale Stränge in das Gewebe ein.

Bei stärkerer Vergrößerung zeigen die Zellen der Randpartie zum Teil eine flache Form, sind andererseits kubischer $\mathrm{Na}$ tur und durch eine feine gegen das Lumen zu hier und da nicht scharfe Linie abgegrenzt. Ihre

Größe beträgt im Durchschnitt 3-4 $\mu$. Die Kerne sind rund, bläschenförmig, mit einem Durchmesser von I-2 $\mu$, haben eine intensiv gefärbte Membran und 2-3 Nukleoli zum Inhalt. Einzelne Kerne, ungefähr $2 / 5$, sind stäbchenförmig und stehen senkrecht zum Lumen, sie sind hier und da oval, etwas verklumpt und durchschnittlich sehr intensiv gefärbt. In diesen Partien ist der Zellrand nicht mehr scharf und deutlich, und das Protoplasma zeigt nach außen eine Auffaserung. 
Die Kerne sind linienförmig angeordnet, der Abstand beträgt bis zu r Kerndurchmesser.

In den soliden undifferenzierten Zellpartien sind die Zellen polyedrisch, die Kerntinktion ist eine verschieden intensive. Die Nukleoli sind zahlreicher, häufig 5-8, und zeigen eine sehr intensive Färbung. In den soliden Follikeln sind die Zellen von zylindrischer Form und haben eine intensive Färbung. Sie sind in Reihen angeordnet. Die Kerne sind ebenfalls intensiv gefärbt und enthalten zahlreiche Nukleoli. In den zylindrischen Zellen, die nach dem feinen, punktförmigen Lumen zu scharf abgegrenzt sind, ist der Kern basal gelegen. Der Zellbelag ist mehrschichtig und geht gewöhnlich ohne Grenze in die indifferenzierten soliden Partien über, so daß oft 3-5 Zellschichten einen derartigen Follikel bilden helfen. Kolloid als Inhalt mit Vakuolen durchsetzt ist da und dort nachzuweisen, fehlt jedoch häufig.

In den vereinzelten, schlauchförmigen Gebilden ist der Zellbelag nicht scharf gegen das umliegende Gewebe abgrenzbar, und man sieht einzelne Fortsätze in das umgebende Gewebe sich fortsetzen.

Je mehr man den zentralen Teilen der Drüse zukommt, desto zahlreicher sind die mit Zylinderepithel versehenen Follikel mit basalem Zellkern, dabei ist der Zelleib mit einem fädigen Gerüst versehen, das Protoplasma rötlichblau tingiert. In diesen Partien finden sich auch äußerst kernreiche Papillen, welche direkt aus dem soliden Gewebe mit 20 und mehr Zellen in das Follikellumen eintreten. Dabei sind die vereinzelten Schläuche mit zahlreichen Kernen im zylindrischen Epithelbelag vorhanden. Die Kerne liegen in diesen Gebilden nicht immer ganz basal; sondern sind häufig gegen die Mitte zu verschoben, so daß auch der Zellbelag ein unregelmäßiger wird und die Lumengrenze des Schlauches von seiner Schärfe verliert. Die Kerne sind zum großen Teile rund, aber neben $2-3$ runden Kernen findet sich da und dort ein mehr länglich gebauter, ovaler, sog. Schaltkern. Die Wand dieser schlauchförmigen Gebilde, aus den soliden undifferenzierten diffusen Zellhaufen bestehend, hat an einer Stelle die Tendenz, sich zu einem regulären Epithelbelag umzubilden. Derartige Bilder wiederholen sich da und dort. Die Kerne stehen dabei sehr enge nebenund übereinander, und nicht wie bei den soliden Gebilden oder Follikeln in einem gewissen Abstand.

Inmersion zeigt heller und dunkler gefärbte Kerne, und scharfe Abgrenzung der Zellen hauptsächlich in den Rand- und follikulären Partien. In den schlauchförmigen Gebilden sind die Kerne, wie auch die Zelle, da und dort aufgefasert, unscharf begrenzt und unregelmäßig gebaut. Besonders die Schaltkerne sind sehr intensiv gefärbt, lassen gewöhnlich keine Nukleoli mehr nachweisen, die Kerne sind dabei etwas klumpig geworden. In den soliden Partien und den schlauchförmigen Gebilden sind die Kerne etwas intensiver gefärbt, die Nukleoli nicht so intensiv hervortretend und mehr randständig als in den follikulären Randpartien. 
Das Gewebe ist ziemlich intensiv da und dort mit großen und kleinen Blutgefäßen, strotzend mit Blutkörperchen gefüllt zu sehen, sehen, so daß dieses sogar hier und da ins Zwischengewebe durchtritt.

Das Gesamtbild macht den Eindruck einer Hyperplasie des soliden wie auch des follikulären Gewebes. Die schlauchförmigen Gebilde würden dementsprechend als die Anfänge der $\mathrm{H}$ i t z i g-M i c h a u dschen Bilder zu deuten sein.

A f f e 3, gest. am I2. VIII., nachdem er Io Wochen mit Aarauer Wasser, roh, gefüttert worden ist. Der Affe starb an Schwäche, sei es, daß er sich nicht akklimatisieren konnte, sei es, daß Durchfälle der letzten I4 Tage ihn zum Verenden kommen ließen. Eine spezielle Todesursache konnte die Autopsie nicht ergeben.

Röntgenologisch war an den Epiphysen nichts besonderes nachzuweisen.

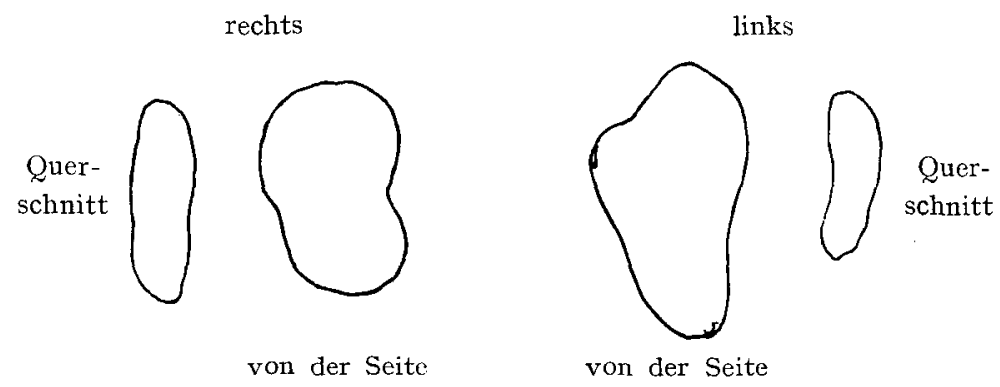

Fig. 5.

Die Schilddrüse, zu beiden Seiten der Trachea gelegen, ist stark auf das Doppelte vergrößert. Bei der Palpation ist sie an einzelnen Stellen etwas stärker anzufühlen, im ganzen ist sie jedoch weich. Auf Schnitt ist sie körnig granuliert gebaut, lobuläre Zeichnung deutlich vorhanden. Der rechte Lappen mißt 20:15:6 mm und wiegt $720 \mathrm{mg}$, der linke Lappen 27:17:5 700 mg, Gewicht (Fig. 5).

$\mathrm{H}$ is tologis cher A u f bau. Hämatoxylin-Eosin $v$ a n Gieson. Entspricht dem Baue von Affe 2 (Fig. 4).

Gegen das Zentrum der Lappen findet sich eine Zunahme der soliden Zellstränge und Follikelbildungen, unter denen sich eine Anzahl (5-6) schlauchförmiger, intensiv gefärbter Gebilde finden, die sehr kernreich und da und dort ein mehrschichtiges zylindrisches Epithel besitzen. In den Lumen sind papilläre Erhebungen anzutreffen.

van $\mathrm{G}$ i e s o n zeigt einen lobulären Bau, durch feine Bindegewebsstränge voneinander getrennt.

Bei starker Vergrößerung sind die Kerne in der Mehrzahl bläschenförmig, können vereinzelt eine längsovale Gestalt annehmen. Ihre Anordnung ist eine unregelmäßige. In den spaltförmigen Lumen der Schläuche ist oft kein Inhalt vorhanden und die Zellen sind 
sehr unscharf begrenzt, ihre Kerne können hier und da eine unregelmäßige Form annehmen und sich berühren. Der Inhalt der Follikel ist ein schön rotes Kolloid; der Epithelbelag ist kubisch, die Kerne sind voneinander getrennt.

Das Gesamtbild zeigt eine deutliche Zunahme des soliden und undifferenzierten Gewebes, dabei hat auch eine Vermehrung der Follikel und eine geringe des bindegewebigen Stromas stattgefunden.

Affe 4 erhielt 4 Monate Seite vorn lang Rupperswiler Wasser in

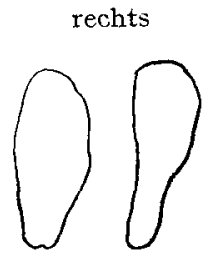
rohem Zustande. Gestorben am I. X. Igo8. Die Autopsie ergab tuberkulöse Lymphdrüsen im Abdomen und vereinzelte tuberkulöse Herde in beiden Lungen. Als Todesursache kann Tuberkulose angenommen werden.

Röntgenologisch sind die Epithellinien genau in demselben $\mathrm{Zu}-$ stande wie bei Affe I. Die Schilddrüsen zu beiden Seiten der Trachea als längliche Lappen haben an Gewicht wie an Größe zugenommen. Der rechte Lappen mißt $17: 6: 7 \mathrm{~mm}$, der andere $19: 8: 7$. Gewicht 560 und $580 \mathrm{mg}$ (Fig. 6).

Makroskopisch zeigen die Schnitte keine deutlich nachweisbare lobuläre Bildung; hingegen können diverse größere und kleinere Lumina konstatiert werden, von durchschnittlich $1 / 4 \mathrm{~mm}$ Durchmesser.

$\mathrm{H}$ is tologis cher $A$ u f b a u. Färbung Hämatoxylin-Eosin. v a n Gi e s o $n$ (Fig. 7). Schwache Vergrößerung.

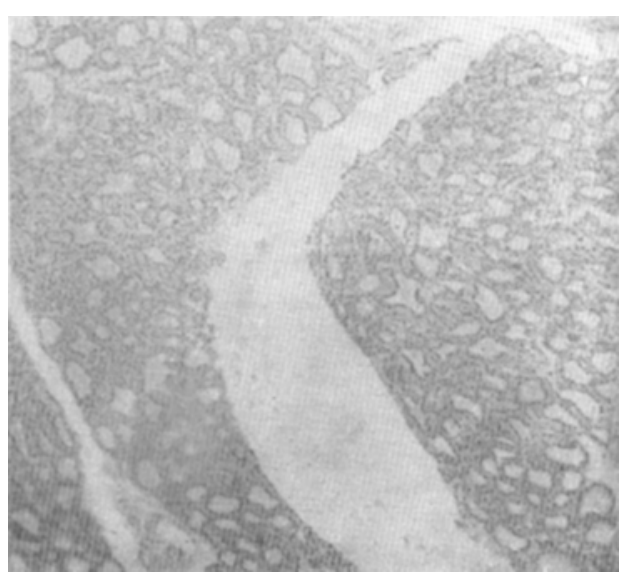

Fig. 7 .

Die Färbung ist bei Obj. 3, Ocular 3, an den verschiedenen Stellen des Präparates eine verschiedene, es treten einzelne sehr intensiv gefärbte Knötchen hervor, welche eine Größe bis zu I40 $\mu$ Durchmesser haben. Diese Knötchen sind durch feine Bindegewebsstreifen vom übrigen Gewebe abgetrennt. Dabei finden sich in ihnen reichlich solide Stränge und solide Follikelanlagen.

Die Lappen zeigen am Rande schön ausgebildete runde oder ovale Follikel, deren Größe im Durchmesser bis zu I20 $\mu$ steigen kann. Die 
großen Follikel sind seltener anzutreffen; während kleinere bei $80 \mu$ Durchmesser recht zahlreich sind. Die Epithelschicht ist an den meisten Stellen flach, kann jedoch auch kubisches Gepräge annehmen. Der hellrot gefärbte Lumeninhalt ist zum Teil wandständig, teilweise zeigt er sich von dem Rand retrahiert und nur mit feinen Fortsätzen im $\mathrm{Zu}$ sammenhang. Wie bei Affe 2 und 3 ist gegen das Zentrum der Schnitte eine Abnahme der normalen und eine Zunahme der soliden Follikel und Zellstränge zu konstatieren.

Die Follikel werden hierbei kleiner und die Epithelschicht wird dicker und kann sogar mehrschichtig werden. Neben diesem Aufbau finden sich in diesem Gewebe verschieden geformte bläschenartige Hohlräume zerstreut vor, in denen Wanderhebungen und papillenartige Vorsprünge ins Lumen vorkommen können. Diese Hohlräume können längere und kürzere schlauchförmige Fortsätze haben. In diesen Gebilden, wie auch da und dort in den Follikeln fehlt ein besonderer Inhalt im Lumen, oder sind sehr stark lichtbrechende Partien vorhanden. Blutgefäße sind an diesen Stellen größere und kleinere, in ziemlich reichlicher Intensität vorhanden; in einem Gefäßlumen können kolloide Schollen nachgewiesen werden. Die Bindegewebskapsel um den ganzen Lappen ist sehr zart und sendet feine, dünne, strangartige Fortsätze entlang den Blutgefäßen in das Gewebe.

In den oberen Partien der beiden Lappen sind die normal gebildeten Follikel am reichlichsten vertreten, während nach abwärts sie an Zahl abnehmen, und in den mittleren Partien solide Zellhaufen und Follikel stark vorherrschend sind, und hier die feinen spaltförmigen Gebilde am zahlreichsten vertreten sind.

In diesen Gebilden ist der Zellbelag durchwegs sehr hoch zylindrisch, kann sich da und dort verdoppeln und vermehren, und in die soliden Gewebspartien übergehen. Je unförmiger diese Gebilde sind, desto höher wird das Epithel. Bei starker VergröB eru ng zeigen sich die Kerne äußerst intensiv gefärbt. In den Zellen sind sie meist basal gelegen, können jedoch auch gegen das Lumen zu ihre Lage haben. Die Zellen sind ungefähr $2 \mu$ breit und bis zu $6 \mu$ hoch. Der Kern hat einen Durchmesser von I,5 $\mu$, und der Abstand zwischen den einzelnen sehr zahlreichen Kernen beträgt gewöhnlich $1 / 4$ Kerndurchmesser. Die Kerne sind in der Mehrzahlrund bläschenförmig, auf I0-I2 solcher Kerne kann ein unförmiger, länglich ovaler Kern entfallen. An Stelle des kolloiden Lumeninhalts, kann man da und dort Zellinhalt aus dem Protoplasma des Epithels haben. Ganz vereinzelte Schläuche zeigen eine völlig unregelmäßige Zellanordnung, und dabei sind auch die Kerne eckig und ausgezackt worden. Zwischen diesen Schläuchen findet sich fein zerstreut ein solides Zellgewebe von feinen Bindegewebsfasern durchsetzt.

Die soliden Zellstränge bestehen aus einem sechseckigen, polyedrischen oder auch kubischen Epithel, und der Zellkern nimmt da und 
dort die ganze Zelle ein. Die Kerne haben einen Abstand von durchschnittlich einen ganzen Zelldurchmesser. In den soliden Partien wechseln heller gefärbte mit dunkler gefärbten Kernen untereinander $\mathrm{ab}$, je nachdem variiert auch die Zahl der Nukleoli. Die Zell- wie Kernmembran ist in verschiedener Deutlichkeit zu konstatieren.

In den rein follikulären Randpartien ist das Epithel flach, kann aber auch, wie einzelne Stellen beweisen, kubischer Natur sein. Die Kerne stehen in Reihen angeordnet in der Mitte der Zelle, ihr Abstand voneinander beträgt durchschnittlich mindestens I-2 Kerndurchmesser. Ihre Tingierung ist variierend. Die Zellgrenzen sind scharf, zum Unterschiede von den schlauchförmigen Gebilden.

Neben diesen einschichtigen Follikeln könnenda und dort mehrschichtige regulär gebaute Follikel gefunden werden, die sich äußerst scharf von den soliden Zellanhäufungen mit ihrem unregelmäßigen Baue unterscheiden. Diese Follikel stehen in regulär ausgebildeten Reihen nebeneinander. Die Kerne zeigen mehrere Nukleoli und da und dort ein fädiges Gerüstnetz. Einzelne Kerne haben eine längliche Gestalt angenommen und liegen in den plattenförmigen Zellen dem Lumen parallel. In vereinzelten Follikellumina finden sich von der Wand losgelöste kernlose, doch intensiv gefärbte Zellen, welche neben dem Kolloid vorhanden sind.

Wie in den mittlern Partien eines Lappens, so finden sich auch in den untern Teilen die unregelmäßig gebauten, schlauchförmigen, sehr zahlreichen Gebilde etwas intensiver vorhanden als in den obern Lappenteilen. Die Wandungen dieser Bläschen werden weder nach dem Lumen $z u$, noch gegen die soliden Zellhaufen scharf abgegrenzt. Der Kern wie der Zellbau weisen starke Irregularitäten auf. An einzelnen Stellen kann jedoch aus diesen Partien eine beginnende Differenzierung von Follikeln konstatiert werden.

Der Übergang des indifferenzierten Gewebes kann scharf gegen die soliden Follikel gegeben werden, ebenso findet sich eine scharfe Scheidung der normalen Follikel gegenüber den schlauchförmigen Gebilden. Solide Zellhaufen finden sich in sehr intensiver Weise ausgebreitet zwischen den Bläschen vorhanden. Diese mit schlauchförmigen Fortsätzen versehenen Bläschen können auf gut 25 Schnitten serienweise stets an derselben Stelle und von derselben Form nachgewiesen werden. Ebenso lassen sich die in ihrem Lumen vorkommenden papillären Exkreszenzen als Stränge auf mehreren Schnitten verfolgen. Die Zellen derselben nehmen an Zahl zu und so vergrößern sich die Papillen, so daß sogar das Lumen eine andere Form annehmen muß. Die Papillen bestehen aus unregelmäßig konturierten Zellen und Kernen, bis zu 20 an der Zahl, welch letztere eine mehrkantige und eckige Form haben, je zahlreicher die Papillen in den einzelnen Lumina werden, desto unregelmäßiger wird auch ihr Bau.

Die I $\mathrm{mmersion}$ zeigt keine wesentlichen Differenzen bei den 
verschiedenen Kernen. Je heller die Kerne gefärbt sind, desto zahlreicher sind die Nukleoli vorhanden. Die Schläuche und Papillen zeigen keine besonderen Einzelheiten.

In den soliden Zellhaufen zwischen den Bläschen können da und dort hellere, feinfädige Partien unterschieden werden, welche als feines Bindegewebe angesprochen werden müssen, wie es auch die normalen Follikeln umgibt.

Von den schlauch- und bläschenförmigen Partien erhält man den Eindruck, da $\beta$ sie einem frischen gewucherten Gewebe angehören, welches hyperplastisch geworden ist, und durch Papillen eine Vergrößerung erfahren hat. Das ganze histologische Bild erweckt den Eindruck, daß es sich dabei um ein Wachstum der parenchymatösen Anteile über das normale Grenzgebiet hinaus im Sinne einer beginnenden Struma handelt.

Aff e 5. Exitus am I8. X. I908. 5 Monate mit rohem Rupperswiler Quellwasser gefüttert. Tod an Schwäche eingetreten, nachdem der Affe in den letzten 4 Wochen an starken Durchfällen gelitten hatte. Überall waren die Lymphdrüsen stark angeschwollen, die jedoch histologisch sich als reine Hyperplasie erwiesen. Der Affe war stets schwach und kränklich gewesen.

Die Schilddrüsen sind auf beiden Seiten der Trachea vergrößert. Auf Schnitt zeigen sie eine körnige Granulierung. In der Dicke ist ebenfalls eine Zunahme zu konstatieren. Das Gewicht der beiden Lappen beträgt 680 bzw. 7Io mg. Knötchen sind darin keine nachweisbar (Fig. 8). Die Größe beträgt 26:6:4 $\mathrm{mm}$ und 24:7:4 mm.

Röntgenologisch kann ein starkes Klaffen sämtlicher Epiphysenlinien konstatiert werden.

Die histologische Untersuchung dieses Tieres zeigt dieselben Veränderungen wie Affe 4 nur in einem wesentlich geringern Maßstabe. Speziell die Follikel zeigen sich an verschiedenen Stellen, von einem lichten Gewebe auseinander gedrängt. Solide Zellpartien sind zurücktretend, ebenso das zylindrische Epithel.

Ein großer Teil der Schilddrüsen besitzt einen normalen Bau, an einzelnen Stellen kann jedoch eine beginnende Gewebswucherung, speziell des Parenchyms, konstatiert werden.

A f $f$ e 6 erhielt 6 Monate lang erhitztes Aarauer Wasser. In den letzten 2-3 Monaten litt er infolge der Kälte an starken Durchfällen. Tod am 28. XII. Igo8. Beginnende Pneumonie. Röntgenologisch sind die Epiphysenlinien etwas enger geworden.

Auf den Seiten der Trachea, etwas nach hinten gelegen, finden sich Schilddrüsenlappen von länglich wurstförmiger Gestalt. Die Farbe ist schön rosarot. Läppchen sind keine $z u$ sehen. Die Größe beträgt links 9:3: I,5 mm, 90 $\mathrm{mg}$, und $\mathrm{I} 3: 4: 2$, Ioo $\mathrm{mg}$ links (Fig. 9).

Im Schnitt ist ein lobulärer Bau deutlich. Daneben sind da und dort feine Lumina nachzuweisen. Histologis ch schwache Vergrö $B$ erung. 
Das Gewebe besteht durchweg aus schönen ovalen oder runden Bläschen, die einen Durchmesser von 15-120 $\mu$ haben. Die Mehrzahl schwankt zwischen $60-80 \mu$. Diese follikulären Bläschen sind in Reihen angeordnet, und Bläschen steht an Bläschen nebeneinander. Ziemlich häufig findet sich jedoch zwischen den Bläschen ein heller Zwischenraum, der durch feines Bindegewebe ausgefüllt ist und bis zu $40 \mu$ Breite haben kann. Hier und da findet sich an Stelle dieses Bindegewebes ein feiner Kern und zellreiches Gewebe, welches keine spezielle Differenzierung zeigt. Papillen wie auch solide Follikel fehlen vollkommen. Das Gewebe trägt überall einen durchaus normalen Charakter.

Die Zellschicht der Follikel ist gewöhnlich einschichtig nach außen und innen scharf begrenzt, mit Ausnahme der vereinzelten mehrschichtigen Follikel, die oft keine scharfe Zellgrenze mehr besitzen. Vereinzelt stehende Zellhaufen ohne irgendwelche Anlehnung können da und dort

rechts

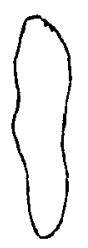

a.

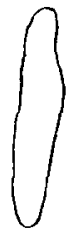

b links

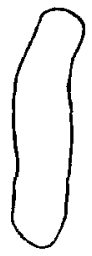

a

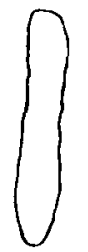

b

Fig. 8.

a von vorn. b von der Seite.

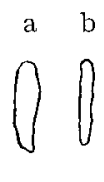

Fig. 9 .

a von vorn. b von der Seite.

nachgewiesen werden. Die Follikel sind durchweg mit schönem roten Kolloid angefüllt, welches nicht bis an die Zellwand herantritt, feine Auszackungen und Ausläufer besitzt und da und dort vakuoläre Bildungen zeigt.

Bei stärkerer Vergrößerung zeigen die Zellen eine kubische Natur, in den größeren Follikeln sind sie flach. Das Plasma der Zellen ist hell tingiert. Die Zellen haben eine Größe von 3:3 $\mu$, da und dort sind sie etwas weniger groß. Die Kerne sind gewöhnlich bis $2 \mu$ im Durchmesser, zeigen eine sehr intensive Färbung und 5-6 Nukleoli. Sie stehen in Reihen angeordnet durchschnittlich I-2 Kerndurchmesser voneinander entfernt. Einzelne der Kerne in dem flachen Epithel der Randfollikel sind oval, parallel dem Lumen gestellt und schön intensiv gefärbt. Die Kerne der vereinzelten soliden Stellen sind etwas größer geworden, die Nukleoli treten ebenfalls etwas stärker hervor. Zylindrische Zellpartien können keine nachgewiesen werden, wohl finden sich einzelne Follikel, die aus mehreren undifferenzierten Zellschichten bestehen und ein irreguläres Lumen angefüllt mit scholligem Kolloid umgeben, das im van-Gieson-Präparat schön braun gefärbt ist. 
v a n Gi e s o n zeigt deutlich die feine Kapsel mit den dünnen bindegewebigen Ausläufern. Das Gefäßnetz ist äußerst fein angeordnet.

A f fe 7. Exitus am I. XII. Ig08, nachdem das Tier 6 Monate mit erhitztem Aarauer Wasser gefüttert worden ist. Der Tod trat infolge Erfrierung ein, da das Fenster des Käfigs einmal über Nacht offen gelassen wurde. Die Leibdrüsen zeigten dabei eine starke Schwellung, doch konnte nichts pezifisches für Tuberkulose nachgewiesen werden. Die Größe der beiden Schilddrüsen beträgt 8:2:2 und 8:3:I mm (Fig. Io). Ihr Gewicht 60 und $76 \mathrm{mg}$. Röntgenologisch ist nichts nachzuweisen. Der histologische Aufbau entspricht vollständig demjenigen von Affe 6 und somit dem normalen Bilde von Affe I.

Affe 8. Gefüttert $7 \frac{1}{2}$ Monate mit filtriertem Aarauer Wasser (mehrfache Papierfilter). Exitus am 15. I. Igog. Der Affe erlag einer Pneumonie, die Abdominallymphdrüsen zeigten sich hyperplastisch. Tuberkulose konnte keine nachgewiesen werden.

Die beiden Lappen der Schilddriise können rechts und links der Trachea um zirka $1 / 2$ im Vergleich zum Kontrolltier als längliche walzen-

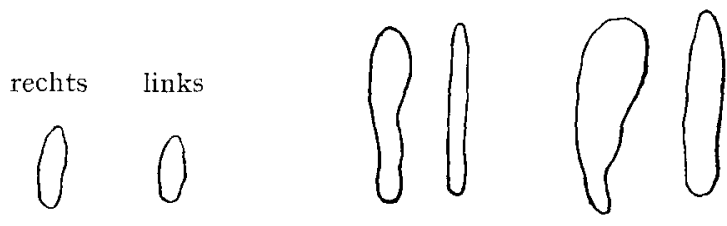

Fig. Io.

Fig. I I.

förmige Gebilde nachgewiesen werden, die ziemlich in die Dicke gewachsen sind. Im obern rechten Lappen spürt man deutlich einen kleinen harten und derben Knoten, während links überall weiches Gewebe zu fühlen ist.

Der rechte Knoten hat eine Größe von I 8: 6: $4 \mathrm{~mm}$ und $490 \mathrm{mgGewicht,}$ während der rechtsseitige Knoten I7:5:3 mm und $420 \mathrm{mg}$ wiegt (Fig. Ir).

Röntgenologisch sind keine Besonderheiten nachzuweisen.

Der Schnitt zeigt einen typisch lobulären Bau, die Läppchen sind überall netzartig durchbrochen.

Der $\mathrm{h}$ is t o log is c h e B a u (Färbung Hämotoxylin-Eosin) entspricht bei schwacher Vergrößerung dem makroskopischen Verhalten. Die Follikel sind in den einzelnen Lobuli netzförmig angeordnet, so daß sie in schönen Reihen dastehen. Sie stoßen Wand an Wand. Vereinzelt dastehende sind ganz selten zu sehen. Die Wand zweier aneinander stoßender kann gemeinsam werden. Die Wände sind ganz schmal, so daß in ihnen keine kubischen Zellen mehr Platz haben. Die Form der Follikel ist vorherrschend oval, seltener werden runde angetroffen. Besonders in den Randpartien sind die ovalen am zahlreichsten vertreten. Vereinzelt können da und dort schlauchförmige Gebilde angetroffen werden, deren Lumen unregelmäßig gebaut ist und 
in Fortsätze ausläuft. Helleres $Z$ wischengewebe, wie es bei 6 und 7 vorhanden war, kann hier nirgends zwischen den einzelnen Follikeln gesehen werden. Überall stehen Follikel, oder zwischen diesen solide Zellstränge, welche in sehr intensivem Maße zugenommen haben. Man gewinnt an einzelnen Partien den Eindruck, daß dieses Zwischengewebe direkt in die Follikelwände übergehe.

Indifferenziertes Gewebe in größern Haufen findet sich selten, nur zwischen den Follikeln wird es reichlicher angetroffen. Der Inhalt der Follikellumen besteht aus einem scholligen Kolloid, welches vakuoläre Aufhellungen zeigt, und da und dort schollig zerfallen ist. In vereinzelten Follikeln können da und dort papilläre Exkreszenzen und Wandvorstülpungen vorhanden sein.

Die Blutgefäße sind ziemlich zahlreich besonders die größern vorhanden. Das Bindegewebe ist in feinen einzelnen Strängen vorhanden, welche zwischen die Follikel eintreten.

Bei stärkerer Vergrößerung zeigt die Großzahl der Follikel einen durchweg platten Epithelbelag, welcher kaum I $\mu$ hoch und $2-4 \mu$ breit ist. An einzelnen Stellen, an denen zellreichere indifferenzierte Partien stehen, kann das Epithel größer, kubisch bis zylindrisch werden; das Epithel der benachbarten Follikel ist dann überall zweischichtig. Die Größe des Epithels der indifferenzierten Partien beträgt $3: 3 \mu$.

In den flachen Epithelien sind die Kerne flach, länglich kaum $0,5-\mathrm{I}, 5 \mu$ lang, sie liegen in wellenförmigen Reihen angeordnet, schön parallel dem Lumen. Der Abstand der einzelnen Kerne voneinander beträgt I $\mu$. In den zellreichen Wänden und den undifferenzierten Haufen sind die Kerne schön rund, bläschenförmig. Der Durchmesser beträgt $3 \mu$.

Die Zellgrenzen, besonders bei den papillären Erhebungen, sind dem Lumen gegenüber nicht scharf zu konstatieren. Die Kerne sind dabei schön tingiert und mit zahlreichen Nukleoli versehen. An einer zirkumskripten Stelle findet sich eine schlauchförmige Bildung, aus kernhaltigen, scharf begrenzten kubischen Zellen bestehend. Zahlreiche Exkreszenzen stehen in das Lumen vor. In den kernreichen soliden Strangpartien sind die Kerne reichlich mit Nukleoli versehen, da und dort kann ein sehr intensiv gefärbter Kern nachgewiesen werden, der eine verklumpte Gestalt angenommen hat.

Mit Immersion sind keine Besonderheiten nachzuweisen.

Das Gewebe macht in der überwiegenden Mehrzahl der Bilder normalen Eindruck, während an vereinzelten Stellen eine beginnende Umwandlung in wuchernde Partien nachgewiesen werden kann.

$\mathrm{R}$ atte $\mathrm{n}$, weiß. Beginn der Versuche am I5. V. Igo8.

Normale Vergleichstiere ${ }^{\mathbf{l}}$ ) mit erhitztem Wasser gefüttert, getötet durch $\mathrm{CHCl}_{3}$ am 20. X., am 2I. VII., I4. XI. I908, am I5. I. I909 und am 2I. VII. Igog.

I) $\mathrm{Zu}$ Vergleichstieren werden wenn immer möglich Tiere vom selben Wurfe wie die. Versuchstiere benutzt. 
Die Bilder der Schilddrüsen all dieser Kontrolltiere sind übereinstimmend, so daß wir uns mit der einmaligen Beschreibung begnügen.

Die beiderseits der Trachea gelegenen Lappen haben durchschnittlich eine Länge von $5 \mathrm{~mm}$, eine Dicke von 2 und eine Breite von $3 \mathrm{~mm}$ (Fig. I2).
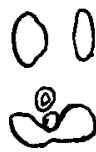

Fig. 12 . Durchschnittl. Größe der normalen Schilddrüse.

Makroskopisch ist auf dem Schnitte ein deutlich lobulärer Bau zu konstatieren. Kleinere und größere Bindegewebsstränge bilden ein feines, netzartiges Gerïstwerk, welches das ganze Parenchym durchzieht.

Bei schwacher Vergrößerung (Fig. I3) sieht man, daß das ganze Gewebe überwiegend aus follikulären Partien besteht, welche durch breite Septen bis zu $40-60 \mu$ voneinander getrennt sind. Diese Läppchen follikulären Gewebes haben eine durchschnittliche Länge von I50 bis $200 \mu$ und eine vier- oder dreieckige Form. Zwischen den Läppchen, wie den Septen finden sich bis zu $50 \mu$ Durchmesser haltende Blutgefäße, die prall mit zahlreichen Blutkörperchen angefüllt sind.

Die Lobuli werden von runden oder ovalen Follikeln gebildet, die einen durchschnittlichen Durchmesser von I2-I8 $\mu$, einzelne auch mehr haben. Die Follikel stehen

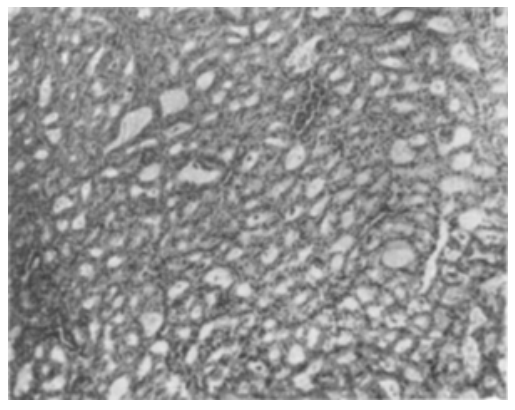

Fig. I 3 . schön in Reihen angeordnet nebeneinander, sie haben alle ein helles Lumen, dessen mittlerer Teil durch schön dunkel gefärbtes Kolloid angefüllt ist. Neben diesen Follikeln ist an einzelnen Stellen solides Gewebe aus soliden Follikeln bestehend nachzuweisen, an andern, besonders in den Randpartien, findet sich undifferenziertes Gewebe. Perifollikulär sind feine Bindegewebsstränge angelegt. Neben den runden Follikeln finden sich an einzelnen Stellen länglich etwas plattgedrückte $\mathrm{Ge}$ bilde von $40-70 \mu$ Länge und $\mathrm{I}_{5}-30 \mu$ Breite. Die plattgedrückten Follikel kommen speziell in den Randpartien vor. Auch in diesen Gebilden ist Kolloid vorhanden, welches mit feinen Fortsätzen an die Epithelwand reicht und von vakuolären Bildungen durchsetzt ist.

Bei starker Vergrößerung, 450, zeigt sich das Epithel vorherrschend kubisch, ganz vereinzelt kann es zylindrisch werden. Die Zellmembran ist stets deutlich zu konstatieren, der Zelleib hat eine leicht rosa Färbung (Hämatoxylin-Eosin). Der Kerne sind rund, bläschenförmig, liegen im Zelleib und haben einen Durchmesser von durchschnittlich $2 \mu$, 
während die kubischen Zellen 3-4 $\mu$ Breite und Höhe haben. Der Kern enthält I-2 intensiv gefärbte Nukleoli. Die Kerne stehen in schönen Linien mit einem durchschnittlichen Abstand von I Kerndurchmesser nebeneinander. Längliche, keulenförmige, sehr intensiv gefärbte Kerne finden sich neben den runden Kernen. Sie sind in nur sehr mäßiger Anzahl vertreten.

Die Follikel sind von dem umgebenden Gewebe sehr scharf abgetrennt, die Wände gehen nirgends ineinander über. Die Randfollikel, die etwas schmal gedrückt sind, zeigen plattes Epithel, in vereinzelten länglichen Gebilden kann ein erhöhtes kubisches Epithel nachgewiesen werden. In den soliden Follikeln sind die Zellen gut ausgebildet, analog den übrigen Follikelzellen. Immersion zeigt keine Besonderheiten.

I.

Weiße Ratten mit Aarauer Wasser gefüttert.

I. $\mathrm{R}$ a t t e geboren I6. VI. Ig08. In $\mathrm{CHCl}_{3}$ getötet am 9. II. Igog.

Makroskopisch beträgt die Größe I2:6:3 $\mathrm{mm}$, der linke Lappen ist etwas kleiner, 9:5:3 mm. Im rechten Lappen auf Schnitt lateral gelegen sieht man deutlich eine helle runde Stelle von 3:3 mm Durchmesser, die mit einer hellen durchscheinenden Masse angefüllt ist (Fig. I4). Bei schwacher Vergrößerung Ok. I, Obj. 3 hat die ganze Schilddrüse auf Schnitt einen deutlich lobulären Bau. Die Läppchen variieren in ihrer Größe von 30 bis
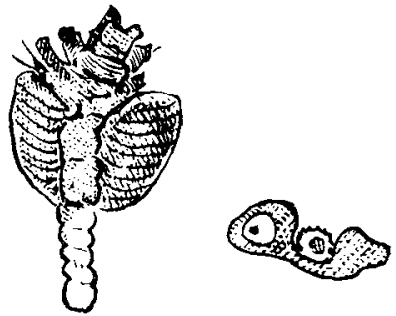

Fig. I4. $90 \mu$ Länge und $40-\mathrm{I} 30 \mu$ Breite. Im Durchschnitt 50:60 $\mu$. Die meisten Läppchen sind längs oval gebaut, einzelne sind rund und von einem feinen Bindegewebe umgeben, welches einzelne feine Fortsätze zwischen die einzelnen Follikel chickt.

Die einzelnen Läppchen bestehen zum Teil aus soliden oder mit Lumen versehenen Follikeln, welche rund oder oval geformt gegen oben erwähntes rundes Lumen immer mehr zusammengepreßt werden. Daneben finden sich reichlich bläschenförmige Gebilde und Schläuche, welche alle möglichen Gestalten annehmen können. Solide Zellstränge und Follikel sind reichlich vertreten.

Rund $1 / 3$ der Follikel sind leer, während die übrigen retrahiertes Colloid besitzen, welches mit feinen Fortsätzen mit dem Wandepithel in Beziehung steht. In dem großen Lumen findet sich ebenfalls Kolloid, welches teilweise von Vakuolen durchsetzt ist, feine Fortsätze trägt, an einzelnen Stellen jedoch völlig ausgefallen ist.

In dem großen Lumen finden sich zahlreiche größere und kleinere papilläre Exkreszenzen, die oft, wenn sie mit den Spitzen zusammen gewachsen sind, follikelartige Lumina bilden (Fig. I5). Diese Papillen 
zeigen reichlich Auswüchse und Verästelungen. Die Zellen um das gr-Lumen haben eine sehr intensive Färbung.

Die einzelnen Follikel haben eine durchschnittliche Größe von I0-50 $\mu$ Durchmesser. Im Durchschnitt beträgt er I6 $\mu$. Ein ganz vereinzelter, sehr großer, hat roo $\mu$. Solide Follikelanordnungen sind da und dort ebenfalls vorhanden. Neben den Follikeln sind schlauchund bläschenförmige Gebilde häufig von papillären Exkreszenzen oder Wandvorsprüngen aus zahlreichen Zellen bestehend durchsetzt, in reichlicher Anzahl vorhanden.

Die soliden Follikel, wie auch die schlauchförmigen Gebilde sind da und dort zu einem großen Gewebekomplex zusammengetreten.

Der Bau der Epithelien ist ein verschiedener, je nach dem Gewebsgebiete, dem sie gerade angehören. In den regulär gebauten Follikeln ist

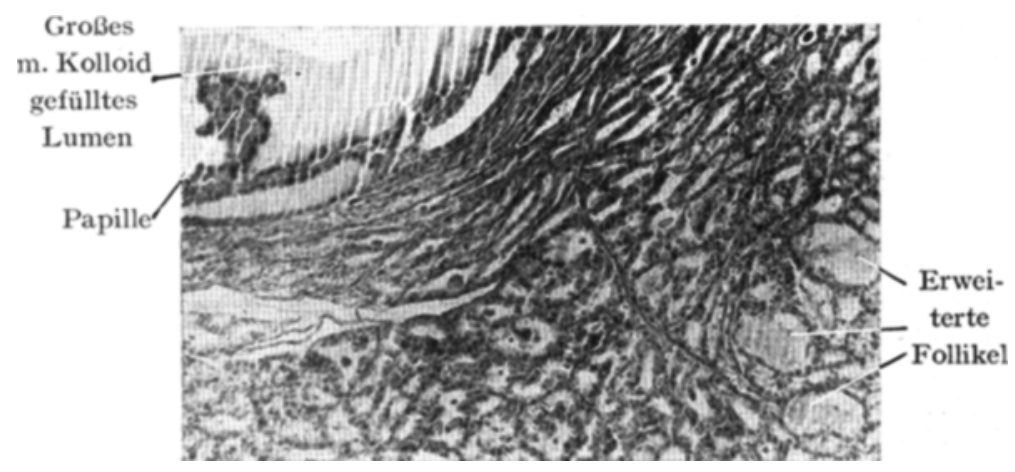

Fig. I 5.

es kubisch, an einzelnen auch flach. Die Größe beträgt durchschnittlich $2: 2$ oder $3: 3 \mu$. Die Zellgrenzen sind deutlich und scharf. Das Protoplasma zeigt ein fädiges Gerüstwerk. Die Kerne sind in der Mehrheit in der Mitte der Zellen gelegen, vereinzelt finden sie sich basal. Das Protoplasma zeigt eine helle Tingierung. Die Kerne sind von runder oder leicht ovoider Gestalt, bläschenförmig und stehen in regulären Reihen angeordnet mit einem Abstand von 2 Kerndurchmessern da. Der Kerndurchmesser beträgt durchschnittlich I,5 $\mu$, kann jedoch auch weniger oder mehr betragen. Schaltkerne von etwas länglicher, mehr unregelmäßiger Gestalt sind da und dort ebenfalls vorhanden. In den großen Hohlräumen findet sich das Epithel meist abgeplattet mit länglichen, dem Lumen längsgestellten, Kernen.

In den weniger zahlreichen soliden Follikeln sind die kubischen Zellen größer, 4:4 oder gar 5:5 $\mu$, ebenso können die Kerne einen Durchmesser bis zu 2 oder $3 \mu$ haben. Die Färbung dieser Partien ist eine bedeutend intensivere. 
Zwischen den Follikeln ist überall ein feines Netz schmaler bindegewebiger Stränge und schmaler Kapillaren zu konstatieren. In den schlauchförmigen Gebilden findet sich ein zylindrisches Epithel sehr erheblich vertreten, dabei sind Wandverdickungen (Mehrschichtigkeit) und papilläre Auswüchse sehr zahlreich $\mathrm{zu}$ konstatieren. Die Zellen und deren Kerne zeigen da und dort eine intensive Färbbarkeit. Im allgemeinen ist sie jedoch etwas wechselnd. Das Zellprotoplasma zeigt an einzelnen Stellen eine mehr oder minder starke Auflockerung an seinem Rande.

Um größere Gefäße herum sind solide Zellstränge mit soliden Follikeln durchsetzt anzutreffen, in denen die Zellen häufig vollständig regellos angeordnet sind.

In den bläschenförmigen irregulären Gebilden ist die Epithelwandung häufig außerordentlich schwierig von den umgebenden großen Zellhaufen $\mathrm{zu}$ isolieren und $\mathrm{zu}$ differenzieren. Der Zellverband ist ein so inniger, daß man den Eindruck erhält, daß diese Partien direkt ineinander übergehen. Die Kerne sind an diesen Stellen sehr intensiv gefärbt, und längliche, unregelmäßig geformte, sogenannte Schaltkerne sind in zahlreicher Menge, hier und da 3 Stück nebeneinander, vorhanden.

In den kleinen cystischen Gebilden ist der Zellbelag flach und kubisch. Die Kerne stehen oft bis zu 4 Kerndurchmessern voneinander entfernt und eine deutliche Membran ist an ihnen zu unterscheiden. Der Inhalt, aus leicht rosa gefärbtem Kolloid bestehend, ist mit zahlreichen Vakuolen durchsetzt, an einzelnen Stellen kann es schollig zerfallen aussehen. Zwischen den Follikeln findet sich verschieden intensiv durchblutetes Gewebe vor.

Eine spezielle Besprechung erfordert die oben erwähnte weite große Höhle. Der Rand ist durchweg mit verschieden großen Papillen durchsetzt, die eine Größe bis zu I können sich verästeln und verzweigen, und diese Äste können durch Zusammenwachsen wiederum neue Lumen bilden, die eine deutliche Epithelwand besitzen. An einer zirkumskripten Stelle sind diese neugebildeten Höhlen ziemlich ausgebreitet. Das Epithel kann an solchen Partien mehrschichtig werden. Die äußere Umhüllung dieser großen Höhle besteht aus einem durchschnittlich Io $\mu$ dicken feinen Streifen Bindegewebes, die sehr kernreich mit größern und kleinern Blutgefäßen durchsetzt ist, in denen deutlich Rhodocyten vorhanden sind. Auf dieser bindegewebigen Basis findet sich eine äußerst zellund kernreiche Epithelschicht, aus einem kubischen, teilweise zylindrischen Epithel bestehend, von fast $5 \mu$ Höhe und $2-3 \mu$ Breite.

Die Kerne sind sehr intensiv gefärbt, unregelmäßig angeordnet, und berühren einander da und dort. Ihr Durchmesser kann bis zu $2 \mu$ betragen.

In den Papillen finden sich undifferenzierte solide Zellhaufen von schwächerer Färbung vor, dazu solide Follikel, und Follikel, die mit hell gefärbtem, etwas scholligem Kolloid durchsetzt sind. 
Diese Follikel haben nirgends flaches, sondern durchwegs ein kubisches Epithel. In einzelnen können wiederum kleine Papillen gefunden werden, die sehr zellreich sind. Die Kerne sind rund, seltener bläschenförmig, einzelne wenige Schaltkerne sind vorhanden. Die Größe der Kerne beträgt durchschnittlich $0,8 \mu$, sie sind im Vergleich zu den übrigen klein geblieben, jedoch sehr zahlreich. Dieser Kern-
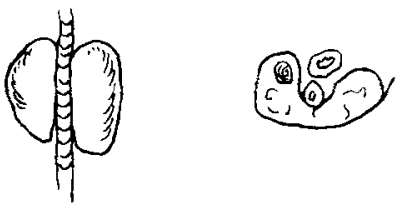

Fig. 16 . reichtum und die stärkere Tinktion der Zellen ist auffallend. Im Stiele der papillären Exkreszenzen sind zahlreiche Blutgefäße rorhanden.

Die Immersion zeigt in den Papillen Kern an Kern ohne Zwischenraum stehen, so daß sie sich berühren. Nukleoli sind nur wenige vorhanden. Die Kerne in den zylindrischen Zellen sind basalständig, während in den kubischen sie in der Mitte liegen und fast den ganzen Zelleib füllen. Die nach dem Lumen zugekehrte Zellpartie zeigt Auflockerungen und Auffransungen.

In den Follikeln zeigt die Immersion die Kerne heller gefärbt und die Nukleoli deutlich sichtbar.

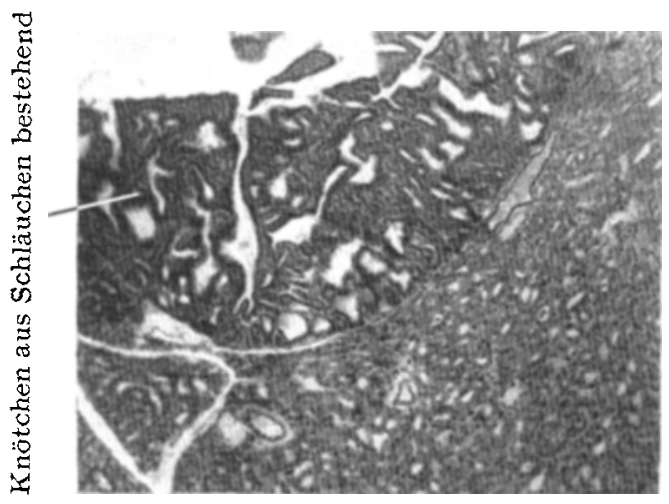

Fig. 17 .

Bei dieser Schilddrüse dürfte es sich um ein Adenoma papillosum im Sinne Wö lf l ers handeln, daneben sind noch zahlreiche andere typisch gewucherte Stellen erkenntlich.

Ratte 2, geb.am I6.X. Beginn der Tränkung am I7. II. Igog in Aarau mit rohem Quellwasser, nachdem sie vorher erhitztes Wasser erhalten hatte, getötet $\mathrm{I} 8$. VI. Igog. Das Tier ist fast ausgewachsen. Im röntgenologischen Bilde sind die

Epiphysenlinien noch zu sehen (Fig. r6).

Die Größe des Schilddrüsenlappens beträgt rechts $9: 5: 5$, links I0:5:4 mm.

Im rechten Lappen sieht man deutlich retrotracheal auf dem Schnitt, gegen den Osophagus zu gelegen, ein durch seine intensive Blaufärbung hervortretendes Knötchen, das fast I mm Durchmesser besitzt (Fig. I7).

Mikroskopisch bei schwacher Vergrößerung System 3, Okular 3 findet sich im linken Lappen ein follikuläres Gewebe, das reichlich mit soliden Partien durchsetzt ist. Die Follikel sind rund oder oval gebaut und haben einen Durchmesser von $20-40 \mu$. Diese Follikel werden 
durch feine bindegewebige Stränge von $6 \mu$ Breite voneinander getrennt, so daß kleine Läppchen auftreten von verschiedener Größe bis $300-450 \mu$ Durchmesser.

In diesen Läppchen finden sich da und dort schlauchförmige Gebilde von einer Länge bis zu Ioo $\mu$ und einer Breite bis $40 \mu$. In diesen Schläuchen, die anscheinend ein sehr hohes Epithel besitzen, findet sich hellgefärbtes Kolloid, das von der Wand stark retrahiert ist und von Vakuolen durchsetzt ist. Die Form dieser länglichen Gebilde ist eine sehr unregelmäßige.

Neben diesen Partien finden sich ähnliche solide Gebilde, deren Belag mehrschichtig erscheint. Die schlauchförmigen Partien zeigen überall eine äußerst intensive Zellfärbung.

Das intensiv gefärbte Knötchen im rechten Lappen ist an einzelnen Stellen scharf vom übrigen Gewebe abgetrennt, am andern geht es direkt in das Parenchym des Lappens über. Diese Stellen sind sehr intensiv gefärbt, besonders in den Kernen, wie sich schon makroskopisch kundgibt. Das Knötchen besteht aus unregelmäBigen schlauchoder bläschenförmigen Gebilden, deren Hohlräume teilweise mit einer schwach gefärbten kolloidartigen Substanz gefüllt sind. Wanderhebungen sind in den Hohłräumen vereinzelt vorhanden. Das Epithel ist meist einschichtig, an einzelnen Partien zu äußerst dichten Haufen zusammengedrängt, die eine sehr zellreiche Partie darstellen. In den größeren Hohlräumen ist wenig Kolloid vorhanden, an anderen Stellen fehlt es vollständig.

Das dieses Knötchen umgebende Gewebe besteht zum großen Teil aus soliden Follikeln oder undifferenzierten Zellpartien. An andern Stellen finden sich bis zu I2 $\mu$ vergrößerte Follikel vor, die gar kein oder nur wenig Kolloid enthalten. Dieses Knötchen ist auf einer größeren Serie von Schnitten zu verfolgen und kann sich bis zu über Iooo $\iota$ Durchmesser verbreitern.

Die Kerne stehen bei starker Vergrößerung in diesem Knötchen sehr nahe nebeneinander, sie sind äußerst intensiv gefärbt und zeigen 3-4 sehr dunkel gefärbte Nukleoli in ihrer Mitte. Die Größe des Kerns beträgt bis zu $2 \mu$ Durchmesser. Neben den schön runden bläschenförmigen Kernen findet sich da und dort vereinzelt dastehend ein länglicher Kern, der als Schaltkern angesprochen werden darf. Die Kerne nehmen in dem doppelt so hoch als breiten Epithel fast das ganze Zelllumen an der Basis ein. Der Kern ist durchweg scharf begrenzt, während die Zellbegrenzung nicht immer eine scharfe ist.

In den übrigen follikulären Partien stehen die Kerne regelmäßig fast einen Kerndurchmesser voneinander $a b$, an andern Stellen kann dieser Abstand bis zu 4 Kerndurchmesser betragen.

In den schlauchförmigen Partien des linken Lappens ist das Epithel 2-, ja 3mal so hoch als breit, der Kern hat ebenfalls basale Stellung und ist bedeutend intensiver gefärbt als in den umliegenden Partien. Der 
Abstand der Kerne beträgt kaum einen Kerndurchmesser. Das Kolloid zeigt sich überall stark retrahiert.

Die übrigen Partien der Schilddrüsen zeigen ein kubisches oder plattes Epithel und die Kerne haben einen größern Abstand voneinander.

Das Bindegewebe ist in feinen Strängen vorhanden, und kann dort verschieden starke Septen bilden. Blutgefäße sind besonders zahlreich in der Nähe des Knötchens vorhanden, daneben sieht man überall feine Grefäßsprossen zwischen die Lobuli und Follikel ziehen.

Das Gesamtbild entspricht teilweise einem normalen Bau der Schilddrüse, andererseits findet sich ein typisches größeres Knötchen im rechten Lappen, welches das ausgesprochene Bild der Struma zeigt, daneben finden sich zahlreiche Partien, die das Bild der beginnenden Struma darbieten.

$\mathrm{R}$ a $t$ t e 3, geboren I5. III. I909, mit der Mutter mit rohem Aarauer Quellwasser gefüttert. Exitus am I8. VI. Igog in $\mathrm{CHCl}_{3}$-Narkose. An den Epiphysen sind noch deutliche Grenzlinien nachweisbar auf dem
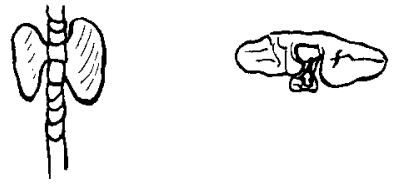

Fig. 18. Röntgenogramme. Die beiden Lappen der Schilddrüse zeigen eine Vergrößerung. Sie messen 8:5:4 und $7: 3: 3 \mathrm{~mm}$ (Fig. I8). Auf Schnitt (Hämatoxylin-Eosin) zeigt sich ein deutlich lobulärer Bau. Die einzelnen Lobuli haben im Durchschnitt eine Größe von $1 / 4-\mathrm{I} \mathrm{mm}$. Die interlobulären Septa können bis ein $1 / 4 \mathrm{~mm}$ breit werden, sind jedoch meistens durchschnittlich $60 \mu$ breit.

Der Bau der Läppchen ist ein stark variierender, in der Nähe der Trachea ist er meistens schön follikulär, gegen die Randpartien nimmt die Zahl der Follikel ab, und wird durch solide Follikel und indifferenzierte Zellpartien ersetzt. Auf der dorsal gelegenen Seite findet sich ein zirka Ioo $\|$ breiter Streifen, der aus einem regellosen indifferenten Zellgewebe besteht, das keine Follikel bildet.

Im rechten Lappen finden sich 8 intensiv gefärbte schlauchförmige Gebilde, die eine unregelmäßige Form haben, und durch zahlreiche Papillen durchsetzt sind. Ähnliche vereinzelte Gebilde finden sich bis zu einer Länge von $60 \mu$ zerstreut über das Gewebe, speziell gegen den Isthmus werden sie zahlreicher. Ihr Epithel ist ein rein zylindrisches mit basalem, großem bläschenförmigen Kern, die sehr zahlreich vorhanden sind, und nahe nebeneinander stehen. In den soliden Randpartien nehmen die Kerne oft eine unregelmäßige Gestalt an. Die follikulären Partien sind weniger kernreich und weniger intensiv gefärbt; deren Epithel ist kubisch. Verklumpte Schaltkerne können da und dort vorkommen.

Neben normalen Partien kann an einzelnen Stellen deutlich eine beginnende Gewebswucherung mit Strumabildung konstatiert werden. 
$\mathrm{R}$ a t te 4, halbwüchsig, 2 Monate in Basel, mit rohem Aarauer Wasser getränkt, getötet in $\mathrm{CHCl}_{3}-\mathrm{Narkose}$ am 27 . VII. I908.

Röntgenologisch ist nichts nachzuweisen. Makroskopisch kann keine Vergrößerung der Schilddrüse nachgewiesen werden. Die Läppchen haben auf Schnitt einen Durchmesser von $\mathrm{I} 1 / 2 \mathrm{~mm}$. Makroskopisch ist ein deutlich lobulärer Bau zu konstatieren.

Der histologische Bau dieser Schilddrüse entspricht einem großenteils normalen Gewebe. Es sind nur geringfügige Änderungen strumöser Natur vorhanden.

$\mathrm{R}$ a t te 5. Ausgewachsenes Tier. 5 Monate mit rohem Aarauer Wasser gefüttert in Basel, am I. XII. I 908 in $\mathrm{CHCl}_{3}$-Narkose getötet. Röntgenologisch lassen sich die Epiphysenlinien als feine dünne Linien deutlich nachweisen. Die Schilddrüsen sind beidseitig vergrößert. Rechts betragen ihre Maße 8:5:4 links 8:4:3. Auf Schnitt zeigen einen mäßig körnigen Bau (Fig. I9 und 20).

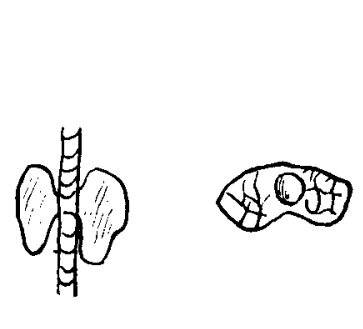

Fig. I 9 .

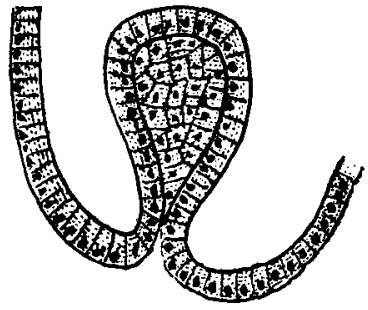

Fig. 20.

Papilläre Exkreszenz.

Auf Schnitt haben die Lappen eine Größe von $4 \frac{1}{2}: 3 \frac{1}{2} \mathrm{~mm}$ links und $5: 4 \mathrm{~mm}$ rechts, der Bau ist ein deutlich lobulärer, reichlich zarte, bis $\mathrm{zu} 1 / 2 \mathrm{~mm}$ breite Stränge durchsetzen das Gewebe. Der Durchmesser der Läppchen variiert von $1 / 4-\mathrm{I} \mathrm{mm}$.

Im mikroskopischen Bild sind runde und länglichovale Follikel vorherrschend. Daneben sind ziemlich reichlich solide Follikel vorhanden, während das solide undifferenzierte Gewebe sozusagen völlig fehlt, und nur in den Randpartien vereinzelt vorhanden ist. Das Kolloid wird nicht regelmäßig in den Follikeln gefunden, wo es vorhanden ist, ist es schön rot gefärbt und von den Wandungen retrahiert.

Daneben finden sich vereinzelte schlauchförmige Gebilde, in denen das Epithel kubisch mit reichlich basal gelegenen Kernen ist.

Eine Zunahme des soliden undifferenzierten Gewebes, wie auch der Follikel ist vorhanden.

$\mathrm{R}$ a t $\mathrm{t}$ e 5 a, geb. im Juni I9o8, getränkt von Ende Juni 1908 bis I2. I. Igog mit rohem Aarauer Wasser in Basel. Das Tier ist beinahe ausgewachsen. Röntgenologisch sind jedoch durchweg offene Epiphysenlinien nachzuweisen, so daß an eine geringe Verzögerung in der Ver- 
knöcherung gedacht werden kann. Die Schilddrüse zeigt makroskopisch geringe Vergrößerung. Ihre Größe beträgt rechts $6: 3: 3 \mathrm{~mm}$, links $5: 3: 2 \mathrm{~mm}$.

Das histologische Bild zeigt neben den schön follikulären Randpartien zahlreiche bläschenförmige Gebilde, die teilweise auch noch eine schlauchförmige Form (3) haben, in denen sich papilläre Erhebungen und septenartige Gebilde finden. Hier findet sich vorherrschend ein kernreiches, zylindrisches Epithel, das intensiv gefärbt ist, während das Epithel der Follikel kubisch oder platt und weniger intensiv gefärbt ist.

Die Kerne sind im allgemeinen rund, doch kommen auch solche unregelmäßigen länglichen Baues vor.

In den Papillen und Septen sind die Kerne regellos zerstreut vorhanden.

$\mathrm{R}$ a t t e 6. 6 Monate mit rohem Aarauer Quellwasser gefüttert in ausgewachsenem Zustande. Getötet am I8. XII. I908. Röntgenologisch kann nichts nachgewiesen werden. Makroskopisch ist die Schilddrüse ganz minimal vergrößert und zeigt auf Schnitt einen völlig lobulären Bau. Rechts beträgt die Größe 6:3:2 und links 5:2:2 mm.

Auf dem histologischen Bilde (Hämatoxylin-Eosin-Färbung) kann ein schön follikulärer Bau (Vergrößerung 80) gesehen werden. Die Follikel sind rund und bilden mit ihrer scharf gezeichneten Follikulärmembran ein wabenförmiges Gewebe. Die Größe der Follikel variiert zwischen 30-60 $\mu$ Durchmesser.

Auffallend ist das Verhalten, welches der Zellepithelbelag zeigt, der in keinem der Follikel einen zusammenhängenden Wandbelag zeigt, sondern der Zusammenhang der Epithelien ist überall aufgelöst, so daß einzelne Stücke des Belags, sich zerstreut im Zentrum des Lumens befinden. Einzelne der Zellen sind zerrissen und zerfetzt, die Kerne ebenfalls dabei sehr klein und intensiv gefärbt. Zwischen den Follikeln sind zahlreiche lichtere Partien vorhanden, die einen septenartigen Bau durch feine Bindegewebsstränge bilden.

Im rechten Lappen finden sich vereinzelt da und dort noch Andeutungen guter vollständig erhaltener Follikel vor, bei denen nur ein kleiner Teil des Wandepithelbelags ausgefallen ist. Daneben sind ganz vereinzelt solide Zellpartien vorhanden.

Bei starker Vergrößerung (Syst. I, Ok. 3) sind die schön rosa gefärbten Zellen im Follikellumen in die Augen springend. 4-5 Zellen können sich im Zusammenhang als feines schmales Band vorhanden zeigen, die deutlich eine kubische Zellform besitzen, der Zellkern findet sich dabei in der Mitte liegend. Neben diesen noch eine ordentliche Form besitzenden Zellen finden sich zahlreiche mit Fortsätzen versehene fetzige Zellen, die zu mehreren zusammengetreten zu einem Klumpen geworden sind, der in seiner Mitte aus Kolloid besteht. Dabei steht noch die Follikelmembran als schmaler dünner Streifen. In den 
noch erhaltenen Zellen ist der Kern bläschenförmig, mißt $2 \mu$ im Durchmesser und nimmt beinahe die ganze Zelle ein. Er ist blau gefärbt und zeigt zahlreiche Nukleoli. An den degenerierten Zellen hat der Kern kaum I $\mu$ Durchmesser, ist sehr intensiv blau gefärbt, und Nukleoli können keine mehr unterschieden werden. Die Zahl dieser Kerne ist groß und sie sind zahlreich, regellos durcheinander zerstreut angelegt. Neben diesen finden sich vereinzelte längliche kommaförmige verklumpte Kerne vor. Einzelne Zellen stehen kernlos da. Mit zahlreichen Nukleoli versehene Kerne sind ebenfalls vorhanden, diese haben dabei eine sehr scharfe Wandzeichnung.

In einzelnen Follikeln fehlen neben Follikeln mit dem chaotischen Wirrwarr die Epithelzellen überhaupt. Mit der Immersion sind keine Besonderheiten zu sehen.

Das Bild entspricht einer völlig degenerierten Schilddrüse, in der normale Zellpartien nach vorhanden sind.

II.

Rupperswiler Wasser, alte Sodbrunnenquelle.

$\mathrm{R}$ a t t e 7, geb. I6. X. r908. Beginn der Tränkung mit rohem Rupperswiler Wasser am I2. I. 1909 in Basel, getötet am I8. VI. I909 in Aarau. Das Tier ist vollständig ausgewachsen, röntgenologisch sind an ihm keine besonderen Merkmale zu sehen. Von Verzögerung im Wachstum ist nichts nachzuweisen.

Makroskopisch ist eine deutliche Vergrößerung der beiden Schilddrüsenlappen nachzuweisen. Rechts beträgt der Lappen $15: 6: 4$, Links $13: 6: 3$ (Fig. 2I). Im rechten Lappen ist in der Mitte ein ganz deutlicher Knoten palpatorisch zu spüren, der auch im Schnitt makroskopisch $\mathrm{zu}$ sehen ist und einen Durchmesser von $2^{1 / 2} \mathrm{~mm}$ hat.

Auf Schnitt (Hämatoxylin-Eosin)

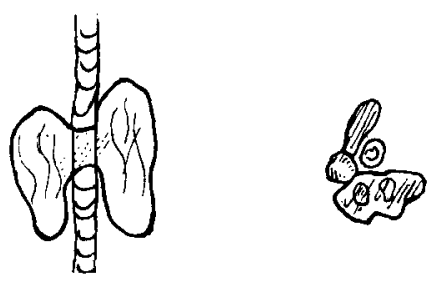

Fig. 2I.

Knötchen im rechten Lappen. sieht man in dem rechten vergrößerten

Lappen, nahe an der Trachea gelegen, deutlich das intensiv gefärbte Knötchen mit I,8 mm bis $2 \mathrm{~mm}$ Durchmesser (Fig. 22). Dieses Knötchen besteht aus einer größeren Anzahl unregelmäßig, teilweise auch oval geformter Bläschen, die eine verschiedentliche Größe haben, und deren Durchmesser $30-300 \mu$ beträgt. Das Epithel ist überall äußerst kernreich und sehr hochgebaut. Zwischen den einzelnen Bläschen findet sich ein teilweise sehr breites und lichtes Zwischengewebe, das aus Bindegewebe besteht, die einzelnen Bläschen sind gegeneinander ziemlich scharf abgegrenzt, wie auch das Knötchen eine scharfe Abgrenzung zeigt. In dem Knötchen können zahlreiche papilläre Bildungen nachgewiesen werden, in denen das Epithel äußerst zellreich 
ist. In einem vereinzelten Bläschen findet sich vakuoläres, stark retrahiertes Kolloid, während in den andern Lumen durchweg ein fädiges Gerüstnetz vorhanden ist. Einzelne Kerne zeigen eine äußerst intensive Färbung. Die ganz großen

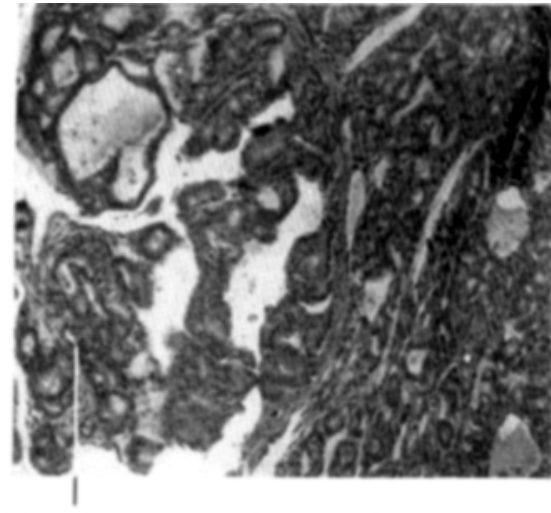

Knötchen Fig. 22. Bläschen zeigen ein kubisches Epithel, während in den kleinern schlauchförmigen Gebilden und Follikeln ein zylindrisches Epithel vorherrschend ist.

Die papillären, verdickten, polypenartigen Bildungen bestehen aus sehr ${ }^{\circ}$ zahlreichen Follikeln solider Natur. Die Kerne sind bläschenförmig und haben einen Durchmesser bis fast $\mathrm{zu}$ $2 \mu$. Die Größe kann eine wechselnde sein, doch ist die runde Form stets vorhanden. Schaltkerne sind nirgends, Nukleoli in Der Zelleib zeîgt keine besondere Färbung. wechselnder Anzahl vorhanden.

Die Größe der zylindrischen Zellen beträgt 2:4 $\mu$. Die Zellgrenzen, speziell gegen das Lumen $z u$, sind nicht besonders deutlich. Die Kerne in den Zellen stehen nicht immer ganz regel-
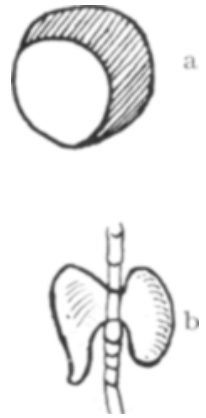

Fig. 23.

a I 200 fach vergrößert.

Kerne mit intensiver, halbmondförmiger Färbung. bung besitzen und aus Follikeln teilweise solider
Natur bestehen, daneben kommt auch indifferenziertes Gewebe vor, welches mit größeren Blutgefäßen durchsetzt ist.

Die Kerne sind in dem größtenteils zylindrischen, teilweise auch mäßig angeordnet, sondern mehr irregulär. Ihr Abstand beträgt durchschnittlich $1 / 2$ Kerndurchmesser. In den kubischen Zellen stehen die Kerne etwas weiter voneinander entfernt und nehmen darin fast den ganzen Zelleib ein. Bindegewebe ist als Stroma in ganz mäßiger Menge vorhanden, dagegen sind Gefäße ziemlich zahlreich vorhanden. In den hellen Zwischenräumen ist das Bindegewebe dagegen intensiver geworden. Der Übergang des Knötchens in das übrige Schilddrüsengewebe ist bei näherer Durchsicht an einzelnen Stellen stark verwischt.

Ein weiteres Knötchen findet sich an anderer, mehr peripherer Stelle im rechten Lappen mit einem Durchmesser bis zu $250 \mu$. Darin finden sich breite (bis $40 \mu$ ) septenartige gewundene Stränge, die eine sehr intensive Kernfär- 
kubischen Epithel zahlreich und können bis zu $3 \mu$ groß werden. An einer Stelle findet sich ein bis zu $750 \mu$ langes schlauchförmiges Gebilde, das nach verschiedenen Seiten Zweige und Fortsätze sendet. Zellen und Kerne dieser Partien sind äußerst intensiv gefärbt. An dem einen Ende geht der. Schlauch in bis I20 $\mu$ große Bläschen über. In den lateralen Partien können die Kerne bis zu $3 \mu$ groß werden, und ganz intensiv gefärbte große Nukleoli besitzen. Die Kerne stehen ganz nahe nebeneinander, am Zelleib sind keine Grenzen mehr zu unterscheiden. In seinem mittleren Teile besteht dieser Schlauch aus sehr vielen zerklumpten viereckigen, länglichen unförmigen Schaltkernen, die gleichmäßig intensiv gefärbt sind und gar keinen Nukleolus zeigen.

Das dicht knotige Gewebe der Schilddrüse zeigt längliche oder ovale Follikel. Sehr intensiv sind solide Follikel und undifferenzierte Zellstränge vertreten.

In den Follikeln findet sich ein äußerst intensiv gefärbtes Kolloid. die Zellen sind kubisch, die Kerne ziemlich groß und mit I Kerndurchdurchmesser voneinander im Abstand. Follikel aus 8-ro Zellen mit ebenso vielen Kernen bestehend sind am zahlreichsten vertreten. Im Follikelzwischengewebe finden sich lange spindelförmige Zellen, die dem Bindegewebe angehören, das gegen die Randpartien an Intensität eine Zunahme erfährt. In den Randpartien wird das normale Gewebe etwas komprimiert und die Zellen werden auf diese Weise flach. Die Kerne längsoval. In den Follikeln sind die Zellen gegen das Lumen zu scharf begrenzt, die Kerne regulär angeordnet.

Mit der Immersion können in den Follikelzellen einzelne fehlende Kerne nachgewiesen werden. Feine Kapillaren und Bindegewebssprossen sind überall vorhanden.

R a t t e 8, geb. im April I908 von kropffreien Eltern. Von Mai weg mit Rupperswiler Wasser von der alten Sodquelle getränkt, getötet am 30. August 1908 in $\mathrm{CHCl}_{3}$-Narkose in Basel. Das Tier zeigt sich im röntgenologischen Bilde nicht vollkommen ausgewachsen, einige der Epiphysenlinien, besonders der hinteren Extremität, zeigen sich noch offen, mit wenig Tendenz zur Verwachsung.

Makroskopisch ist nur eine sehr geringe Vergrößerung der beidseitigen Schilddrüsenlappen nachzuweisen. Die Lappen haben eine Größe von 5:4:3 mm rechts und 5:4:4 mm links. Auf dem Schnitt bei Hämatoxylin-Eosinfärbung, zeigen sie ein gleichmäßiges Gepräge.

Histologisch bei mäßiger Vergrößerung (Objekt. 3, Syst. 3.80) besteht keine reguläre Anordnung, Lobuli können keine nachgewiesen werden. Das Bild ist diffus aus soliden Follikeln, aus undifferenzierten Partien und normalgebauten Follikeln zusammengestetzt.

Die Follikel weichen in ihrem Bau völlig von den normalen Zellpartien $\mathrm{ab}$. Ihre Form wird eine unregelmäßige verzerrte, jedoch nicht durch Fortsätze, die der Wand entspringen, sondern durch eine Auflockerung und Auffasserung des Wandepithelbelages, deren Kontu- 
riërung eine ganz unregelmäßige geworden ist. Ein Teil der Epithelien stehen mitten im Lumen drin, andere bilden auf diese Weise haufenartige Klumpen. Der Wandbelag der Follikel ist zerfetzt. Die einzelnen Follikel kann man an einer Follikelmembran noch deutlich unterscheiden, doch herrscht in ihren Lumina wechselnd ein kolossaler Wirrwar (siehe Fig. 24, 25 und 26 von Ratte II, I2 und I3).

Die Lumina enthalten kein Kolloid, hier und da sind einzelne Bröckelchen davon vorhanden. Die Dicke der Follikelwand kann ziemlich stark variieren, die Färbung speziell der Kerne ist eine sehr intensive. Einzelne Partien sind so zellreich, wie wenn es sich um eine zellige Infiltration handeln würde. Schlauchförmige Gebilde oder größere Partien rein follikulärer Bildungen sind keine vorhanden. Rein normale Partien können absolut keine mehr nachgewiesen werden. Das Bindegewebe ist gut entwickelt, doch nicht in übermäßigem Grade. Es umgibt die wenig zahlreichen Gefäße die zwischen den einzelnen follikelartigen Bildungen verlaufen. Die Größe der Follikel schwankt zwischen $30-50 \mu$. Kolloid ist ganz selten in der Mitte vorhanden.

Stärkere Vergrößerung (45o Ok. 3, Syst. 7) zeigt einen ganz unregelmäßigen Aufbau der Zellen. Sie sind kubisch-zylindrisch, sechseckig gekerbt usw. Ihre Größe beträgt im Durchschnitt 3-4 $\mu$. Ihre Kontur ist undeutlich, unscharf, sie sind regellos zerstreut angeordnet. Ganze Zellen oder einzelne Kerne können fehlen, und mitten im Lumen liegen, die Zellen stoßen häufig nicht enge aneinander, sondern sind durch einen bis zu I $\mu$ Breite betragenden $Z$ wischenraum voneinander getrennt. Der Zelleib ist durchbrochen von einem filumartigen Gerüstwerk. Scharfe Grenzen sind keine vorhanden. Die Färbung des Leibes wechselt zwischen intensiverer und schwächerer Färbung.

Um die Follikel herum finden sich reichlich intensiv gefärbte spindelförmige Kerne, die dem Bindegewebe angehören.

Die Kerne zeigen ein völlig anderes Bild als wir bis jetzt zu sehen gewohnt waren. Sie sind klein, kaum I $\mu$ im Durchmesser, äußerst intensiv gefärbt und durchweg basal gelagert. Nukleoli sind keine zu sehen. In vielen Zellen sind die Kerne in eine Ecke verschoben. In den noch halbwegs etwas regulär angeordneten Zellreihen stehen die Kerne oft mindestens 3-5 Kerndurchmesser voneinander entfernt. Verschiedene Kerne können etwas größer werden, aber diese sind sehr selten. Einzelne Kerne weichen von der runden Form ab, sind vieleckig, verklumpt und haben einen eingekerbten Rand. Die langgestreckten Kerne des mehr perifollikulären und spindelförmigen Gewebes sind davon deutlich $\mathrm{zu}$ unterscheiden.

Die soliden, etwas undifferenzierten Zellpartien zeichnen sich durch eine Kernarmut aus. In vielen Zellen können überhaupt keine Kerne mehr nachgewiesen werden. Die Kerne nehmen nur einen ganz kleinen Teil des 'Zelleibes ein. Andere Kerne zeigen eine halbmondförmige intensiv gefärbte Partie, während der Rest ganz hell gefärbt ist (Fig. 23a). 
Ovale oder stäbchenförmige Kerne sind in diesen Partien keine vorhanden, während Kerverklumpungen nachgewiesen werden können.

Mit Immersion (I200) sind in keinem Kern Nukleoli oder nukleolenartige Bildungen nachgewiesen, nur eine hellere wie dunklere Halbmondzellpartie sind sehr scharf voneinander zu unterscheiden (Fig. 23a). Ganz vereinzelt zwischen diesen Kernen können normal große ( 2 bis 2,2 $\mu$ Durchmesser) Kerne bläschenförmiger Natur gefunden werden, in denen ein vereinzelter Nukleolus nachweisbar ist. Derartige Beobachtungen sind selten.

Der Zelleib zeigt eine durchweg netzartige Struktur, ohne scharfe Begrenzung, so daß keine Membran nachgewiesen werden kann. In den Randpartien sind die verklumpten Kerne etwas reichlicher vorhanden. Kolloid ist auch auf diese Weise ganz selten zu sehen.

Das Bild entspricht einer völligen Degeneration und Auflösung des normalen Zellverbandes, wie man es nicht selten in Strumen von Kretinen antreffen kann. Normale Partien sind fast keine mehr vorhanden.

R a t t e 9. Geboren im Mai I908. 6 Monate mit rohem Rupperswiler Wasser in Basel gefüttert. Getötet am I2. I. I909. Röntgenologisch ist eine ganz geringe Verzögerung im Schlusse der Epiphysenlinien eventuell anzunehmen.

Die Schilddrüse zeigt makroskopisch eine deutliche Vergrößerung. Sie ist körnig granuliert, ein Knötchen kann ihr nicht nachgewiesen werden. Die Größe des rechten Lappens beträgt 12:5:4, des linken I0: 5:3 mm (Fig. 23b). Auf Schnitt (Färbung Hämotoxylin-Eosin) ist nur eine diffuse Färbung zu erkennen, ein lobulärer Bau oder ein bindegewebiges Netzwerk ist nicht vorhanden. Histologisch sind zahlreiche Gefäße vorhanden.

Neben degenerierten Partien, wie bei Ratte 8, kommen speziell rein follikuläre Randpartien vor. Daneben finden sich länglich gebaute Follikel mit septenartigen und papillären Bildungen. In den medial gelegenen Partien sind schlauchförmige Gebilde ziemlich zahlreich vorhanden. Eine vereinzelte, I20 $\mu$ Durchmesser haltende Höhle ist vorhanden, deren Epithel ist kubisch, vielerorts platt. Solide Partien sind ziemlich reichlich vorhanden, deren Zellen sind klein $0,5-\mathrm{I} \mu$ und sehr intensiv gefärbt. Hier finden sich die zahlreichen oben beschriebenen Degenerationsprodukte. Zahlreiche Kernanhäufungen können da und dort vorkommen.

Das Gesamtbild zeigt einzelne normale Schilddrüsenpartien, daneben findet sich der Großteil des Gewebes in Degeneration, an einzelnen Stellen können jedoch auch beginnende Wucherungen des Gewebes nachgewiesen werden.

$\mathrm{R}$ a t t e Io. Nicht völlig ausgewachsen. Seit I. V. mit Rupperswiler Wasser in Basel gefüttert, getötet am 6. XI. 1908 in $\mathrm{CHCl}_{3}$-Narkose. 
Rötgenologisch können keine Veränderungen in den Waichstumsgrenzen nachgewiesen werden, dagegen zeigen sich beide Schilddrüsenlappen vergrößert. Rechts $8: 5: 4$, links $7: 5: 4$.

Auf Schnitt zeigt sich kein ausgesprochener lobulärer Bau, hier und da schmale und breitere Septen. Schwache Vergrößerung zeigt eine diffuse Anordnung des Gewebes. Die Follikel haben neben einer runden und ovalen Form überall noch diverse andere Formen angenommen, indem sie vieleckig geworden sind. Der Durchmesser variiert zwischen $40-60 \mu$. Einzelne zeigen einen doppelschichtigen Wandbelag, Histologisch zeigt der Epithelbelag der Follikelwand diese hochgradige Auflockerung und Zersetzung wie wir sie oben beschrieben haben. Normal gebaute Follikel sind nur noch ganz wenige vorhanden. Ein spezielles Interesse beansprucht der Kernbau.

Unter den Kernen können 3 verschiedene Gruppen voneinander unterschieden werden.

Die größte Zahl der Kerne bietet das Bild kleiner runder, äußerst intensiv gefärbter Punkte, in denen keine Nukleoli mehr zu unterscheiden sind. Der Durchmesser der Kerne beträgt kaum I $u$. Die Kerne können mitten in den Zellen stehen oder randständig sein.

Neben diesen Kernen sind ziemlich zahlreiche 1 ä n g li i c h e kleine, ebenso intensiv gefärbte Kerne vorhanden, die teilweise eine ovoide Form annehmen können und hier und da mehr zerklumpter Natur sind. Dabei finden sich halbmondförmig gebaute Kerne vorhanden, wie wir sie oben beschrieben haben.

In der Zahl am mäßigsten sind die normal großen mit Nukleoli versehenen Kerne vorhanden.

Diese verschiedenen Kerne kommen da und dort nebeneinander vor. Bei den kleinen runden Kernen kann mit Immersion ein dunkler gefärbter Rand um eine hellere Kernmitte konstatiert werden. Die Zahl der Nukleoli schwankt in den verschiedenen normal gebauten Kernen. Zwischen den einzelnen Zellgruppen gibt es Kerne die sich scharf weder zu der einen noch der andern Gruppe weisen lassen, so daß man den Eindruck erhält, daß die normalen Kerne zu verklumpten und dann $\mathrm{zu}$ den kleinen punktförmigen degenerieren.

Der Abstand der Kerne voneinander kann an einzelnen Stellen ein recht großer sein, speziell auch an den Stellen, an denen ein normaler Zellbelag vorhanden ist.

Die ganze Schilddrüse hat eine Vergrößerung erfahren, das Gewebe zeigt entschiedene Degenerationserscheinungen, daneben kann etwas normales Gewebe nachgewiesen werden.

$\mathrm{R}$ a t $\mathrm{t}$ e II. 6 Monate altes Tier, gefüttert vom Io. Mai bis I4. November 1908 mit rohem Rupperswiler Wasser in Basel. Das Tier ist vollständig ausgewachsen, und zeigt röntgenologisch kein abnormes 
Wachstum an den Epiphysenlinien. Die Schilddrüse zeigt sich erheblich vergrößert. Rechts I5:6:4, Links $\mathrm{I}_{4}: 5: 4 \mathrm{~mm}$ (Fig. 24).

Das histologische Bild entspricht Ratte ro. Die Degeneration ist nicht so stark fortgeschritten wie bei dem vorhergehenden Tiere. Normal gebaute Follikel sind in recht ansehnlicher Anzahl vorhanden. In den größeren Follikeln können da und dort Papillen nachgewiesen werden.

Die Auflockerung des Epithelbelages findet sich speziell in den mehr medialen Partien. Vereinzelte schlauchförmige Gebilde haben ein typisches zylindrisches Epithel.

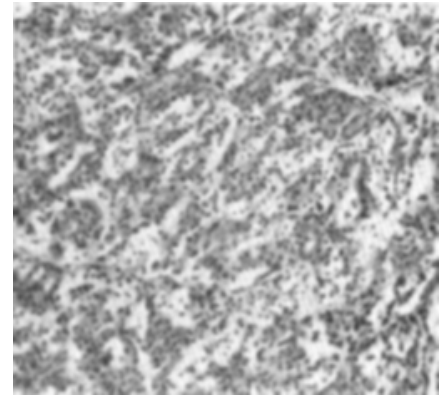

Fig. 24.

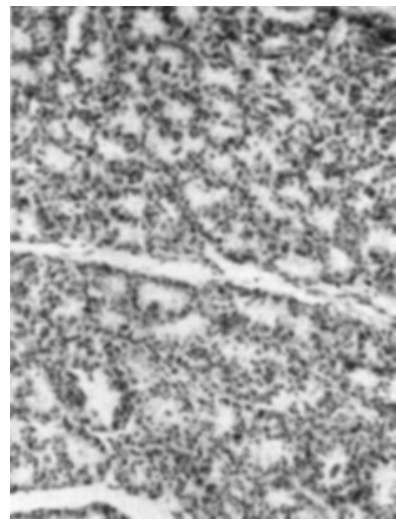

Fig. 25 .

R a t t e I2. 4 Monate altes Tier, vom I6. V. bis 8. XI. I908 in Basel mit rohem Rupperswiler Wasser gefüttert. Röntgenologisch kann nichts an den Epiphysen nachgewiesen werden.

Makroskopisch zeigt sich die Schilddrüse auf beiden Seiten etwas vergrößert $6: 4: 3 \mathrm{~mm}$ und $5: 4: 3 \mathrm{~mm}$ (Fig. 26).

Auf dem mikroskopischen Schnitte entspricht das Bild im großen und ganzen dem Befunde bei Ratte ro. Der größere Teil der Drüse zeigt ebenfalls die diffusen Auflockerungen und Lösungen des Epithelbelages, jedoch nicht über das ganze Gesichtsfeld zerstreut; sondern an einzelnen zirkumskripten Partien in Läppchen von $250 \mu$ Länge und I30 $\mu$ Breite finden sich runde und ovale Follikel vor, die einen normalen Epithelbelag besitzen. Allerdings kann auch dieser schon da und dort beginnende Auffasserung zeigen. Kolloid ist intensiv blaugefärbt an einzelnen Stellen vorhanden. Der Zelleib zeigt sich hell gefärbt, die Kerne sind bläschenförmig.

Bei starker Vergrößerung (Syst. 7, Ok. 3) sind nicht die kleinen runden Kerne, die dunkelgefärbt sind, am zahlreichsten vertreten, sondern 
die größeren oval unregelmäßig geformten Kerne, mit eingekerbtem Rand, die eine verklumpte Form haben. Diese Schaltkerne sind in allen Gesichtsfeldern am häufigsten anzutreffen. Am geringsten an Zahl sind die großen bläschenförmigen mit Nukleoli versehenen Kerne vorhanden. Kernbilder, die als Übergangsformen betrachtet werden können, sind sehr zahlreich vertreten.

Solide Zellhaufen und Stränge sind vereinzelt vorhanden, in andern Gesichtsfeldern fehlen sie.

Der ganze Bau dieser Schilddrüse entspricht völlig den Degenerationserscheinungen der Bilder von Ratte ro. An einzelnen Stellen ist der Prozeß weiter fortgeschritten, während er an anderen zurückgeblieben ist. Normale Zellpartien sind nur in ganz mäßiger Ausbreitung vorhanden.

$\mathrm{R}$ at te I3. Ausgewachsenes Tier, gefüttert von Ende Juni Ig08 bis zum 9. II. I909, an welchem das Tier in Chloroformnarkose getötet wurde. Röntgenologisch sind sämt-

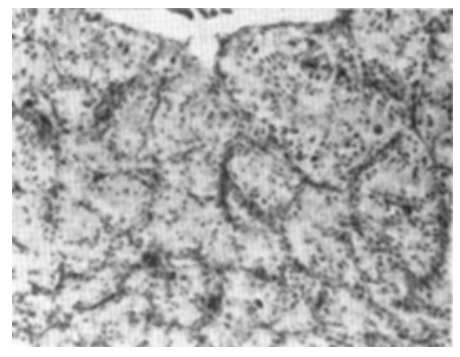

Fig. 26. liche Epiphysen verstrichen und alle Knochenkerne angelegt.

Die Drüse zeigt sich makroskopisch erheblich vergrößert. Links Io:6:5, Rechts I2:4:4. Auf Schnitt ist eine Granulierung sehr deutlich zu sehen (Fig. 25 und 3I b Seite 3I7).

Die Randpartien zeigen ein mehr follikuläres Gewebe, während in den zentralen Partien zahlreiche schlauchförmige Gebilde und solides undifferenziertes Gewebe vorhanden ist. Diese Partien treten durch eine intensive Kernfärbung hervor. In größerer unregelmäßig gebauter bläschenförmiger Lumina finden papilläre Wanderhebungen. die eine intensive Färbung zeigen.

In den Randpartien findet sich normales kubisches Epithel, während die zentralen Partien, in den Schläuchen, das typische mehrmals geschilderte zylindrische Epithel besitzen, das da und dort in die soliden Partien übergeht.

Degenerative Prozesse sind keine vorhanden, an verschiedenen Stellen ist ein Wachstum des parenchymatösen Gewebes vorhanden und eine Neubildung von indifferenzierten Zellpartien.

Die folgende $\mathrm{R}$ a t $\mathrm{te} \mathrm{I}_{4}$ bildet ein Übergangsstadium $\mathrm{zu}$ der folgenden Versuchsreihe.

Sie wurde anfangs März geboren und erhielt vom I3. V. bis I9. XI. I908 Aarauer Quellwasser, welches mit Rückständen vom Beckefeldfilter und den Papierfiltern durchsetzt war. Der Ratte wurde dieses verabfolgt, in der Meinung, daß die strumöse Degeneration dementsprechend rascher eintreten solle. 
Röntgenologisch war an dem Tiere nichts nachzuweisen. Makroskopisch war die Schilddrüse beidseits in ganz geringer Weise vergrößert. Io: $3: 2 \frac{1}{2}$ und 9:21/2:3 (Fig. 27). Auf Schnitt konnte nichts von einem lobulären Bau nachgewiesen werden. Histologisch bei der Färbung (Hämatoxylin-Eosin) finden sich keine Septen (Ok. 3, Syst. 3) (Fig. 28).

In den Randpartien ist ein deutlich follikulärer Bau vorhanden. 3, 4 oder mehrere Follikel stehen in einer Gruppe nebeneinander. Der Durchmesser der Follikellumen kann 25-40 $\mu$ betragen, im Durchschnitt beträgt er $20 \mu$.

Je mehr man ins Gesichtsfeld gegen die medialen Partien zu kommt desto zahlreicher ist das solide undifferenzierte Gewebe vorhanden.

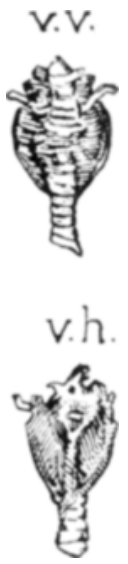

Fig. 27 .

Aarauer Filterrückstand und Wasser.

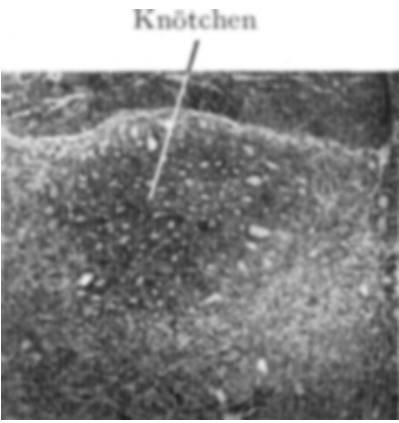

Fig. 28 .
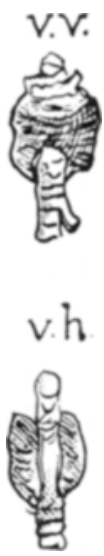

Fig. 29 .

Filter und Satz in Milch aufgeschwemmt.

In diesen Partien finden sich länglich-schlauchförmige Gebilde, die einen Längsdurchmesser bis zu Ioo $\mu$ haben können und durch eine intensivere Färbung hervortreten. In den Follikeln findet sich stark gefärbtes Kolloid, das von dem Epithelbelag retrahiert ist.

Im linken Lappen findet sich direkt neben dem Epithelkörperchen eine längsovale zirkumskripte Gewebsstelle, die durch ihre intensive Färbung auffällt. Sie hat einen Durchmesser von $200 \mu$ und ist aus dem übrigen Gewebe stark hervortretend. Sie besteht aus ca. 40-50 kleinen Follikeln, die einen Maximaldurchmesser von Io-20 $\mu$ haben, und sehr nahe nebeneinander stehen. Daneben finden sich auch noch solide Bildungen vorhanden (Fig. 28).

In demselben Lappen findet sich am vorderen Rande ein ähnliches Knötchen, von $20 \mu$ Durchmesser, das aus $3-4$ bläschenförmigen langgezogenen Schläuchen besteht. Gegen den lateralen Rand finden 
sich im rechten Lappen fünf oder sechs intensiv gefärbte längliche Follikel mit einem Durchmesser bis zu $60-80 \mu$, die durch ein matthellrotes Kolloid. das mit Vakuolen durchsetzt ist, gefüllt sind.

Syst. 7, Ok. 3 zeigt die Follikel aus kubischem oder plattem Epithel bestehend, das letztere findet sich hauptsächlich in den gegen den Rand zu gelegenen Partien. Dieses Epithel ist 3-4 $\mu$ hoch und ebenso breit. Auch die Kerne haben fast einen Durchmesser von $3 \mu$. Die Kerne sind zahlreich und ihr gegenseitiger Abstand beträgt $1 / 4$ ihres Durchmessers. Die Zellen haben eine deutliche Membran, die Kerne ebenfalls und sind intensiv blau gefärbt. Im Kern findet sich ein großer Nukleolus neben mehreren kleineren. Es können sich auch 3-4 größere Nukleoli in einem Kerne vorfinden.

In den solid gebauten Partien können da und dort die polyedrischen Zellen durch lichte $Z$ wischenräume voneinander getrennt sein. Der Zelleib ist ebenfalls hellrosa tingiert, während der Kern eine bläulich helle Farbe aufweist. In dem hellroten Kolloid einiger größerer Follikel findet sich eine große, fast $8 \mu$ messende Zelle, die einen dunkel gefärbten wandständigen Kern besitzt, der keine Wandmembran zeigt, Vakuolen hat und an einzelnen Stellen dem Kolloid ähnlich sieht.

Die Kerne des soliden Gewebes und der undifferenzierten Folikel sind hell gefärbt, ihre Größe hat da und dort etwas zugenommen, dabei finden sich jedoch in deren Nähe zahlreiche dunkelblaue, kleine runde Kerne, die kaum I $\mu$ Durchmesser haben. Im Processus pyramidalis sind diese Kerne vorherrschend, indem sie neben verklumpten unregelmäßig gebauten Kernen stark überwiegend vorhanden sind. Daneben finden sich einige normale Follikelbildungen, in denen das Kolloid sehr intensiv gefärbt ist. Die Kerne haben hier an Zahl eine starke Zunahme erfahren. Das bindegewebige Zwischengewebe, aus spindelförmigen Zellen bestehend, ist nicht besonders hervortretend.

Bei starker Vergrößerung kann das oben beschriebene Knötchen nicht scharf von dem übrigen Gewebe abgegrenzt werden. Es zeigt einen follikulären Bau mit äußerst zahlreichen Kernen in dem kubischen Epithel, das an einzelnen Stellen zylindrisch geworden ist. Das Epithel ist einschichtig, doch steht überall Kern an Kern, die nicht in Reihen angeordnet, sondern stark durcheinander gewürfelt sind. An einzelnen Stellen machen die Kerne den Eindruck, als ob sie gerade durch ihre große Zahl lumenwärts gepreßt werden. Die Kerne haben zum wenigsten eine runde Gestalt, sondern sie sind längsoval, hier und da, allerdings selten, finden sich unförmige dunkelgefärbte kleinere Kerne, die keine Nukleoli aufweisen.

Das Lumen enthält kein Kolloid, ziemlich weite Blutgefäße sind vorhanden. Ganz dasselbe Bild zeigt das kleine randständige Knötchen. In den großen schlauchförmigen Partien sind die Zellen plattenförmig geworden. Der kolossale Zell- und Kernreichtum ist im Vergleich zum soliden Gewebe, das in der Nähe liegt in die Augen springend. Im- 
mersion zeigt in diesen Partien eine auffallend geringe Anzahl von Nukleoli und eine sehr intensive Färbung des Zelleibes. In den übrigen Partien sind die Kerne heller gefärbt und haben nụr wenige Nukleoli.

Neben einem typischen Strumaknötchen finden sich wuchernde Zellpartien, aber auch noch normales Gewebe.

III.

Ratten, gefüttert mit dem Filterrückstand von Berkefeldfiltern und Papierfiltern in Milch a uf g e 1 öst.

$\mathrm{R}$ a t t e $\mathrm{I}_{5}$. Junges Tier, 3 Monate alt. Beginn der Fütterung Mai I908, getötet am I7. II. Ig09. Das Tier ist ausgewachsen. Röntgenologisch kann nichts nachgewiesen werden. Es ist fertig entwickelt.

Makroskopisch ist die Schilddrüse nicht vergrößert und zeigt einen lobulären Bau auf dem mikroskopischen Schnitte (Fig. 29).

Bei schwacher Vergrößerung ist ein durchweg follikulärer Bau zu konstatieren. Die Follikel sind in der Mehrzahl von runder Form, einzelne längsoval, nur ganz vereinzelte sind bläschenförmig und etwas unregelmäßig geformt. Die Größe beträgt bei den meisten Follikeln I5-20 $\mu$, einzelne können 30-40, seltener bis Ioo $\mu$ groß werden.

An zirkumskripten Partien findet sich zwischen einzelnen Follikeln solides Gewebe, welches strangartig angeordnet ist dabei sind seiten Follikel schlauchförmig ausgebildet. In einigen Follikeln findet sich dunkel gefärbtes, scholliges Kolloid, in den übrigen ist die Färbung eine weniger intensive hellere. In vereinzelten Follikeln findet sich da und dort, immerhin recht selten, eine papilläre Erhebung, deren Zellen eine intensive Färbung zeigen. In den Randfollikeln ist das platte Epithel vorherrschend, während in den mehr zentral gelegenen Partien mehr kubisches Epithel vorhanden ist. Zylindrisches Epithel kann nirgends nachgewiesen werden. Das platte Epithel ist $3:(3-4) \mu$ groß und enthält einen längsovalen Kern, die Kerne stehen durchschnittlich $1 / 2$ des Kerndurchmessers voneinander ab. Ihre Färbung ist eine intensive, es können darin nur vereinzelte Nukleoli nachgewiesen werden. In den mehr soliden Partien haben die Kerne bis. 3-4 $\mu$ Durchmesser, sind hier und da vieleckig, ihre Tingierung ist eine hellere. Bindegewebe ist überall nur sehr spärlich vorhanden.

Vereinzelt sind dunkler gefärbte Kerne zu sehen, die eine verklumpte Gestalt zeigen. Um die Follikel finden sich da und dort feine Bindegewebsstränge, die aus schönen spindelförmigen Kernen bestehen.

Immersion zeigt keine Besonderheiten. Die Kerne stehen stets in schönen Reihen angeordnet, nirgends irgendwelche Kern- oder Zelldegenerationen nachzuweisen.

Diese Schilddrüse zeigt einen durchaus normalen Bau im histologischen Bilde. Degeneration oder Wucherungen sind keine vorhanden. 
$\mathrm{R}$ a t $\mathrm{t}$ e $\mathrm{I} 6$. Getränkt vom $\mathrm{I}$. Juni als $2-3$ Monate altes Tier mit Filterrückstand des Aarauer Quellwassers, getötet am I. XII. I908 in Chloroformnarkose. Röntgenologisch kann an dem Tiere eine geringe Wachstumsstörung nachgewiesen werden, die jedoch nicht bindend auf die Nahrung zurückgeführt werden kann.

Die Schilddrüse ist nicht vergrößert, $6: 2: 2 \mathrm{~mm}$ und $5: 2: 2 \mathrm{~mm}$, und zeigt einen deutlich lobulären Bau auf dem Längsschnitte.

Der histologische Bau dieser Drüse zeigt auf Schnitt einen größtenteils normalen Bau, an ganz vereinzelten seltenen Stellen ist der Aufbau nicht genau dem normalen Gewebebau entsprechend.

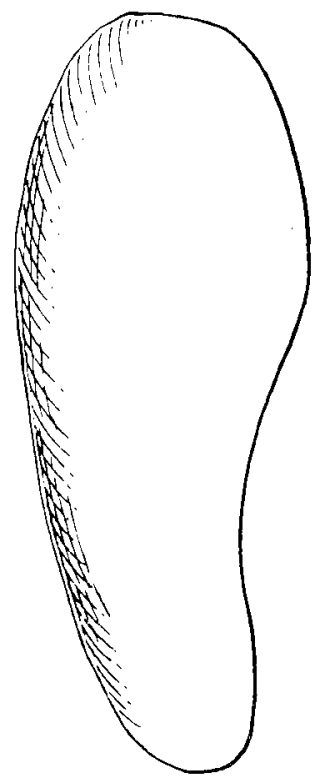

a Vorderansicht.

Fig. 30.

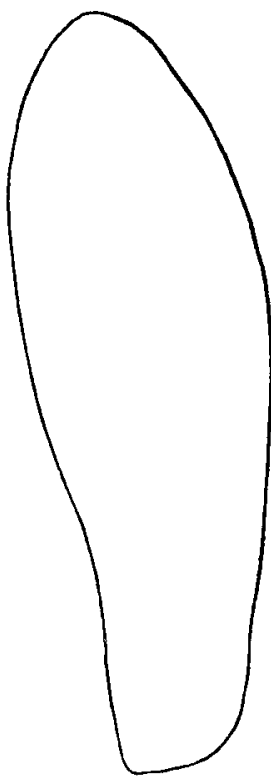

b Seitenansicht.

$\mathrm{R}$ a t t e I7. 4 Monate altes Tier, gefüttert von Anfang Juni bis I2. II. I909 mit Filterrückständen des Aarauer Quellwassers in Basel. Getötet im ausgewachsenen Zustande am I2. II. Ig09 in Chloroformnarkose. Im röntgenologischen Bilde kann nichts nachgewiesen werden.

Die Schilddrüsenlappen zeigen sich in keiner Weise vergrößert. Ihre Größe beträgt $5: 3: 2 \mathrm{~mm}$ und $4: 4:$ I mm. Ein lobulärer Bau ist undeutlich vorhanden.

Der histologische Bau der Drüse entspricht vollständig demjenigen

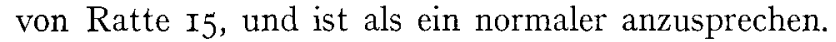

IV.

$\mathrm{H}$ u n d e.

6 Monate alte Schnauzer, gefüttert vom I. Mai bis zum I5. Dez. I908 mit Rupperswiler Wasser. Die Hunde entstammen demselben Wurf. 
H u n d I, grauhaariger Schnauzer, Männchen. Die jeden Monat vorgenommene Palpation ergibt eine langsame Zunahme der beiden Schildrüsenlappen, die stets größer werden. Das Aussehen der Hunde ist ein vorzügliches. Haare nicht struppig, sie sind stets sehr lebhaft.

I5. Dez. 1908 in ruhiger Athernarkose halbseitige Strumektomie. Die beiden Lappen sind gleichgroß, der entfernte linke hat ein Gewicht von IIo g. Die Größenverhältnisse betragen $7 \frac{1}{2} \mathrm{~cm}$ Länge zu $3 \mathrm{~cm}$ Breite zu $21 / 2 \mathrm{~cm}$ Dicke (Fig. 30).

Auf Schnitt ist die Schilddrüse schön hellrot gefärbt, hat eine körnige Oberfläche und ist von größeren und kleineren Gefäßen reichlich durchsetzt. Palpatorisch ist der Lappen sehr derb anzufühlen. Im Vergleich zum Kontrolltier ist der Lappen sowohl im Gewicht als auch in der Größe auf

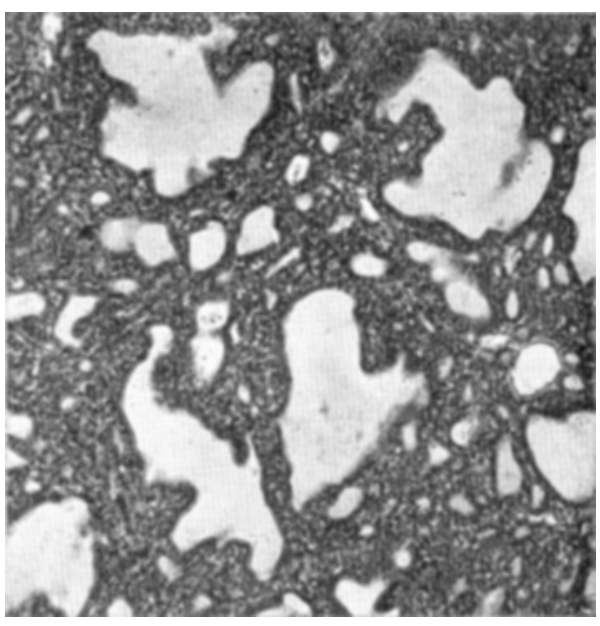

Fig. 31 a. das dreifache angestiegen.

Färbung (Hämatoxylin-Eosin und van Gieson). Auf Schnitt kann deutlich ein lobulärer Bau konstatiert werden. Hellere und dunklere Partien wechseln miteinander ab. An einigen Stellen sind größere kolloidale Schollen deutlich sichtbar. Daneben finden sich einzelne größere Gefäßlumina (Fig. 3I a).

Bei schwacher Vergrößerung, Objekt 3, Okular I, sieht man, daß der größte Teil des Gesichtsfeldes von unregelmäßig geformten weiten Hohlräumen eingenommen wird, welche ganz verschiedene Größendurchmesser haben, die von 20-I70 $\mu$ variieren können. Am Rande sind diese Gebilde schlauch- und bläschenförmig, während mehr gegen die Mitte zu runde und ovale Follikel sie durchsetzen. An einzelnen Stellen finden sich reine, solide strangartige Zellgebilde, die äußerst zellreich sind.

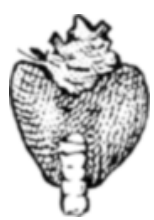

Fig. 3 I b (Ratte I3).

In den großen unregelmäßigen Hohlräumen finden sich zapfenförmige Zellkonglomerate vorhanden, die in den Lumen selbst Septen bilden können. Die Färbung dieser Bläschen, wie auch der schlauchförmigen Gebilde ist eine sehr intensive. Der Inhalt der Lumina zeigt eine homogene Färbung, an einzeinen Steilen ist er schollig und tritt nicht überall an den Endothelbelag heran. Speziell in den Bläs- 
chen ist er hell gefärbt, stark schollig und vom Epithelbelag retrahiert.

Die papillenförmigen Vorsprünge zeigen häufig in ihrer Mitte eine Aufhellung.

Im allgemeinen zeigt das Kolloid in den randständigen Bläschen eine gute Färbung und ist von vakuolären Bildungen durchsetzt, während es in den schlauchförmigen Gebilden, heller gefärbt, und mehr körniger Natur ist. V a n G i e s o n zeigt, daß die randständigen Follikel von einem gutgefärbten Bindegewebe umgeben sind, welches ins Innere des Gewebes Fortsätze schickt. Gefäße sind einzelne von nicht besonderer Größe vorhanden.

An einzelnen Stellen finden sich ganz schmale spaltförmige Lumina. Je mehr man gegen die Mitte des Lappens zukommt, desto zahlreicher werden die großen unregelmäßigen Lumina, während die soliden Zellpartien seltener werden, ebenso nehmen die schön gebauten Follikel an Zahl ab. Die Septen und Papillen in den großen Lumina werden jedoch um so zahl- und zellreicher. Das Bindegewebsnetz ist sehr deutlich ausgebildet und feine fibrillären Züge gehen überall hin und teilen größere und kleinere Läppchen ab.

Zwischen den einzelnen Septen finden sich größere und kleinere Lumina, und in den Septen selbst können sich derartige Lumina finden. Vereinzelte Stellen sind vorhanden, in denen kleine runde Follikellumina sehr reichlich vertreten sind, ebenso solide Drüsenhaufen. Dabei sind größere Blutgefäße vorhanden. Bei den sehr intensiv ausgebildeten papillären Erhebungen kann keine scharfe Zellgrenze konstatiert werden. Einzelne Papillen zeigen an ihrer Basis Schnürfurchen wie wenn eine Abschnürung hier stattfinden würde.

Bei starker Vergrößerung (Objekt. 7, Okul. 3). Die bläschenförmigen unregelmäßigen Gebilde zeigen sich da und dort, durch solide Zellstränge miteinander in Verbindung getreten.

Die Größe der unregelmäßigen Bläschen variiert zwischen einem Durchmesser von I20-150 $\mu$. Der Bläscheninhalt ist hellblau gefärbt, und teilweise körnig zerfallen. Die Kerne sind schön rund, mit einem Durchmesser von $I-2 \mu$. Das Epithel ist vorwiegend zylindrisch. $5 \mu$ hoch zu $2 \mu$ Breite, es ist bei den engen spaltförmigen Lumina nicht immer zusammenhängend, und bildet lumenwärts hier und da eine scharf gezackte Linie. Die Kerne sind größtenteils basalständig, stehen nahe beieinander, so da $\beta$ sie sich da und dort berühren. Ihr Abstand voneinander beträgt kaum $1 / 4$ des Kerndurchmessers. Sie bilden nicht eine schöne wellenförmige Linie.

In den ins Lumen einspringenden Septen treten die Kerne noch näher zueinander, so daß sie häufig nicht scharf voneinander unterschieden werden können. Zwischen den einzelnen Septen ist eine sehr intensiv gefärbte fadenförmige Substanz ausgespannt. An einzelnen Stellen kann das Epithel etwas niedriger werden, während die lumen- 
wärts gekehrte Zellfläche etwas eingekerbt ist. Der Zelleib besteht aus einem grauroten, dunkelgefärbten und gekörnten Protoplasma. In den faltigen Wanderhebungen der Hohlräume pann hier und da ein eigentliches Lumen konstantiert werden.

In den ganz großen Hohlräumen findet sich verschiedentlich kubisches Epithel, in denen der Zellkern mehr gegen die Mitte zu gelegen ist. Hier und da kann das Epithel noch flachere Formen annehmen. In den mehr schlauchförmigen Gebilden ist die Kontur des Lumens eine völlig unregelmäßige. Die Zellen stehen unregelmäßig da, sind aufgefasert und aufgerissen an ihren Randpartien, an anderen Lumenrändern sind auch vieleckige Kerne und Zellen vorhanden. Bei diesen Partien ist eine scharfe Abgrenzung gegen die soliden Zellpartien nicht zu machen. Die unscharfen Grenzen schließen sich den papillären Erhebungen sehr deutlich an. Die zapfen- oder kolbenförmigen Papillen bestehen aus einem größeren Konglomerat von als Haufen angeordneter Zellen. Bei den ganz großen Papillen sind die Zellen oft kubisch hier und da gar abgeplattet. Der Zellkern kann fast so groß wie die Zellen werden. Um die Kerne kann hier und da ein leichter Hof vorhanden sein. Die Kerne in den papillären Exkreszenzen sind häufig zweireihig, und dabei dicht gedrängt, sie nehmen nicht durchwegsweise basale Stellung ein. In den Exkreszenzen kann hier und da ein bindegewebiger Strang des Stroma vorkommen; sie sind vereinzelt durch derartige Stränge mit den soliden Zellpartien verbunden, im allgemeinen wird jedoch diese Verbindung, wie auch mit den Follikeln, durch solide Zellstränge hergestellt. Vereinzelt können die größern Hohlräume da und dort zusammenstoßen, und so ein neues Lumen bilden.

Die Zellen der soliden Zellhaufen besitzen eine polyedrische, sechseckige Form, und stehen meist sehr enge nebeneinander, so daß sie da und dort eine geradezu wabenförmiges Gebilde darstellen. Die Kerne sind intensiv tingiert. An einzelnen Partien sind die Kerne völlig aus den Zellen ausgefallen. In einzelnen Partien wird die Wand der unregelmäßigen Räume von kernarmen Zellen gebildet, an die sich wabenförmig angeordnete solide Zellpartien anschließen, während die übrigen Wände durch kubische Zellen hergestellt werden. Diese leeren Zellen sind nicht immer ganz scharf von dem Lumeninhalt zu trennen.

Feine Blutgefäße können da und dort bis in die Papillen hinein verfolgt werden. Die Follikel, die einen mehr normalen Bau haben, zeigen ein ausgesprochen kubisches Epithel mit einem zentralstehenden sehr intensiv gefärbten runden Zellkern. Die Zellgrenzen sind sehr deutlich. Das Epithel hat kaum eine Höhe von I $\mu$. Der Lumeninhalt der sehr intensiv gefärbt ist, tritt nicht an die Zellwand heran und zeigt eine schollige Trübung. Der Zellkern ist $3 / 4 \mu$ im Durchmesser. Das Protaplasma besteht aus einem fädigen Gerüstnetz. Der Zellrand ist nicht immer scharflinig, sondern eher zackig. Längsovale Kerne sind 
da und dort vorhanden. In den Follikeln kann nirgends eine papilläre Erhebung konstatiert werden. Das deutlich differenzierbare perifollikuläre Bindegewebe zeigt da und dort vereinzelte Blutgefäße.

Einzelne vergrößerte Follikel, die da und dort eine unregelmäßige Form angenommen haben, zeigen ein merkwürdiges Verhalten. An mehreren zirkumskripten Stellen zeigt sich die Wand scharf von papillenähnlichen zellreichen Partien durchbrochen, die von einer nicht scharf abgegrenzten helleren Partie umgeben sind.

Vereinzelt sind auch die Zellen in den soliden Partien lichter angeordnet.

Mit der v a n Gi e s o n schen Färbung sind wenige ganz schmale Bindegewebsstränge als Stroma nachweisbar. Das Kolloid zeigt sich braun gefärbt, und in einigen Hohlräumen sehr enge an der Wand anliegend, so daß man eine Abflachung der Zellen durch das Kolloid annehmen kann. In den Follikeln von mittlerer Größe ist Kolloid noch durchgehends vorhanden, in den verzweigten Schläuchen nicht immer. Ganz selten können längsovale stäbchenförmige Kerne nachgewiesen werden, die in den Zellen dem Lumen parallel verlaufen. Einzelne Fortsätze der Lumina werden da und dort durch eine schmale lichte Schicht etwas intensiver gefärbten Gewebes abgegrenzt.

Mit Immersion sind in den Kernen die verschieden zahlreichen Nukleoli nachzuweisen, deren Färbungsintensität ebenfalls eine verschiedene ist. Die Nukleoli sind in den soliden Partien am zahlreichsten, während bei den normalgebauten Follikeln sie etwas zurücktreten.

Die ganze Schilddrüse zeigt neben normalen Partien ein Gewebe, welches vorherrschend, aus unregelmäßig begrenzten und gebauten Follikeln besteht und bei dem das solide Gewebe sich in einem wuchernden Zustande sowohl intra als extra der Lumina befindet.

$\mathrm{H}$ und 2, grauhaariger Schnauzer. Männchen. Jeden Monat ist eine geringe Zunahme am Halse zu konstatieren. Der Hund hat stets ein gutes Aussehen.

Am I5. Dezember halbseitige Strumektomie in ruhiger Äthernarkose. Beide Lappen sind gleichmäßig vergrößert, der exstirpierte mißt 6,6 cm Länge 2,3 cm Breite und I,8 cm Dicke (Fig. 32).

Auf Schnitt hellrot gefärbt. Leicht gekörntes Aussehen, von größeren und kleineren Gefäßen durchsetzt. Derb elastisch anzufühlen. Das Gewicht beträgt Ioo g. Zum Kontrolltier ist die Vergrößerung eine $21 / 2$ fache.

Auf Schnitt zeigt sich ein deutlich lobulärer Bau; die Läppchen haben einen durchschnittlichen Durchmesser von $1 / 2-1 \mathrm{~mm}$. An verschiedenen Stellen sind die Lumina von Gefäßen sichtbar, die einen verschieden großen Durchschnitt haben. Heller gefärbte Stellen können mit dunkleren abwechseln.

Der histologische Aufbau entspricht in großen Zügen demjenigen von Hund r. Vorherrschend sind solide Zellpartien. Schlauch und 
unregelmäßig geformte bläschenförmige Gebilde sind reichlich vorhanden, in denen zahlreiche papilläre Erhebungen und septenartige Gebilde vertreten sind. Bindegewebe ist nur schwach entwickelt. Kolloid ist in den Follikeln vorherrschend, in den Schläuchen zurücktretend. Die unregelmäßig gebauten Schläuche sind etwas kleiner als bei Tier I. Einzelne Randpartien, da und dort, das Zentrum, können aus runden Follikeln bestehen.

Im soliden Gewebe sind die Kerne stark tingiert. Die Schläuche zeigen das typische sehr hohe Epithel, mit zahlreichen einander sehr nahestehenden runden basal gelegenen Kernen, dasselbe Epithel findet sich
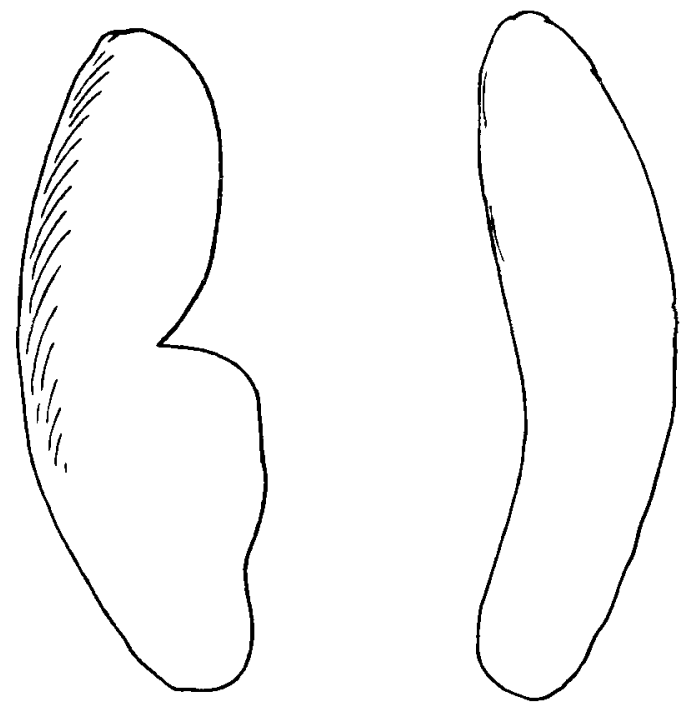

Fig. 32 .

in den Bläschen. Das Follikelepithel ist kubischer, in den Randpartien auch platter Natur.

Aus den soliden Zellhaufen können da und dort zapfenförmige Partien in das Schlauch- und Bläschenlumen hervorwuchern. In diesen Zapfen können sich selbst wieder Follikel bilden. Papilläre Erhebungen sind im allgemeinen weniger zahlreich als bei Hund I, dagegen ist das solide Gewebe viel intensiver vorhanden.

Die Kerne sind meist rund und bläschenförmig, sie können jedoch eine mehr klumpige Gestalt annehmen. Die untere Partie der Drüse besteht fast vollständig aus follikulären Partien.

Das Gesamtbild ergibt diverse normal gebaute Partien, daneben finden sich vorwiegend in Wucherung befindliche Teile der Schilddrüse, so daß das histologische Bild der makroskopischen Vergrößerung entspricht. 
$\mathrm{H}$ und 3, grauhaariger Schnauzer, Weibchen. Die monatliche Zunahme der Schilddrüse ist kaum zu konstatieren. Das Aussehen des Hundes ist stets ein sehr gutes.

Am I5. Dezember Igo8 wird die halbseitige Thyreoidektomie vorgenommen. Beide Lappen zeigen sich nur mäßig vergrößert. Die Maße des exstipierten Lappens betragen: $4: \mathrm{I}, 5: \mathrm{I} \mathrm{cm}$. Das Gewicht des Lappens beträgt $36 \mathrm{~g}$, Größe wie Gewicht sind im Vergleich zum Kontrolltier nur gering erhöht (Fig. 33).

Der Schnitt zeigt makroskopisch einen rein lobulären Bau. Die einzelnen Läppchen haben im Durchschnitt einen Durchmesser von $1 / 2 \mathrm{~mm}$. Hellere und dunklere Partien können deutlich unterschieden werden. Einzelne Lumina sind deutlich sichtbar.

Auf dem Bilde des Schnittes ist ein rein follikuläres Gewebe vorherrschend. Daneben finden sich solide Strangpartien, während die
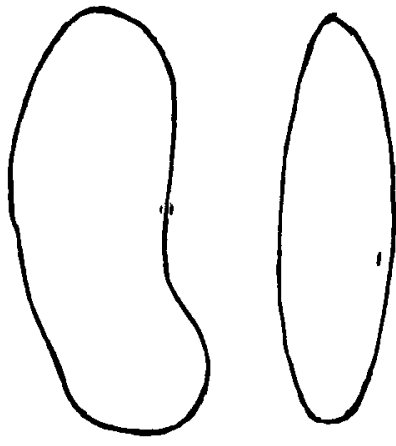

Fig. 33 . Bläschen zurücktretend sind. Die Follikel zeigen ihre reichlichste Entwicklung in den Randpartien und haben im Durchschnitt einen Durchmesser von I5-30 $\mu$, daneben finden sich zahlreiche kleinere mit $3-5 \mu$ Durchmesser. Der Inhalt ist hellblau gefärbt, teilweise mit Vakuolen durchsetzt, an einzelnen Stellen von den Wandungen retrahiert.

Die schlauchförmigen Partien sind im allgemeinen wenig zahlreich, solide Partien können da und dort vorherrschend werden. Auch die papillären Bildungen sind erheblich zurücktretend. Das Bindegewebe ist nur schwach vertreten. Das Epithel entspricht in Anordnung und Bau, den bei Hund I gemachten Erhebungen.

Die Papillen können da und dort aus dem soliden Gewebe exogen in die Bläschen- und Schlauchlumina eindringen, und sich darin verästeln und verzweigen.

Der Gesamteindruck des histologischen Bildes ist folgender:

Der Großteil der Schilddrüse besteht aus einem normalen Gewebe, daneben finden sich zahlreiche Stellen die eine beginnende Wucherung der Epithelien zeigen und bei denen eine beginnende Strumabildung sicher vorhanden ist.

$\mathrm{H}$ und 4. Zur Kontrolle wurde die Schilddrüse eines Schnautzers benutzt, der, von einer andern Mutter stammend, 3 Monate älter war, jedoch stets mit dem Wasser der Basler Leitungsquelle von Grellingen (Jura) getränkt worden war.

Makroskopisch hatte der exzidierte Lappen eine Größe von 2,5: I,4: $0,8 \mathrm{~cm}$. Das Gewicht war $25 \mathrm{~g}$. 
Auf dem histologischen Bilde zeigt sich makroskopisch ein schön lobulärer Bau. Die Größe der Lobuli ist variierend.

Bläschenbildungen schlauchförmiger oder unregelmäßiger Natur sind sozusagen keine vorhanden. An verschiedenen Partien kommen vereinzelte vor, aber nirgends in vergleichbarer Anzahl wie bei Hund I bis 3. Die Bläschen können wohl eine unregelmäßige Form annehmen, aber schlauchförmige Bildungen sind keine vorhanden. Papilläre Bildungen sind ebenfalls zurücktretend. Der Inhalt der Bläschen besteht durchweg aus einem hellbläulich gefärbten Kolloid. Nirgends geht die Wand der Bläschen direkt in die soliden Zellpartien über, durchweg ist eine scharfe Grenze zu konstatieren, oder es stößt Bläschenwand an Bläschen.

Der Großteil der Bilder wird von rein follikulärem Gewebe eingenommen. Follikel stößt an Follikel, während solide Zellhaufen und Zellstränge zurücktretend sind. Die indifferenzierten Partien sind ebenfalls sehr selten hervortretend, an deren Stelle finden sich zu Follikeln differenzierte solide Partien. Sind vereinzelte Papillen vorhanden so bestehen sie aus einer einzigen Zellschicht. Zellreiche Einwucherungen papillärer Natur können nirgends nachgewiesen werden. Die Papillen sind nur als Einstülpungen der Epithelschicht zu betrachten.

Das Epithel ist durchweg kubischer Natur, 3,5:3,5 $\mu$, an einzelnen Stellen flach. Die Kerne sind rund $2 \mu$, in den flachen Partien der Epithelien stäbchenförmig und den Lumina parallel verlaufend. Auch im interzellulären Gewebe finden sich da und dort stäbchenförmige Kerne. Längsovale Kerne sind etwas seltener vorhanden, sie gehören ebenfalls dem flachen Epithel an. Einzelne Kerne sind zwischen den Bläschen in geringer Menge vorhanden. Sie sind meist stäbchen-, teilweise auch lanzettförmig und etwas stärker tingiert, eher etwas unregelmäßig angeordnet, während die Kerne in den Follikeln in schönen Reihen angeordnet sind und einen Abstand von gut I-2 Kerndurchmesser haben. In den Kernen findet sich durchschnittlich I-2 dunkelgefärbter Nukleolns.

Das perifollikuläre Gewebe ist leicht und durchsichtig und mit wenig verschieden geformten Zellen angefüllt, während die runden und regelmäßig gebauten Zellen zurücktretend sind. Da und dort nimmt das Zwischengewebe einen soliden Charakter an.

In den Randpartien ist eine starke Bindegewebswucherung vorhanden, so daß die Follikel komprimiert und die Kerne stäbchenförmig werden. Die Follikel nehmen eine Spaltenform an. Das Kolloid zeigt sich intensiv gefärbt.

Die Färbung nach v a n Gies o n zeigt überall den schön follikulären Bau und ein feines dünnes Bindegewebsnetz, daß um die Gefäße am ausgesprochensten ist, im allgemeinen ist das Bindegewebe zurücktretend. 
Mit Immersion sind keine besonderen Verhältnisse zu konstatieren. Die Nukleoli treten etwas deutlicher hervor, während sie in den mehr länglich gebauten Kernen zurücktretend sind.

$$
\text { Versuche in Aarau. }
$$

$\mathrm{H}$ und 3 wurde von der halbseitigen Thyreoidektomie weg am I5. Dezember mit gekochtem Wasser gefüttert. Am I2. März Ig09 warf sie 8 junge Hunde, von denen 3 sofort nach der Geburt, weitere zwei in den nächsten I4 Tagen starben. 3 wurden von der Mutter während 7 Wochen gestillt. Während dieser Zeit erhielt die Mutter stets gekochtes Aarauer Wasser in Aarau.

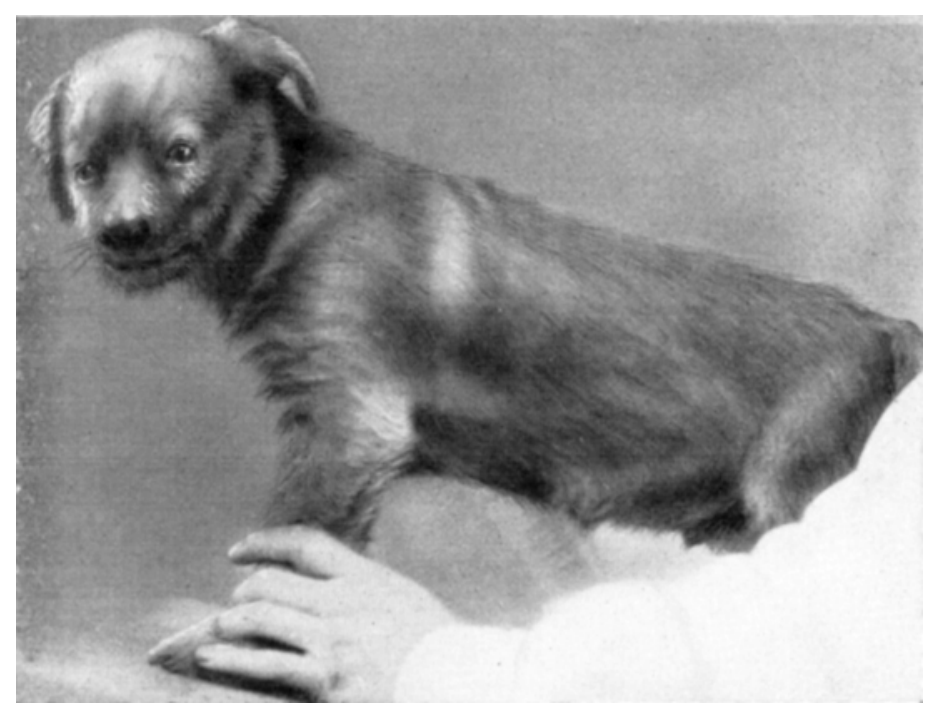

Fig. 34. Man beachte die kurz eingezogene Schnauze.

Die Schilddrüsen der neugeborenen Tiere hatten durchschnittlich folgende Größenverhältnisse: II : $5: 3 \mathrm{~mm}$.

Am I5. Mai Igog wurden die Hunde der Mutter weggenommen, und zwei erhielten täglich 2 Liter Rupperswiler Wasser von der alten Sodquelle, während einer als Kontrolltier mit dem Wasser der neuen Rupperswiler Wasserversorgung aus der Auensteiner Quelle im Jura ernährt wurde.

$\mathrm{H}$ und 5, Schnauzer. Beginn der Fütterung am I5. Mai I909 in Aarau. Palpatorisch ein haselnußgroßer Lappen nachzuweisen. Eine deutliche Vergrößerung der Schilddrüse beider Lappen kann am I5. Juni konstatiert werden. Beide Lappen sind gut hühnereigroß und sehr deutlich zu fühlen. Der Hund hat ein ziemlich struppiges Aussehen, die Haare sind borstig und legen sich dem Körper nicht gut an. 
I5. Juli. Die Struma ist palpatorisch noch bedeutend größer geworden, so daß sie auch von bloßem Auge konstatiert werden kann. Das Fell des. Tieres ist struppig, der Gang wackelig, er macht einen sehr apathischen Eindruck. Er frißt wenig und langsam. Bellt nicht. Liegt im Käfig umher. Keine Freudenbezeugungen, wenn jemand in die Nähe des Stalles tritt. Im Wachstum zeigt er sich in der Länge um Io $\mathrm{cm}$ hinter dem Kontrolltier zurückgeblieben. Länge $40 \mathrm{~cm}$, Höhe $20 \mathrm{~cm}$. Der Unterschied beider Tiere ist schon in der Photographie zu konstatieren (Fig.34 und 38). Deutlich dyspnoetische Beschwerden sind vorhanden.
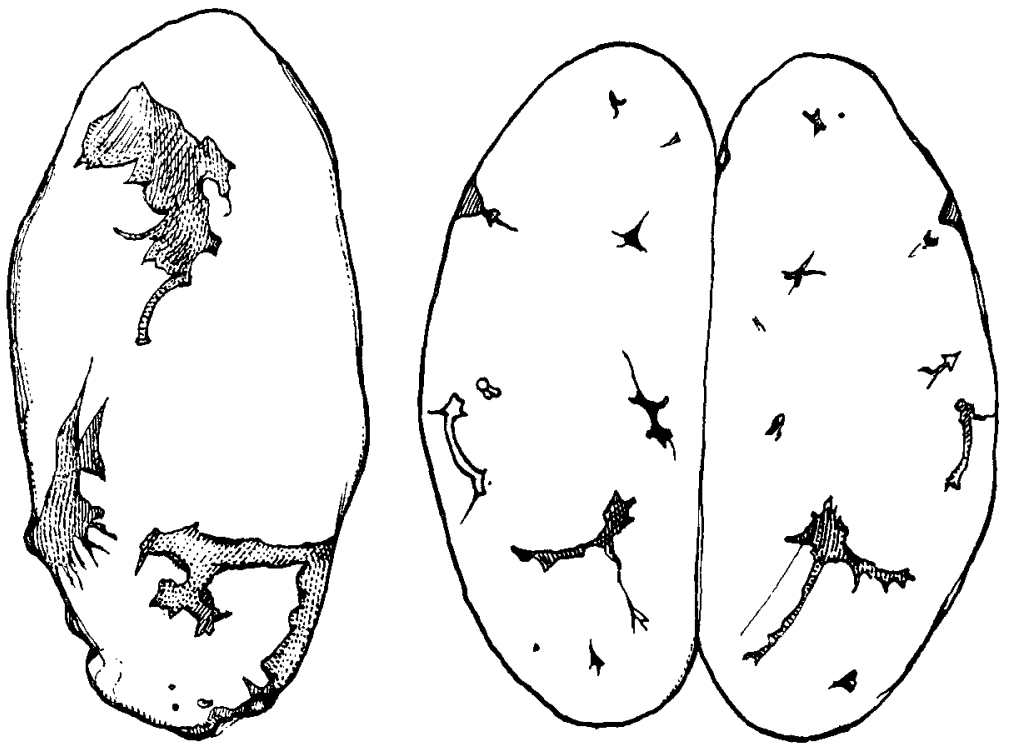

Fig. 35.

I5. Juli. Halbseitige Strumektomie in ruhiger $\mathrm{MoCHCl}_{3}$-Narkose.

Palpatorisch spürt man auf der linken Seite einen stark über hühnereigroßen, fast faustgroßen Strumaknoten, der gut hin und her beweglich ist. Rechts findet sich ein etwas kleinerer Knoten. Die halbseitige Excision wird unter mäßigem Blutverlust vorgenommen.

Der Knoten ist von derbelastischer Konsistenz. Auf Schnitt schön hellrosa, Gefäße sind deutlich zu sehen.

Das Gewicht des Knoten beträgt I65 g. Die Größe beträgt 7,5 lang 4,5 dick und $2,5 \mathrm{~cm}$ breit (Fig. 35). Er ist 7 mal so schwer und 4-5 mal so groß wie der Lappen des Kontrollhundes.

In der Folgezeit erhält der Hund weiter Kropfwasser. Am Io. VIII. erhält er Wasser mit dem Kontrolltier von der kropffreien Auensteiner 
Juraquelle. Bei Beginn mit dieser Fütterung war die restierende rechte Schilddrüsenhälfte gut über faustgroß.

Nach 4 Wochen konnte eine merkliche Abnahme des Tumors konstatiert werden, bei Palpation war sie kaum hühnereigroß.

Am I5. X. war die restierende rechte Seite noch gut nußgroß. Das Benehmen des Hundes war ein anderes, lebhafteres geworden. Er ist von dem Kontrolltiere kaum mehr zu unterscheiden. Die Freilegung des restierenden Knotens erzeigt einen Schilddrüsenlappen von 2,8: $\mathrm{I}, 6 \mathrm{~cm}$ Dimensionen, wohl kaum vom normalen unterscheidbare Verhältnisse.

Histologischer Befund der am I5. VII. Igog exzidierten Struma. Färbung. Hämatoxylin-Eosin. V a n Gi e s o n (Fig. 36).

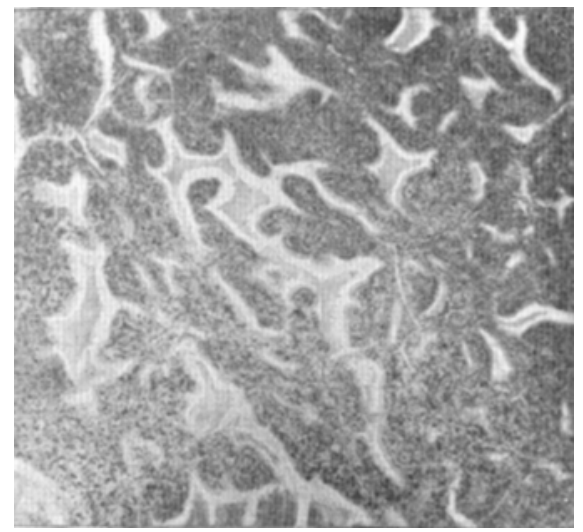

Fig. 36 .

Im histologischen Bilde sind drei Partien deutlich zu unterscheiden.

In mäßiger Anzahl sind schöne runde oder oval geformte Follikel vorhanden, welche einen durchschnittlichen Durchmesser von 20 bis 30 bis $40 \mu$ haben. In größerer Ausbreitung ist ein solides undifferenziertes Gewebe vorhanden. Den weitaus breitesten Raum nehmen die schlauch- und bläschenförmigen Gebilde ein, die von ganz unregelmäßiger Form und Gestalt sind. Sie haben verzweigte Formen, die wiederum Fortsätze nach allen Richtungen abgeben. Von den Wandungen treten zahlreiche Papillen in das Lumen hinein und bilden teilweise Septen. Die Breite der Schläuche beträgt $50-60 \mu$ und die Länge kann bis zu roo-r $20 \mu$ reichen. Die größten messen $400 \mu$ Länge und Ioo $\mu$ Breite.

Die Ausläufer der Lumina selber sind wiederum nach allen Richtungen verzweigt, und reichen als schlauchförmige Bänder oft weit ins Gewebe hinein.

Die Papillen sind äußerst zahl- und zellreich und der Epithelbelag kann schon bei schwacher Vergrößerung als zyindrisch mit basal stehendem Kerne konstatiert werden. Der Epithelbelag kann nicht überall strenge von dem umgebenden soliden Zellgewebe getrennt werden. Die Papillen können lumenwärts bis $30 \mu$ breit sein, ihre Höhe beträgt häufig bis zu roo $\mu$ und mehr, während ihre Basis oft nur mit einem feinen Stiel mit dem Gewebe in Verbindung steht. Die Lumina sind mit einer intensiv rotgefärbten Masse angefüllt, welche an ein- 
zelnen Stellen Vakuolen und Aufhellungen zeigt und da und dort bis zu Io $\mu$ von der Epithelwand absteht.

Bei starker Vergrößerung Sy. 7, Ok. 3, zeigen diese schlauchförmigen Gebilde ein gut 6-7 $\mu$ hohes Epithel von $2 \mu$ Basisbreite. Die Kerne sind rund, bläschenförmig und basal stehen Kern an Kern aneinander gereiht indem sie sich beinahe berühren.

An einzelnen Stellen sind die Kerne in den Zellen lumenwärts vorgetrieben. Die Kernbegrenzung, wie auch die der Epithelien, ist eine sehr scharfe. In den Kernen können I -2 sehr intensiv gefärbte größere Nukleoli nachgewiesen werden, neben denen noch mehrere kleinere vorhanden sind. Die Epithelschichte geht da und dort direkt in das solide indifferenzierte Gewebe über, speziell am Ursprunge der Papillen ist dies in der Regel der Fall. Die Anordnung der Kerne in den zylindrischen Zellpartien ist eine durchweg unregelmäßige, wellenförmige.

Im soliden Gewebe finden sich neben den undifferenzierten Partien sehr zahlreiche solide Follikel, die aus einem rein zylindrischen Epithel bestehen. Die eigentlichen normalen Follikel bestehen aus 8-i2 kubischen Zellen von 3:3 $\mu$ Größe. Der Kern hat einen Durchmesser von fast $2 \mu$ und steht in der Mitte der Zelle. Der Kernabstand beträgt durchschnittlich 2 Kerndurchmesser. Nukleoli sind nur wenige vorhanden. Ein ähnliches Bild zeigen die soliden Follikel.

Im undifferenzierten Gewebe sind die Zellen polyedrisch, rhombisch und zeigen denselben Zellbau. Zwischen den Bläschen, Follikeln und dem soliden Gewebe findet sich

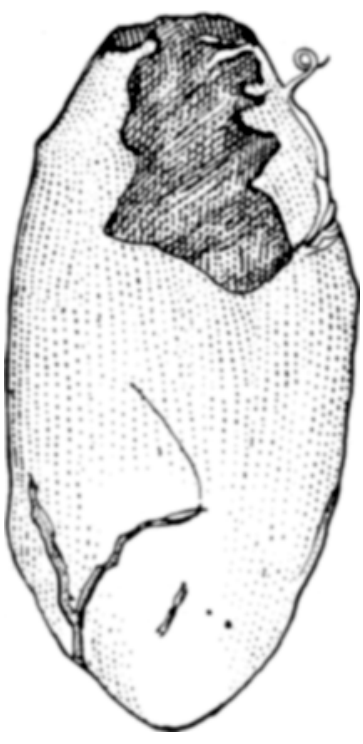

Fig. 37 . ein feines Gewebe mit länglichen spndelförmigen Zellen. Daneben sind feine Blutgefäße vorhanden.

Bei v a n Gi e s o n-Färbung zeigt sich das Kolloid schön gelb gefärbt. Ein feines Bindegewebsnetz zeigt den lobulären Bau an.

$\mathrm{H}$ u n d 6 wurde ebenfalls vom I5. Mai weg mit Rupperswiler Wasser gefüttert. Bei Beginn der Fütterung kann am Halse beidseits ein etwas über haselnußgroßer Knoten nachgewiesen werden. Am 20. VI. waren beide Lappen auf gut Hühnereigröße angewachsen. Das Verhalten des Tieres war ein dem normalen stets entsprechendes gewesen. Am I9. VIII. waren die beiden Lappen nur um ein weniges größer geworden. Am I2. X. zeigten sich beide Lappen stark über hühnereigroß. Bei der operativen Freilegung der Schilddrüse und 
Excision des linken Lappens bestätigte sich der Befund. Gewicht betrug I70 g. Größe 75:40:30 mm (Fig. 37). werden.

Im Benehmen des Tieres konnte nie etwas Besonderes konstatiert

Der Ausfall des Versuches kann nach dem makroskopischen Befunde als positiv betrachtet werden. Die histologische Untersuchung ergibt dasselbe Bild wie bei Hund 5 .

H u n d 7. Kontrolltier. Er erhält vom I5. Mai bis zum I5. Juli auf $100^{0}$ gekochtes Rupperswiler Wasser. Sein Benehmen ist stets sehr lebhaft. Im Wachstum ist er den beiden andern Tieren erheblich voraus. Am I5. Juli mißt er $50 \mathrm{~cm}$ in der Länge (Fig. 38).

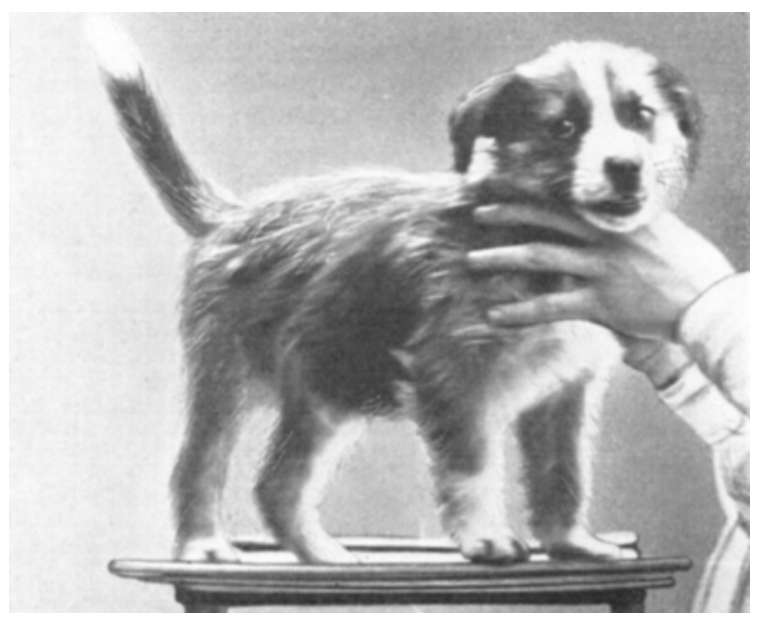

Fig. $3^{8}$.

I5. Juli halbseitige Thyreoidektomie zum Vergleich mit Hund 5. Sehr geringe Blutung. Die Größe des entfernten Lappens beträgt 3: I,5:I cm. Das Gewicht $30 \mathrm{~g}$ (Fig. 39).

Palpatorisch waren die Lappen immer von derselben Größe, kaum etwas über haselnußgroß nachzuweisen. Vom I5. Juli bis 15 . Oktober wurde das Tier mit der neuen Rupperswiler Quelle aus dem Jura getränkt. Die Größe der Schilddrüse blieb stets dieselbe.

Histologischer Befund Fig. 40. Makroskopisch kann auf dem Schnitte ein deutlich lobulärer Bau konstatiert werden. Die bindegewebigen Septen sind 5-Io $\mu$ breit.

Bei weitem der größere Teil des zentralen Gewebes besteht aus einem rein follikulären Gewebe, von runden oder ovalen Follikeln 
Ganz selten findet sich dazwischen ein unregelmäßiges bläschenförmiges Gebilde, wie dies bei Hund 5 so häufig der Fall war. Gegen die Randpartien finden sich da und dort zahlreichere derartiger unregelmäßig gebauter Bläschen, mit einem unregelmäßig geformten Lumen, die jedoch nirgends eine Schlauchform annehmen.
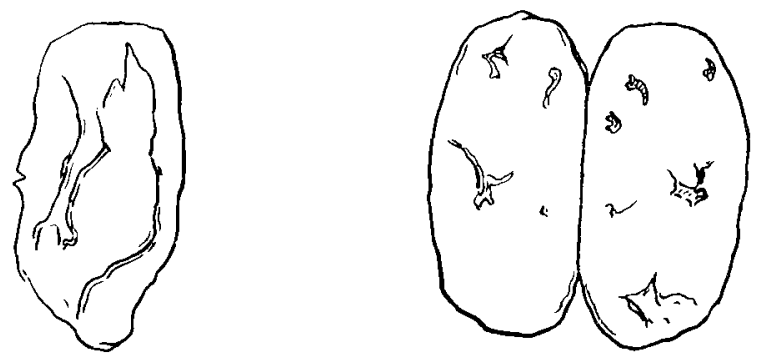

Fig. 39 .

Die Größe dieser unregelmäßigen Gebilde bleibt jedoch weit hinter der bei Hund 5 zurück, und überschreitet in keinem Durchmesser die Zahl von $70 \mu$. Der Inhalt besteht aus einer schönen rosa gefärbten Masse, welche der Wand nirgends völlig anliegt. Wandvorstülpungen und papilläre Erhebungen sind ganz wenige ausnahmsweise vorhanden und an diesen finden sich keine Ausläufer, keine Auswüchse und Verästelungen. Der ganze Bau ist bedeutend einfacher als bei Hund 5 .

In den soliden Partien finden sich ganz vereinzelt da und dort Spalten von $40 \mu$ Länge und $20 \mu$ Breite, welche mit Kolloid prall angefüllt sind. Der Epithelbelag ist im allgemeinen auch in den größern Bläschen niedriger als bei Hund 5. Es sind viel weniger Unregelmäßigkeiten in seinem Bau vorhanden.

Im Großteil der Bläschen zeigt sich der Epithelbelag auch in den unregelmäßig gebauten Partien bei stärkerer Vergrößerung Ok. 3, Syst. 7, kubischer

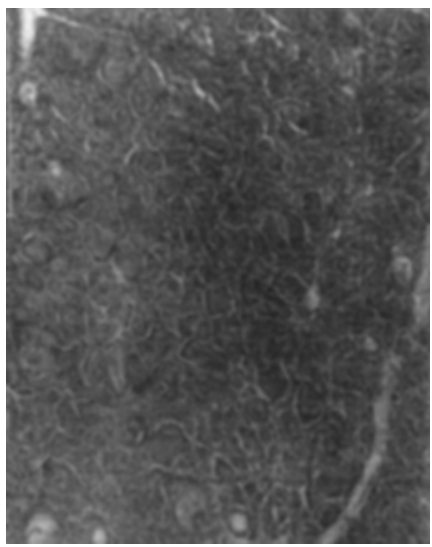

Fig. 40. Natur, mit 3:3 $\mu$ Größe und einem Kerndurchmesser von $2 u$. Die Kerne stehen zentral, sind gleichmäßig angeordnet und haben einen Abstand von einem Kerndurchmesser.

In der Minderzahl der Bläschen sind die Epithelien zylindrisch bis zu $6 \mu$ hoch. Der Kern steht dabei basal. Die Wand geht hier und da in das undifferenzierte Gewebe ohne Unterschied über. Der Inhalt ist hellrot. Um die Bläschen finden sich spindelförmige Zellpartien. 


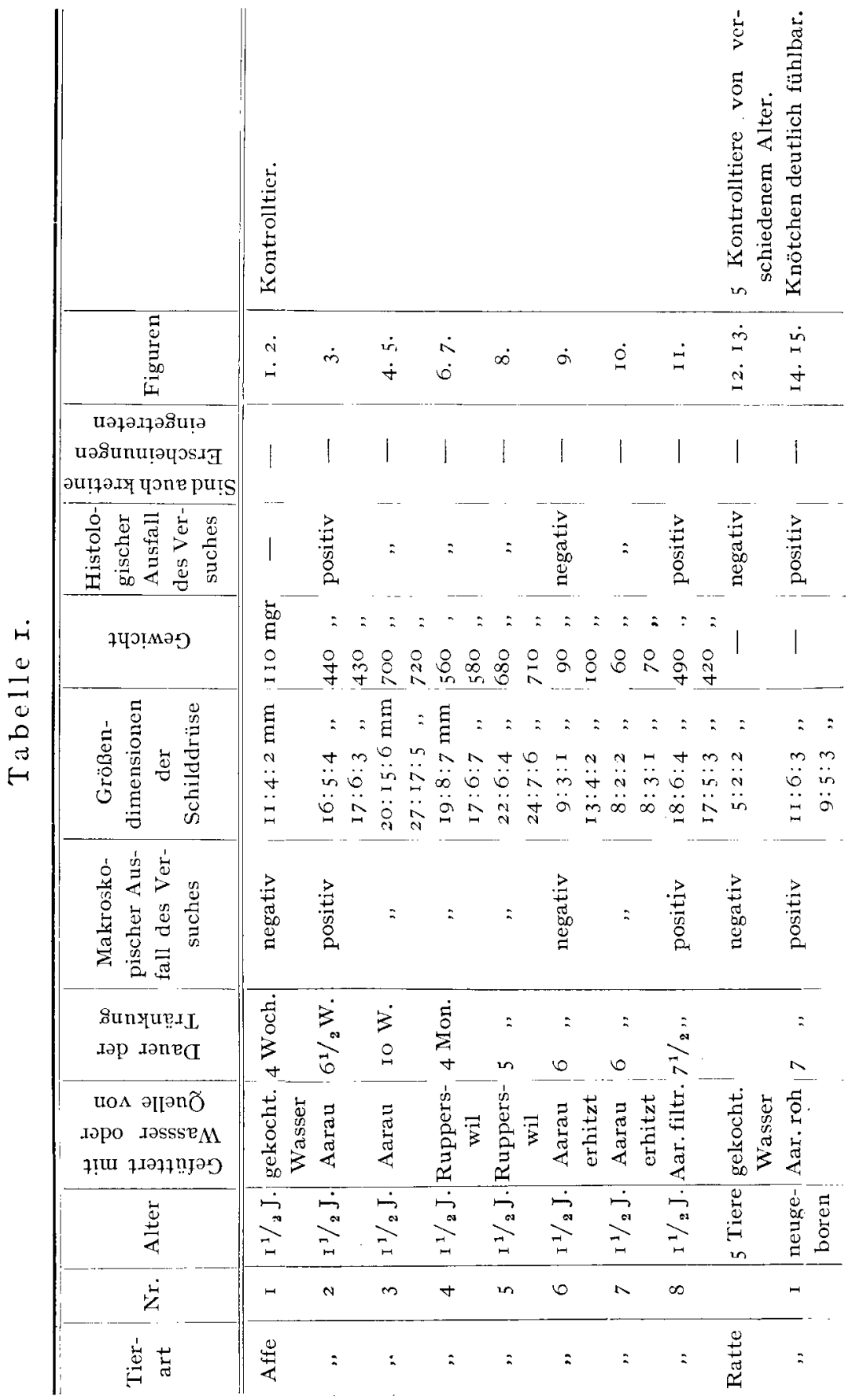


Zur experimentellen Erzeugung der Struma usw.
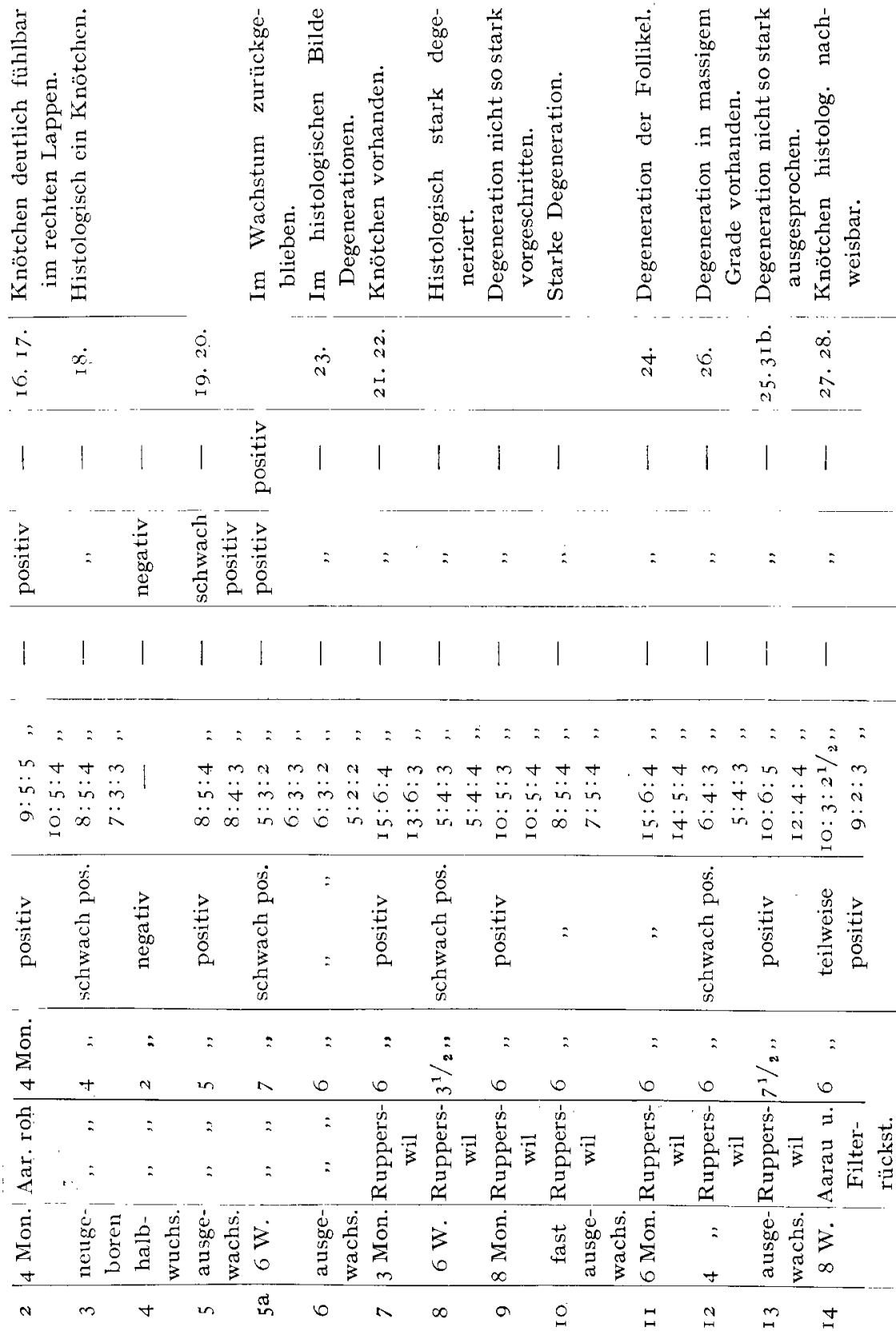

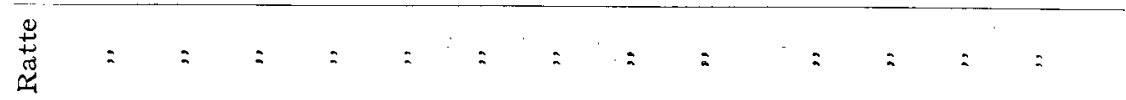




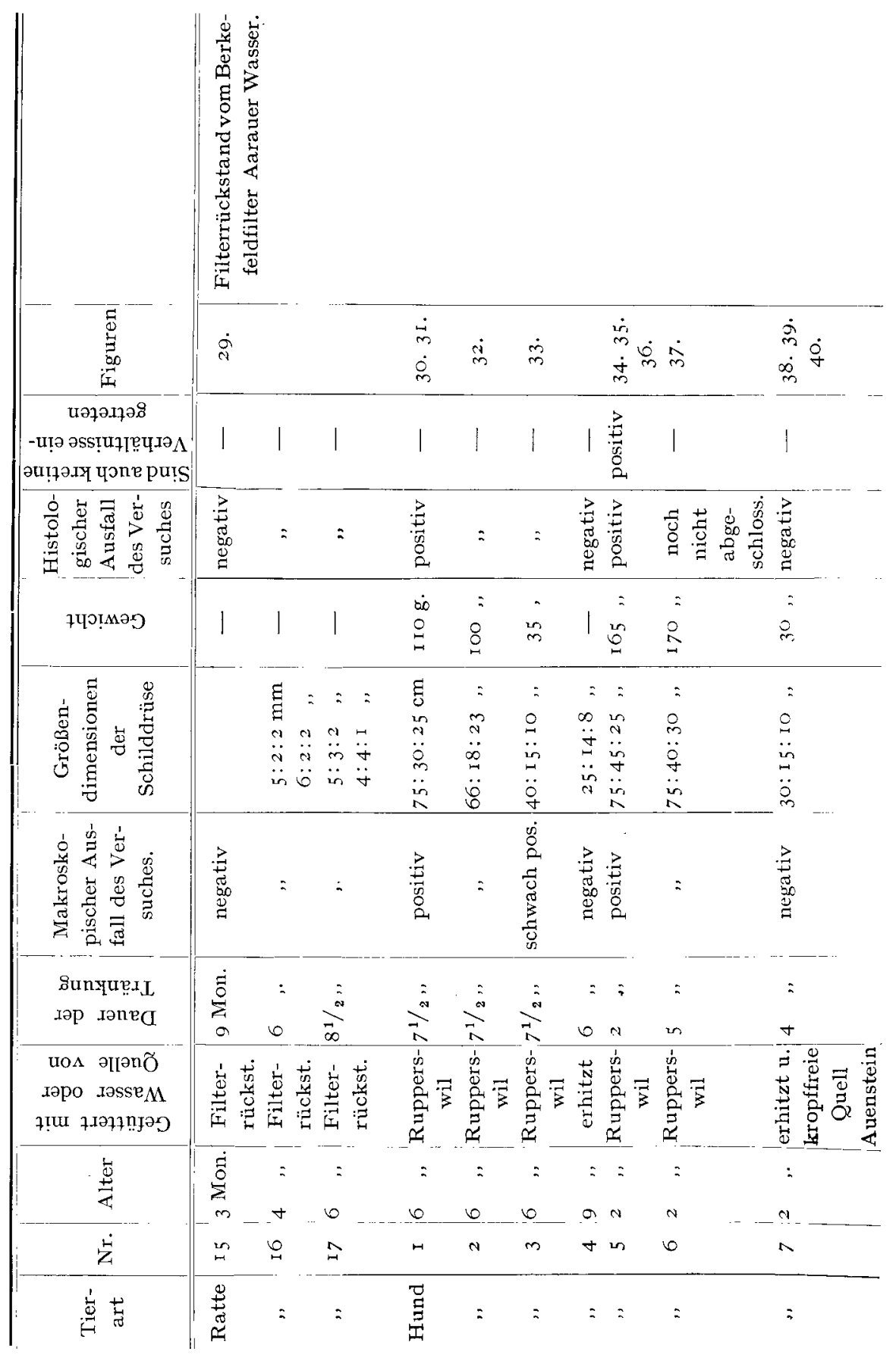


Die soliden Partien bestehen teilweise aus soliden follikulären Bildungen mit kubischen Zellen oder aus polyedrischen Zellen. Kernund Zellrand ist stets äußerst scharf gezeichnet.

Die eigentlichen Follikel bestehen aus einem kubischen Epithel, das $z \mathrm{U}$ IO - I5 an der einen Follikel bildet. Die sehr scharf begrenzten Kerne stehen durchschnittlich zwei Durchmesser voneinander ab und sind scharf begrenzt. Das Kolloid steht $5-6 \mu$ von dem Zellsaum entfernt.

Zwischen den einzelnen Follikeln sind einzelne leichte Zwischenräume vorhanden.

Feine Bindegewebsstränge durchsetzen das ganze Gewebe und trennen einzelne Läppchen voneinander $a b$.

Der Bau dieser Drüse ist im Vergleich zu Hund 5 ein wesentlich einfacherer. Der parenchymatöse Teil ist gegenüber den Verhältnissen bei Hund 5 stark zurückgetreten.

\section{Epikrise.}

Wenn wir die auf der Tabelle I kurz zusammengestellten wichtigsten Daten unserer Versuche durchgehen, so können wir konstatieren, daß wir auf die uns bei der Aufnahme der Experimente vorgelegte Frage eine befriedigende Antwort erhalten haben.

Dasheißt, wir können den B e weis a ls e r b r a cht betrachten, daB es bei Tieren durch Tränkung mit dem Wasser gewisser kropfuerdächtiger Quellen gelingt, eine VergröBerung der Schilddrüse in vielen Fällen einen richtigen Kropf zu erzeugen.

Wir glauben damit den richtigen Weg zu einer Aufklärung der so eminent wichtigen Kropffrage gefunden zu haben. Es ist klar, daß die Versuche nicht durchweg in einem positiven Sinne ausfallen konnten. Aber e i n positives Resultat kann bedeutend mehr besagen als viele negative. Erfreulich war es, konstatieren zu können, daß die positiven Resultate bei weitem die Versager überwiegen. Wenn wir auch mehr Versager erhalten hätten, so dürfte diese Tatsache nicht allzusehr frappieren, denn bekanntermaßen werden nicht alle Leute in Kropfgegenden von der Affektion ergriffen und neben der Wasserinfektion müssen sicher noch andere Dinge, wie persönliche Disposition, Erblichkeit, Menge des genossenen Wassers usw, mitspielen.

Andererseits ist auch klar, daß die verschiedenen Tierarten 
auch ganz verschieden auf die Noxe reagieren, so kann bei Affen nur sehr langsam eine Vergrößerung der Schilddrüse entstehen, da diese Tiere es vorziehen, ihren Flüssigkeitsbedarf mehr durch Früchte als durch Wasser zu decken. Immerhin glauben wir, zur Behauptung berechtigt zu sein, daß bei Affe 2, 3, 4, und 5 ein positiver Ausfall der Versuche vorhanden ist. Im Vergleiche zum Kontrollaffen I. zeigten sich die beim Exitus entfernten Schilddrüsen, mit dem Tasterzirkel gemessen, doch in allen Dimensionen erheblich vergrößert, die bei Tier 2,5 und $6 \mathrm{~mm}$ in der Länge, bei Tier 3, 9 und $16 \mathrm{~mm}$, bei Tier 4,8 und $6 \mathrm{~mm}$, bei Tier 5 , II und I3 $\mathrm{mm}$ betrug. Aber auch das Gewicht zeigte sich bei diesen Tieren verdreifacht, versechsfacht und verfünffacht gegenüber dem Gewichte beim Kontrolltier. Aus den Umrissen der Fig. I, 3, 6, 9, II kann deutlich die Größenzunahme konstatiert werden.

Die Zeit, während welcher diese Zunahme stattgefunden haben muB, ist eine verschiedene, doch scheint die Zunahme im allgemeinen ziemlich gleichmäßig vor sich gegangen zu sein. Das beweisen die Tiere 3 und 5 , bei denen die größere Zunahme stattgefunden hat als bei 2 und 4 , weil die Tränkung auch längere Zeit dauerte.

Daß diese Zunahme nicht in einem Zusammenhang mit den Todesursachen gebracht werden darf, beweisen Tier 6 und 7 , die an denselben ähnlichen Ursachen eingegangen sind, und bei denen, da mit erhitztem Kropfwasser getränkt, keine Vergrößerung der Schilddrüse eintrat. Wir glauben bei diesen beiden Beobachtungen annehmen zu dürfen, daß durch das Kochen des Wassers die strumigene Noxe eine Störung exfahren hat. Bei beiden Tieren fand sich eine Vergrößerung der Schilddrüsenlappen weder an Umfang noch an Gewicht vorhanden.

Gewissermaßen ein Hinweis, wenn auch kein Beweis für die Theorien der Ätiologie der Struma bietet der Befund bei Affe 8 dar. Das Tier, welches $7 \frac{1}{2}$ Monate filtriertes Aarauer Kropfwasser erhielt, zeigte eine sicher nachweisbare Vergrößerung der Schilddrüse, ebenso war eine Gewichtszunahme zu konstatieren. Histologisch war nicht viel zu konstatieren. Die Filtration geschah durch Papierfilter. Wenn uns auch dieser vereinzelte Versuch noch keinen stringenten Beweis gebracht hat, so hat er uns doch dazu geführt, weitere Versuche in dieser Richtung zu unter- 
nehmen, über deren Endresultat wir noch nichts Bestimmtes sagen können. Dieser Punkt ist von so eminent wichtiger, praktischer Bedeutung, da $B$ er einer eingehenden Bearbeitung bedarf. Denn praktisch. ist es sehr wichtig $\mathrm{zu}$ wissen, ob wir uns durch Filteranlagen vor der strumigenen Noxe schützen können.

Kretinoide: Veränderungen konnten bei den Tieren weder im Äußern, noch im röntgenologischen Bilde konstatiert werden. Um diese zu erzeugen, waren die Tiere auch mit. $1 \frac{1}{2}$ Jahren zu alt. Für derartige. Versuche müssen junge, im heranwachsenden Alter sich befindliche Tiere verwandt werden, denn jenseits der Wachstumsgrenze konnte bis jetzt niemals die Entstehung eines Kretins konstatiert werden. Zudem müßte die Fütterung sich bei Affen wahrscheinlich über Jahre erstrecken, und dies kann bei unsern klimatischen Verhältnissen kaum erreicht werden. Wir müssen uns mit $1 / 2-$ I Jahr zufrieden geben, besonders da strumigene Wasser sicher nicht nur die Schilddrüse, sondern den ganzen Körper in nachteiliger Weise beeinfluBt ${ }^{1}$ ). Sicher ist, daß die Struma nur auf eine chronische Einwirkung der Noxe hin entsteht, und daß bei unsern Affen mit ihren Tränkzeiten von der Dauer von I $1 / 2-5$ Monaten nicht noch schlagendere Erfolge, wie z. B. einzelne Knoten im Gewebe, zu erwarten waren.

Wesentlich klarer und eindeutiger sind die von uns an Ratten gewonnenen experimentellen Resultate. Die Gewichtsbestimmung der entfernten Schilddrüsen konnte dabei natürlich nicht ähnlich wie bei den Affen zu einem Vergleiche herangezogen werden, da die Strumen stets mit der Trachea zusammen exstirpiert werden mußten. Zum Vergleiche konnten daher nur die Maße der Dimensionen herangezogen werden; was jedoch wichtiger ist, die histologischen Untersuchungen ergaben wesentliche und wichtige Aufschlüsse über die Strumabildung.

Von den 7 mit Aarauer Wasser getränkten Tieren zeigten 3 bei der grobmakroskopischen Untersuchung in bezug auf ihre Größendimensionen einen positiven Ausfall. Die Schilddrüsen-

1) Anmerkung bei der Korrektur. So haben wir in letzter Zeit bei Hunden und Ratten bei der Autopsie auf das Herz geachtet und bei den kropfigen Tieren regelmäßig eine Hypertrophie an Gewicht und Größe (Kropfherz) nachwcisen können. Es ist dies eine Tatsàche die wichtig ist, auf die wir in eine s.päteren Arbeit zurückkommen werden. 
lappen waren dabei bis auf das Doppelte, im Vergleich zu den Kontrolltieren, angewachsen ( $I, 2,5)$. Einen schwach positiven Ausfall konnte man bei 3 Tieren konstatieren, bei denen die Größenzunahme rund das $I \frac{1}{2}$ fache gegenüber der normalen Größe betrug $(3,5 \mathrm{a}, 6)$. Bei Tier 3 fand sich jedoch ein deutliches Knötchen in einem Lappen, während 5 a sogar einen ziemlichen Rückstand im Wachstum aufwies und 6 eine histologisch degenerierte, also sicher beeinflußte Schilddrüse aufwies. Also auch diese 3 Tiere dürfen in einem positiven Sinne aufgefaßt werden. Bei einem Tiere, das allerdings nur 2 Monate dem Experimente unterzogen wurde, konnte keine Veränderung im Aufbau der Schilddrüse konstatiert werden.

Ziehen wir das Alter und die Tränkungsdauer der Tiere in Betracht, so kann im allgemeinen gesagt werden, da $B$ je älter die Tiere sind, desto weniger rasch die Veränderung eintritt, je kürzer die Tränkungszeit ist, desto geringfügiger die pathologische Einwirkung ist. Es ist dies eine Tatsache, die von vornherein zu erwarten war.

Die noch kräftiger kropferzeugende Rupperswiler Quelle ergab denn auch noch klarer die Tatsache, daß die Intensität der Intoxikation sicher an die Quelle gebunden ist, indem von sieben damit vorgenommenen Versuchen sämtliche positiv, worunter nur zwei schwachpositive, und gar kein Fehlgänger zu verzeichnen war. Die Größendimensionen konnten bei dieser starken Einwirkung selbst bis zum Dreifachen gegenüber den normalen Kontrolltieren zunehmen (Ratte II). Fin Punkt, der aber von wesentlicher Bedeutung ist, scheint mir darin zu liegen, daß das histologische Bild ein anderes als bei den mit Aarauer Wasser getränkten Tieren war. Während das Aarauer Wasser mehr Knötchen erzeugte (Ratte I und 2,3), so fanden sich bei den Rupperswiler, Drüsen mehr Entartungserscheinungen im histologischen Bilde, nur bei Tier 7 konnte auch ein Knötchen nachgewiesen werden. Was das Alter und die Dauer der Tränkung anbetrifft, so ergeben sich dieselben Befunde wie beim Aarauer Wasser.

Einen interessanten Befund konnten wir bei Tier I4 erheben. Wir wollten den Versuch unternehmen, die Intensität des strumigenen Agens dadurch zu verstärken, daß wir einzelnen Tieren den abgeschabten Rückstand der Berkefeldschen Tonkerze oder die mit dem Rückstand durchsetzten Papierfilter zu fressen gaben. 
Wir gingen dabei von der Annahme aus, da $B$ ein miasmatischer Erreger Ursache des Kropfes sei, eine Anschauung, wie sie auch Ew a ld neuerdings wiederum vertritt. Diese Filterrückstände wurden nun entweder in Milch oder in Kropfwasser aufgeschwemmt. Die Papierfilter zeigten sich regelmäßig vollständig aufgezehrt.

Der Erfolg dieser Versuchsanordnung war für uns ein überraschender, er stimmte jedoch genau zu dem Versuch bei Affe 8 . Diejenigen Tiere ( $\mathrm{r}_{5}, \mathrm{I} 6, \mathrm{I} 7$ ), welche die konzentrierten Filterrückstände erhielten, wurden niemals strumös, weder der histologische noch der makroskopische Befund ließen irgendeinen positiven Befund konstatieren, einzig die Ratte I4, welche neben dem Filterrückstand noch Aarauerwasser erhielt, zeigte einen kleinen Strumaknoten, aber auch dieser war, wie die Fig. 34 zeigt, erst in seinen Bildungsanfängen. Der konzentrierte Filterrückstand war auch hier nicht imstande gewesen, eine Beschleunigung des pathologischen Prozesses zu erzielen.

Wir haben diesem Punkte ein weiteres Augenmerk zugewandt, und an einer größeren Reihe von Ratten dieselben Tränkversuche, wie auch mit filtriertem Wasser ausgeführt ${ }^{1}$ ), unsere Befunde in jeder Weise bestätigt gefunden. Es spricht nun diese Tatsache mit aller Entschiedenheit dafür, daß es sich bei der Entstehung der Struma weniger um einen organischen Erreger handelt, als um ein Toxin, wie dies von $\mathrm{W}$ i $1 \mathrm{~m}$ s zuerst angenommen und ausgesprochen worden ist. Unsere neuen Befunde über diesen Punkt werden wir in einer späteren Arbeit beibringen. Welcher Art und Weise dieses Toxin ist, darüber müssen weitere Untersuchungen, die im Gange sind, uns belehren.

$\mathrm{DaB}$ die Strumabildung weniger auf einen Organismus als auf einer Intoxikation beruht, kann bei der pathologischen Anatomie der Struma mit vollem Rechte angenommen werden. In der Pathologie ist kein Analogon bekannt, daß stets ein und dieselbe Drüse von einem Erreger aufgesucht würde und stets dieselben Veränderungen erlitte. Viel eher ist zu erwarten, daß eine

1) Mit den Rückständen erhielten wir in den letzten Versuchsreihen niemals Strumen, während das filtrierte Wasser stets eine Vergrößerung der Drüse machte. Hingegen machten uns die mit den Rückständen gefütterten Tiere den Einđruck, als ob sie im Wachstum zurückgeblieben wären. Dies würde ein neues Licht auf die Atiologe des Kretinismus werfen. 
Drüse, besonders wenn sie, wie die Schilddrüse, entgiftend auf den Organismus wirken soll, durch bestimmte zugeführte Toxine, die durch sie bekämpft werden, zu einer Hypertrophie gelangen können. Es wäre dies ein analoger Vorgang, wie die Vergrößerung der Milz beim Typhus, der Lymphdrüsen bei Infektionen.

Praktisch ist diese Tatsache insofern von Bedeutung, als wir nur durch Kochen imstande sind, das strumigene Agens zu zerstören, und da $B$ nach geeigneten Filteranlagen, die das Toxin durchlassen, es jedoch zu zerstören imstande sind, erst noch gefahndet werden muB. Derartige Versuche, speziell mit Gesteinsarten nicht kropfführender geologischer Schichten sind im Gange, und soweit wir die Sache bis jetzt beurteilen können, mit befriedigendem Erfolge.

Daß die heutigen im Handel sich befindlichen Filtrierapparate nicht genügend das kropferzeugende Agens zerstören können, haben wir schon einige Male Gelegenheit gehabt zu konstatieren. In verschiedenen, uns selbst sehr nahestehenden Familien, in denen wir oder H. B irch e r derartige Apparate empfohlen haben, ist der Kropf weder zurückgegangen noch verschwunden, während das Trinken gekochten Wassers regelmäßig eine glatte Einwirkung zeigte.

Ebenso eindeutig wie bei den Ratten sind die Versuche bei den Hunden ausgefallen.

Bei den 3 in Basel getränkten Hunden war der Erfolg bei I und 2 stark positiv, indem das Gewicht der Drüse auf das drei und vierfache anstieg, während die Größendimensionen ebenfalls eine Vergrößerung um das zwei und dreifache zuließen. Bei Tier 3 war der Ausfall nur schwach positiv bei der makroskopischen Kontrolle, während histologisch sichere Veränderungen nachgewiesen werden konnten, Wenn wir auch zur Kontrolle kein Tier desselben Wurfes verwenden konnten, so kann dies nicht als Einwand gegen unsere Versuche gelten, besonders da die später unternommenen Versuche in dieser Beziehung einwandfrei sind. Das von uns benützte Kontrolltier zeigte übrigens, was Größe und Bau des Tieres anbetraf keine wesentlichen Unterschiede gegenüber den Versuchstieren. Es ist bemerkenswert, daß nach der Thyreoidektomie nur bei Hund I der restierende Lappen eine Zunahme erfuhr, während bei Tier 2 derselbe die gleiche Größe beibehielt, wie die Sektion erwies, eine Tatsache, die-mit den Erfahrungen. 
bei Kropfoperationen am Menschen übereinstimmen würde nach der auch in nur zo Proz. der Fälle Rezidive auftreten. Bei Hund 3, bei einem Weibchen, wurde die Fütterung nicht weiter geführt, weil es zur Züchtung weiter benutzt wurde. Die Jungen dieses Tieres zeigten denn auch nach der Geburt, wic bei 5 sezierten, in den ersten 4 Wochen krepierten Tieren nachgewiesen werden konnte, weder makroskopisch, noch histologisch absolut keine Strumen. Auch während der Säugungszeit konnte niemals palpatorisch ein Kropf nachgewiesen werden, der sonst bei Hunden sehr leicht zu palpieren ist.

Das Wachstum der Struma trat erst ein, wie Hund 5 und 6 zeigen, nachdem die Tiere von der stillenden Mutter entfernt mit Rupperswiler Molassewasser ernährt wurden. Erbliche und kongenitale Einflïsse konnten sich daher nicht geltend machen.

Von größtem Interesse ist der Verlauf des Versuches bei Hund 5, bei dem, wie die Fig. 35 zeigt, eine rapide Schilddrüsenzunahme konstatiert werden kann, bei dem aber auch sicher ein Zurückbleiben im Wachstum, eine Änderung in seinem äußeren Aussehen nachgewiesen wurde. Eine incipiente kretinische Degeneration $m u B$ daher als sicher vorhanden angenommen werden.

Sobald ein Wechsel im Tränkwasser stattfand, trat eine Abnahme in der Größe des restierenden Kropfes ein. Das äußere Aussehen des Tieres wurde ein anderes, sein Benehmen weniger läppisch. Der kretine Ausdruck des Tieres entsprach ganz demjenigen, wie er vor kurzem von $A$ le $x$ a $n$ d e r für einen Kretinenhund aus Steiermark geschildert und abgebildet worden ist. $\mathrm{Da}$ diese einzige Beobachtung vorläufig feststeht, so ist sie uns noch nicht genügend Beweismaterial. Mit aller Deutlichkeit weist sie doch darauf hin, daß die von uns und $\mathrm{s}$. $Z$. schon von $\mathrm{H}$. B i r $\mathrm{ch}$ e r vertretene Anschauung, daß der Kretinismus eine dem Kropf parallele Intoxikation höheren Grades mit Wasser aus endemisch verseuchten Gegenden ist. Speziell auch die histologischen Befunde bei den Ratten zeigen manche Ähnlichkeit, wie wir noch sehen werden, mit den Schilddrüsen von Kretinen. Tier 6, welches 3 Monate länger von dem Rupperswiler Kropfwasser erhielt, zeigte ebenfalls eine recht erhebliche Zunahme der Schilddrüse, die makroskopisch über 4 mal so groß, an Gewicht das Sechsfache gegeniiber dem Kontrolltier betrug. Daß es sich hier nicht um 
Zufallerfolge handelt, beweist neben dem wechselnden Zustande der Schilddrüse je nach dem Wechsel in der Zufuhr des Wassers bei Hund 6, das völlige Ausbleiben einer Struma bei dem von demselben Wurfe stammendem Kontrolltier 7, welches erst erhitztes Wasser, nachher Wasser von der kropffreien neuen Rupperswiler Quelle aus dem Jurakalk in Auenstein erhielt.

Wichtig für die Bewertung der Befunde sind nun auch die histologischen Tatsachen, die sich bei der Untersuchung der Präparate ergab.

Trotzdem über die histopathologische Entstehung der Struma, trotz der eingehenden Untersuchungen von $W$ ölfle r, Gutknecht, Zielinska, Hitzig and $\mathrm{Michaud} \mathrm{die}$ Akten noch lange nicht geschlossen, und die komplizierte Histologie der SchiJddrüse und ihrer Erkrankungen mehr denn je der Klärung bedarf, so können doch heute schon auf Grund der von $\mathrm{H}$ i t z i g und $\mathrm{M}$ i c h a u d festgestellten Tatsachen einige Punkte ihre Erledigung finden.

Und gerade von der experimentellen Erzeugung der Struma ist $\mathrm{zu}$ erwarten, daß durch das Experiment noch viel Licht auf manchen strittigen Punkt geworfen werden kann. Speziell die Ratten scheinen uns in dieser Beziehung ein vorzügliches Experimentiermaterial darzubieten.

Ohne uns in den Streit zwischen Wölfler einerseits und $\mathrm{Hit} z$ ig- Mich a d andererseits einmischen $\mathrm{zu}$ wollen, so möchten wir nur in Kürze, so weit es unsere Untersuchungen erlauben, zu diesen Fragen Stellung nehmen.

Speziell M i c h a u d war es, derdie von $\mathrm{H}$ i t $\mathrm{z}$ i g angebahnte Untersuchung der vermutlich ersten Anfänge der menschlichen Struma wesentlich vertiefte und erweiterte.

Auf Grund einer größeren Reihe von Serienschnitten verschiedener Strumen gelang er zu folgenden Punkten, die ihm für die ersten Anfänge der Struma zu sprechen schienen. Als ersten Anfang betrachtete er Schläuche, die sich von dem umgebenden Schilddrüsengewebe in folgenden Punkten unterschieden.

I. Durch ihre Durchmesser, die vielfach sowohl in Länge I20-240 $\mu$ und Breite I5--45 $\mu$ variieren.

2. Durch die Form. Die der normalen Schilddrüse besteht fast durchweg aus runden oder ovalen Bläschen und Follikeln, während 
diese Anfänge aus schlauchförmigen Bläschen mit den verschiedensten Formen (Ausläufern und Fortsätze) bestehen können, die allerdings nach $\mathrm{Ebner}$ auch in ähnlicher Weise in normalen Schilddrüsen, doch nicht in Mehrzahl vorkommen können.

3. Durch die Form der Epithelzellen. Während sie normalerweise mit Ausnahme im jugendlichen Alter von $\mathrm{M}$ i $\mathrm{ch}$ a $\mathrm{u}$ d eher niedrig und breit, seltener kubisch befunden wurden, so fanden sich in den Schläuchen durchweg zylindrische und zwar sehr hohe Zellen, mit basal gelegenen hier und da verschobenem Kerne. Der Zellleib war häufig intensiver gefärbt. Der Innenrand des Lumens zeigte sich flach und gezackt.

4. Durch die Zellkerne: a) die Kerne sind rund, bläschen förmig, intensiver gefärbt als normal, mit intensiv gefärbten Nukleoli. Keine Kernwanddegeneration.

b) Schaltkerne. Sie sind länglich, stäbchenförmig, drei-, vierund mehreckig. Der Rand ist feinzackig. Sie sind homogen gleichmäßig intensiv gefärbt, und in geringerer Anzahl als a) vorhanden. Sie sind nicht etwa als Unterschiede der $\mathrm{L}$ a $\mathrm{n} g$ e $\mathrm{n} \mathrm{d}$ o $\mathrm{r} f \mathrm{f}$ schen Haupt- und Kolloidzellen aufzufassen. Die Zellen mit Schaltkernen sind kleiner als die übrigen Zellen.

5. In den jungen Stadien ist ein großer Kernreichtumi vorhanden, die Kerne sind außerordentlich dicht angeordnet daß sie sich fast berühren, oder daß sie nicht linien- sondern mehr wellenförmig angeordnet sind. Hier und da fand sich statt einer einschichtigen Epithelwand ein mehrschichtiger Epithelmantel, der auf Vermehrung der Zellen beruht.

Uber die Entstehung dieser Strumen läßt er sich in Anlehnung an $\mathrm{Hitzig}$ wie folgt aus. Ein schlauchartiges Gebilde entsteht zwischen normalen Bläschen ohne Verdrängungserscheinungen, mitten in einem Lobulus oder an der Peripherie.

Dieser aus zylindrischen Epithel bestehende Schlauch vergrößert sich, treibt Ausläufer und Fortsätze und nimmt alle möglichen Formen an. Es treten mehrere Schläuche auf, so daß ein kompliziertes Kanalsystem entsteht. Diese Schläuche können nun in diesem Zustande verharren und so ein Knötchen bilden, oder von den Schläuchen schnüren sich Bläschen ab.

Die Abschnürung dieser Bläschen kann auf verschiedene Weise vor sich gehen. Die Epithelwand kann mit und ohne Lumen- 
fortsatz nach außen sprossen, und dies in der verschiedensten Form, die Sprossen können sich vergrößern und zuletzt kann sich ein Lumen ausbilden, das sich vom Hauptlumen abtrennt. Durch bindegewebige Stränge kann das Bläschen vom Hauptlumen abgetrennt werden.

Der zweite Modus ist der, daß in einem Schlauche in regelmäßigen Intervallen Quersepten auftreten, die aus einer doppelten Epithelschicht bestehen. Nach und nach werden aus den sechseckigen Gebilden perlschnurförmig Bläschen abgetrennt.

In diesen Bläschen findet sich gewöhnlich noch kein Kolloid, oder wenn es in jungen Bläschen vorhanden ist, so ist es gegenüber den umgebenden Bläschen heller gefärbt und gegen die Epithelwand $\mathrm{zu}$ reichlicher angeordnet. Hat die Bläschenabschnürung begonnen, so ist das Bild ein sehr variables, die neuen Bläschen sind rund oder oval, teilweise komprimiert, sie können verschiedene Größen haben. Wandüberreste ragen in das Lumen hinein, und neben den Bläschen finden sich noch sehr viele Schläuche, mit breitem und spaltförmigem Lumen. Die Schläuche können dann gewunden, breit büschelförmig verzweigt und radiär angeordnet sein. Der Kernbau dieser Partien ist derselbe wie bei jungen Stadien. Kommunikationen der Gebilde untereinander können vorkommen.

Sind die Bläschen rund geworden, und die unregelmäßigen Bildungen verschwunden, so ist ein späteres Stadium vorhanden. Die Bläschen können noch dicht gedrängt sein und das Stroma noch gering. Nimmt das Stroma zu, so rücken die Bläschen ebenfalls auseinander.

$\mathrm{H}$ i t $\mathrm{z}$ ig, der der erste war, der auf Grund eines größeren Materiales die Frage schon frühzeitig in einem ähnlichen Sinne wie $\mathrm{M}$ i c h a u d löste, hielt sich an die Systematik, wie sie s. $Z$. von $\mathrm{Gutknecht}$ gegeben worden war, indem er $\mathrm{I}$. eine allgemeine gleichmäßige, 2. eine knotige (Struma nodosa) Hyperplasie unterschied, die dann bald mehr parenchymatös ist, d. h. Zellstränge und Schläuche produziert oder durch Kolloidansammlung zu Struma colloides führt. Zwischen beiden hält er Ưbergänge und Mischformen für gegeben.

Auf Grund der von ihm untersuchten Schilddrüsen im Alter von r.4-30 Jahren, in denen er speziell nach mikroskopischen 
Anfangsstadien, wie sie sich in den unteren Partien der Drüse darboten, gelangte er $\mathrm{zu}$ folgenden Endergebnissen.

I. Die ersten Anfänge der Strumabildung beruhen wahrscheinlich auf Wucherungsvorgängen des normalen kolloidhaltigen und kolloidfreien Drüsenepithels (Virchow contra Wölfler).

2. Die ersten deutlich sichtbaren Anfänge der Struma nodosa sind vereinzelte Schläuche besonders differenzierten Epithels, welche in sekundären Läppchen an Stelle des normalen Gewebes liegen.

3. Weiterhin ersetzt dieses Gewebe schrittweise metaplastisch das Normale eines sekundären oder auch eines primären Läppchens.

4. Die so veränderten Läppchen bilden, indem sie an Volumen zunehmen, sich runden und das Nachbargewebe verdrängen, die kleinsten eigentlichen Strumaknötchen.

5. Benachbarte, in der gleichen Art veränderte Läppchen können auf diese Weise multilokuläre zusammengesetzte Strumaknötchen abgeben, indem sie entweder:

a) durch Durchwachsen der Schläuche durch die Septa vollkommen verschmelzen oder

b) sich gegenseitig abplatten, aber eine gemeinsame runde Oberfläche haben, oder endlich

c) indem die äußeren Läppchen sich schalenartig komprimiert um die zentral stärker gewucherten legen, aber doch auch ihrerseits an der Wucherung und Vergrößerung des Knötchens aktiv teilnehmen.

6. Die metaplastische Bildung des Strumagewebes im Knoten endet, wenn die Grenze der primär betroffenen Läppchen erreicht ist, dann findet ein Wachstum der Knoten aus sich heraus mit Verdrängung der Umgebung statt.

7. Die diffuse Struma beruht auf gleichförmiger Proliferation in allen Läppchen der Drüse.

8. Die knotige Struma kommt durch Verschiedenheit der Wachstumsenergie der verschiedenen benachbarten Teile zustande.

9. Es existieren die verschiedensten Übergänge zwischen den beiden Formen.

$\mathrm{Hitzig}$ wie $\mathrm{Mich}$ a d bekämpfen energisch die von Wölfler verfochtene Anschauung, wonach sich die Adenome der Schilddrüse, zum Unterschied gegenüber der Hypertrophie, aus embryonalen, atypisch vaskularisierten Zellhaufen, die zur Zeit 
der Geburt in oft reichlicher Menge an der Peripherie der Schilddrüse sich befinden, entwickeln. Er nennt diese Knoten fötale Adenome, die von $\mathrm{H}$ i t z i g- $\mathrm{M}$ i c h a u d als die ersten Anfänge der Struma betrachtet werden, und nicht embryonal angelegt sind. $\mathrm{H}$ i t $\mathrm{z}$ i g konnte auch nicht die von $\mathrm{W}$ ö $\mathrm{lf} l \mathrm{e} \mathbf{r}$ illustrierte Gewebsbeschaffenheit konstatieren, und glaubt, daß pralle Füllung der Gefäße bei den Wölfle rschen Injektionspräparaten die Struktur des dazwischenliegenden Gewebes verdeckte.

Auch $\mathrm{M}$ i c h a u d konnte die von Wölf le r beobachteten interlobular gelegenen Zellhaufen nachweisen, aus denen, als fötalen Überresten das Adenoma interacinosum entstehen soll. Nach M i ch a ud sahen diese nach Wölfler lymphoid aussehenden Zellhaufen etwas anders aus. Sie waren dunkelblau, im Stroma einzeln und zu Gruppen angeordnet, die Zellen waren klein, die Kerne polyedrisch, keilförmig oder länglich. Die Bildungen sind solide, eine Anordnung der Zellen um ein Lumen fehlt. Dabei vermißt er von $W$ ö $l \mathrm{fl}$ e r den Nachweis, daß aus diesen Partien sich tatsächlich Knötchen entwickeln, und daß sie wirklich fötalen Ursprunges seien. Zudem fanden sich bei fötalen Schilddrüsen größere Bläschen am Rande und die kleineren im Zentrum, ebensowenig fanden sich am Rande solide Zellschläuche und Zellstränge. Die Randpartien können daher genetisch nicht die jüngsten sein wie $W$ ölf le r annimmt.

Aber auch für die Struma diffusa scheint nach den Ausführungen von $\mathrm{H}$ it $\mathrm{z}$ i g die $\mathrm{W}$ ölf l e r sche Anschauung nicht immer zu stimmen.

Der Gallertkropf oder das Adenoma gelatinosum, welches aus kleineren oder größeren neugebildeten, kolloidhaltigen Drüsenblasen zusammengesetzt ist, welche aus embryonalen Bildungselementen hervorgehen, teilt $\mathrm{W}$ ö $\mathrm{lf} \mathrm{l}$ e $\mathrm{r}$ folgendermaßen ein:

I. in das interacinöse Adenom, wie wir dasselbe oben nach $\mathrm{H}$ i t $\mathrm{z}$ i g beschrieben haben, welches in seiner einfachsten Form aus verschieden großen Drüsenblasen besteht. Zwischen den Drüsenblasen können sich embryonale Zellhaufen, oder die aus ihnen hervorgegangenen und in Entwicklung begriffenen Drüsenhaufen oder zum Teil schon vollendete kleine Drüsenblasen befinden. „Es entwickelt sich aus den zwischen den Drüsenblasen befindlichen Bildungszellen und erscheint entweder in 
Form von Drüsenhaufen und Drüsenblasen, welche die interacinösen Räume oft mächtig verbreitern, aber nicht durchbrechen, oder es substituiert einen Teil oder das ganze interacinöse Gewebe samt dem die Drüsenblasen umgebenden Bindegewebe und den die Drüsenblasen begrenzenden Epithelzellen durch Bildungszellen und setzt sich entweder in Form von fungus- oder knospenartig wuchernden Gebilden an der einen oder der andern Partie der ursprünglichen Drüsenblasenwand fest, oder verwandelt in seiner Entwicklung das ganze interacinöse Gewebe in aus Bildungszellen bestehende Septa. Auf diese Weise erscheint oft die Wand einer einzigen Drüsenblase, je nach der Menge der an sie grenzenden Blasen, von 3-4 solcher aus Bildungszellen bestehenden substituiert. Entwickeln sich nun in diesen drüsigen Septis runde Zellenhaufen oder Drüsenblasen, so ist die Ausdehnung des Prozesses für eine Zeitlang sistiert; ist dies aber nicht der Fall, dann wuchern die Bildungszellen von den Septis in die Hohlräume der angrenzenden Blasen und erfüllen dieselben ganz oder zum größten Teile mit ihren Produkten (Adenoma interacinosum proliferans)“ . . . „Ich bin mir bewußt, daß manche der angegebenen, beim interacinösen Adenom zu beobachtenden Erscheinungen noch rätselhaft sind" usw. usw.

Gutknecht wie Hitzig können die Wölflersche Deutung der erhobenen Befunde nicht annehmen und glauben, daß es sich dabei um schräg getroffene Schnitte handele, und daß es sich beim ,,interacinösen Adenom“ um nichts anderes als um eine Struma diffussa colloides handele, die nicht von den übrigen Strumen abzutrennen sei.

Als weitere Gruppe des Adenoma gelatinosum scheidet W ö $1 \mathrm{f} l$ e $\mathbf{r}$ das Cystoadenom aus, daß er in a) profileres, b) papilläres Cystoadenom scheidet.

Zum proliferen Cystadenom rechnet er die papillären Exkreszenzen in die Cysten hinein, und spricht dabei von $\alpha$ ) exogenenen, $\beta$ ). endogenen Vegetationen. Die exogenen oder interacinösen Vegetationen beschreibt er folgendermaßen (S. 63):

„,R o kita nsky war der erste, welcher auf diesen Prozeß in den Schilddrüsenblasen die Aufmerksamkeit gelenkt hat, doch konnten seine Anschauungen nicht zur vollen Geltung gelangen, da Virchow und andere mit ihm an der Meinung festhielten, 
daß die an den Cystenrändern zu beobachtenden papillären Vegetationen keine neuen Bildungen seien, sondern bloß die Reste alten Drüsenparenchyms, welches bei der Entstehung der Cysten aus kleineren Blasen zurückgeblieben ist.

Ich hatte vielfach Gelegenheit, die Befunde R okit ans k y s zu bestätigen und zu erweitern; vielleicht wird es nur durch die folgende Beschreibung der Vegetationsformen zu erklären möglich sein, aus welchem Grunde jene Meinungsdifferenz zwischen Rokitansky und Virchow zustande gekommen ist. Es wäre gewiß vollkommen unbegründet, wenn wir der Entstehung aller Vegetationen, welche man in großen Drüsenblasen und Cystenräumen findet, die einheitliche Auffassung zugrunde legen würden, daß sie endogene Produkte darstellen, welche von der Wand der Drüsenblase, beziehungsweise vom Grenzepithel ausgegangen sind. Wir müssen in dieser Hinsicht verschiedene Vorgänge unterscheiden: Fürs erste finden wir in den Drüsenblasen hügel- und kuppenartige von einem Teile der Wand ausgehende Rundzellenwucherungen, welche an ihrer Oberfläche kein Begrenzungsepithel tragen und bei genauerer Besichtigung nichts anderes darstellen, als interacinöse, nicht organisierte Zellenproliferationen, welche an irgendeiner Stelle die Blasenwand perforiert haben; sie sind sehr häufige Befunde im gelatinösen Adenom und stellen hinfällige, der kolloiden Degeneration nicht selten anheimfallende Gebilde dar. Sind solche Haufen in ihrem Durchschnitte gerade an derjenigen Stelle getroffen, wo sie die Blasenwand perforiert haben, so sieht man, daß auch die Blasenwand, d. i. das Bindegewebe und das Grenzepithel, in ähnlicher Weise zu Rundzellen umgewandelt ist; es fehlt demnach an der Basis dieser Bildungen das normale Grenzepithel, und man erkennt gerade an diesen Durchschnitten den innigen Zusammenhang zwischen Haufen und interacinösen Drüsenparenchym. Sind dagegen diese Haufen nicht an der Perforationsstelle getroffen, so sieht man das Epithel der Drüsenblase intakt, und erst bei tieferer Einstellung die Basis des Drüsenzellenhaufens, welcher an einer anderen Stelle die Wand durchbrochen hat.

In anderen Fällen findet man entweder einen Teil oder fast die ganze Höhe der Drüsenblase eingenommen von einer kolbigen, von gut entwickeltem Epithel begrenzten Prominenz, wodurch 
das Kolloid der ursprünglichen Blase zu einem oft schmalenStreifen zusammengedrängt ist; es sind dies jene Bildungen, welche $\mathrm{R} \mathrm{o} \mathrm{k} \mathrm{i} \mathrm{-}$ t a nsky als endogene Produkte aufgefaßt hat. Die Entstehung derselben wird uns klar, wenn wir andere größere Blasen besichtigen, in welchen die Veränderungen noch nicht so weit gediehen sind. Es ist eine an vielen solchen Blasen zu beobachtende interessante Erscheinung, daß das Grenzepithel ein und derselben Drüsenblase nicht an allen Stellen gleich hoch ist. Ich habe den Durchschnitt des Kropfes eines jugendlichen Individuums vor mir, bei welchem der Kropf von unzählbaren mohnkorn-, stecknadelkopf- bis erbsengroßen Cystchen durchsetzt ist. Abgesehen davon, daß an vielen Stellen die in den Drüsenblasen sich ausbreitende interacinöse Adenomwucherung in gelatinöser Degeneration findet, sieht man in anderen größeren Blasen an denjenigen Stellen der Wand, wo dieselbe an eine andere Blase direkt angrenzt, daß das kubische Grenzepithel niedrig und schmal ist; an anderen Stellen derselben Wand dagegen sieht man das schönste Zylinderepithel; es waren dies diejenigen Stellen, welche nicht direkt an die Wand anderer großer Drüsenblasen grenzten, sondern an ein in stärkerer Proliferation begriffenes interacinöses Drüsenparenchym; es profitieren offenbar die angrenzenden Epithelzellen der Drüsenblase von der hochgradigen Vaskularisation des interacinösen Gewebes. An solchen Stellen findet man auch, daß die Wand der Drüsenblase gegen ihr eigenes Lumen verdrängt erscheint. Je mehr sich nun das interacinöse Gewebe vermehrt und verbreitert, desto mehr drängt es den angrenzenden Teil der Blasenwand gegen ihr eigenes Lumen vor; während unterdessen im interacinösen Gewebe diese Neubildung von Drüsenblasen und die Vergrößerung derselben weiter fortschreitet, schiebt sich das ganze interacinöse Parenchym immer mehr gegen die Blasenwand vor, und so kann man aus den zahlreichsten Übergängen sehen, daß es sich auch in diesem Falle wieder nur um das Resultat eines Grenzkrieges zwischen interacinösen Parenchym und den alten Drüsenblasen handelt, in welchem, wie gewöhnlich, die letzteren unterliegen, mit dem Unterschiede jedoch, daß das Epithel der Drüsenblasen in diesem letzteren Falle nicht durchbrochen wurde, und dadurch die ,scheinbar" endogenen Bildungen im Sinne Rokitanskys im Gegensatz zu den früher beschrie- 
benen epithelialen Vegetationen von einem ,gut entwickelten Epithel der Drüsenblase begrenzt erscheinen".

Von den e n d o g e n e $\mathbf{n}$ oder interacinösen Vegetationen entwirft er folgendes Bild:

„Andere Bildungen stellen jene papillären Exkreszenzen dar, welche wir als endogene bezeichnen müssen, weil sie aus einer Proliferation des Begrenzungsepithels selbst hervorgegangen sind, Es sind das diejenigen Bildungen, welche identisch sind, mit manchen polypösen Wucherungen der Schleimhaut, den papillären Vegetationen in den Ovariencysten, an der Vaginalportion, am Penis usw. Es ist zwarnicht zu leugnen, daß bei der Entwicklung dieser papillären Bildungen das interacinöse Gewebe immer noch einen größeren oder geringeren Anteil nimmt, insofern es das Substrat für die Entwicklung solcher papillären Vegetationen liefert; dasselbe ist jedoch ein verhältnismäßig untergeordneter; vom interacinösen Gewebe aus werden die Papillen durch schlingenförmige Kapillargefäße ernährt und von dem sie begleitenden Bindegewebe gestützt. Auch ist es wohl richtig, daß gleichzeitig mit Vergrößerung und Verbreiterung der Papillen eine immer größere Beteiligung des interacinösen Gewebes insofern zustande kommt, als gleichzeitig mit dem intermediären Ernährungsapparate auch Drüsenparenchym in die Substanz der Papille gelangt und daselbst weiter zu Drüsenblasen sich entwickelt, allein die wesentlichste und wohl auch primäre Veränderung ist dennoch die Umwandlung des Grenzepithels zu vielgestaltigen und vielverzweigten, von $Z$ ylinderepithel besetzten Vegetationen".

Die zweite Art des Cystoadenoms, welche papillärer Natur ist, hält er für allgemein nicht häufige Geschwülste und entwirft davon folgende Beschreibung:

„,Der Bau der bei unseren Kranken beobachteten proliferen Cystoadenome stimmt insofern überein, als hier lediglich die Entwicklung interacinösen Adenomgewebes zu multilokulären Cystenbildungen wahrzunehmen war; es führte dieser Modus zu den allergrößten Kropfgeschwülsten, welche wir in der Klinik beobachten konnten. Hervorzuheben wäre noch, daß in allen Fällen die ganze Drüse in gleichmäßiger Weise an der Adenombildung partizipierte, und daß deshalb jedesmal die totale Kropfexstirpation vorgenommen werden mußte. Erwähnenswert ist weiter- 
hin, daß in jenen beiden Fällen, in welchen gleichzeitig hier und da an dem Oberflächenepithel der Cystenbrut papillare Vegetationen sich entwickelten, kleine Rezidive auftraten, welche zwar langsam, aber stetig sich vergrößerten. Bei beiden Kranken sind es nunmehr drei Jahre, seitdem die Exstirpation vorgenommen wurde; die Rezidivgeschwülste hatten bei der letzten Untersuchung, Okt. I88I, ungefähr die Größe eines Hühnereies erreicht.

Wir gelangen nunmehr zur zweiten Art des Cystoadenoms, jenes, in welchem papillare Gebilde durch Proliferation des Grenzepithels der Schilddrüsenblasen zustande kommen. Der Entwicklung solcher Papillen wurde schon bei der Beschreibung der fötalen Adenome gedacht. Die papillare Bildung ist wohl das einzige Produkt, welches die Epithelzellen der fertigen Drüsenblasen liefern, und ist, da ja in der Fötalzeit die Drüsenblase noch nicht vorhanden ist, streng genommen keine den EmbryonalProdukten gleiche Erscheinung; insofern jedoch jede Papille als ein schlauchartiges Gebilde angesehen werden kann, welches wie schon Bill roth hervorhebt - handschuhfingerförmig umgestülpt erscheint, so kann sie dennoch als eine den embryonalen Schläuchen ähnliche Formation aufgefaßt werden.

Beim Hunde und Affen finden sich schon in der normalen Drüse papilläre Exkreszenzen; von der Ziege, sowie vom Kalbe wissen wir nach den bemerkenswerten Untersuchungen von P f 1 u g , daß die bei ihnen zu beobachtenden kongenitalen Kröpfe aus papillären Bildungen bestehen; auch bei Hunden habe ich mich mehrfach überzeugen können, daß die Kropfbildung in Form eines papillären Adenoms auftritt. $\mathrm{Da}$ im allgemeinen das in Hohlräumen proliferirende Epithel sich gerne in Form von $\mathrm{Pa}$ pillen erhebt ( $\mathrm{Rindfleisch}$ ), so ist es begreiflich, daß die papillären Vegetationen im Kropfe des Menschen ebenfalls in der Regel in großen Blasenräumen oder in Cysten sich entwickeln."

Wir glauben nicht, da $\beta$ es stets möglich sein dürfte, einen scharfen Unterschied zwischen dem prolifer en und papil$1 \ddot{a ̈ r}$ e n Cystadenom zu machen.

Die Deutung, der auch von $\mathrm{H}$ i t $\mathrm{z}$ i g beobachteten papillären Exkreszenzen, wie sie sich besonders in großen kolloidalen Strumen zeigten, wird von diesem anders gegeben: Hitzig konnte die verschiedenartig gebauten Papillen von der einfachen Wand- 
erhebung bis zum komplizierten Bau aus soliden Zellsträngen mit follikulären Hohlräumen beobachten. Er fand deren Epithel ebenfalls in Proliferation begriffen, in das das benachbarte Strumagewebe, nach und nach eindringe. Er verwirft die Anschauung Wölflers, daß das interacinöse Gewebe das Epithel vor sich herstülpe und so zur Papillenbildung führe, eine Tatsache, die doch nach den an Hunden von uns erhobenem Befunde hier und da zuzutreffen scheint. Den Unterschied zwischen exogener und endogener Vegetationen möchte er, und wie uns scheint mit Recht, fallen lassen, da beide ja aus einer Proliferation des Grenzepithels hervorgehen.

Man wird mit $\mathrm{H}$ i t $\mathrm{z}$ i g einig gehen, wenn er die $\mathrm{W}$ ö $\mathrm{l} \mathrm{fle} \mathrm{r}$ sche Einleitung der Struma diffusa als gekünstelt und unnötig kompliziert bezeichnet. Hitzig betrachtet daher die Struma diffusa als eine Erweiterung der kolloidhaltigen Blasen, indem sich die Epithelzellen vermehren und demgemäß mehr Kolloid produzieren. Wo die Blasenvergrößerung der Zunahme der Epithelzellen nicht entspricht, kommt es zu Epithelwucherungen in die Blase hinein und es können an den Papillen Proliferationsmerkmale auftreten, zudem kann das zwischen den Blasen liegende noch kein Kolloid führende Gewebe auswachsen.

Wir haben die Literatur über die Histiogenese der Struma erst durchgegangen, nachdem wir an unsern Versuchstieren die histologischen Befunde schon erhoben hatten. Wir taten dies aus dem Grunde, um unsere Untersuchungen nicht von vornherein $\mathrm{zu}$ beeinflussen, und die Bilder nicht unter einem bestimmten Gesichtspunkte betrachten zu müssen. Um so interessanter und überraschender war daher der Vergleich für uns.

Wenn es uns bei unsern experimentellen Untersuchungen weniger um die Histogenese der Struma zu tun war, und wir im Hinblick darauf keine speziellen Färbungsmethoden angewandt haben, so scheinen uns die gewonnenen Resultate immerhin von solchem Werte zu sein, daß wir sie zu berühren müssen glauben. Wir hoffen bei Gelegenheit uns noch eingehender mit der Histogenese speziell der experimentell zu erzeugenden Struma befassen zu können.

Unsere histologischen Befunde, von einem systematischen Gesichtspunkte aus betrachtet, weisen nun mit aller Deutlichkeit auf die Gutknecht-Hitzigsche Einteilung in eine a $11 \mathrm{ge-}$ 
m e i n - g l e i c h m ä $\mathrm{B}$ i g e und die k n o t i g e Hyperplasie hin, zwischen deren beiden Gruppen es ja sicherlich viele Ubergänge gibt. Bei den Hunden und Affen handelte es sich mehr um die erste Form, während bei den Ratten mehr die letztere und Übergangsformen vertreten waren. Die von $W$ ölf $l$ e $r$ in seinem System gegebenen feinen Unterschiede zwischen den einzelnen Gruppen konnten wir nicht machen.

Zunächst die Affen. Wir konnten bei diesen Tieren keine eigentlichen Knoten nachweisen, sondern die Hypertrophie war wie sie sich makroskopisch ausdrückte eine allgemeine diffuse.

Im Gegensatz zu dem normalen Kontrolltier und dem mit erhitztem Wasser gefütterten Tieren 6 und 7 zeigten sich bei den Affen 2-5 und teilweise 8, histologische Bilder, die doch im wesentlichen als strumös pathologische Veränderungen gedeutet werden.

Neben der makroskopisch sicher nachweisbaren Zunahme der beidseitigen Lappen zeigte das interacinöse oder interfollikuläre Gewebe das teilweise aus soliden Zellsträngen oder Follikeln eine Ausbreitung, wie sie bei keinem der Kontrolitiere beobachtet werden konnte. Bei unsern normalen Befunden war das solide Gewebe im großen ganzen überhaupt völlig zurücktretend, und nur ein reines, schönes, follikuläres Gewebe zeigte sich vorhanden. Der follikuläre Bau war bei den Versuchstieren gegenüber dem soliden indifferenzierten Gewebe zurücktretend. Das können nun keine embryonal angelegten Haufen im Sinne Wölflers gewesen sein, sondern dabei handelte es sich sicher um ein gewuchertes Gewebe, das über seine Grenzen hinaus zwischen den Follikeln gewachsen war, wie dies Bilder beweisen.

Zudem fand sich dieses undifferenzierte Gewebe am Rande ganz zurücktretend, während es am ausgebreitetsten in den zentralen Partien vorkam. Auch dies würde nicht zu der $W \ddot{~ o ̈ ~} l f l$ e r schen Anschauung passen, daß das genetisch jüngste Gewebe. sich an der Peripherie der Lappen vorfinde. Das bindegewebige Stroma war nur in mäßiger Intensität vorhanden, und der lobuläre Bau zeigte sich ziemlich verwischt gegenüber den Befunden beim normalen Kontrolltier.

Das alveoläre Gewebe zeigte sich dem normalen gegenüber, schon dadurch unterschieden, daß die einzelnen Follikel nicht waben- oder pfahlbauförmig nebeneinander sich angeordnet fanden, 
sondern daß sie sehr oft vereinzelt von soliden Gewebe umgeben waren.

Die Form der Follikel konnte, wie auch ihre Größe, eine sehr wechselnde sein. Neben schön runden und ovalen Follikeln fanden sich solche mit unregelmäßigen Umrissen. Bis zu den schlauchförmig angelegten Gebilden konnten alle möglichen Übergangsformen konstatiert werden. Schlauchförmige Bildungen, wie sie den $\mathrm{Hitzig-Michaudschen} \mathrm{Bildern} \mathrm{allgemein} \mathrm{ent-}$ sprachen, konnten in wechselnder Intensität nachgewiesen werden.

Am zahlreichsten fanden sie sich bei Affe 4 vertreten, bei dem sie durch ihre intensive Färbung hervortraten, ein Zeichen, wie es schon von $\mathrm{Hitzig}$ als diagnostisch angegeben worden ist. Bei Affe 3 zeigten sie sich auch noch relativ zahlreich vorhanden, und durch intensive Färbung in die Augen springend, während bei 2 und 6 die Schläuche nicht so zahlreich vorhanden waren, und auch keine besondere Färbungsintensität aufwiesen.

An diesen schlauchförmigen Gebilden fanden sich so ziemlich alle Merkmale wie wir sie oben nach der $\mathrm{Mich}$ a u dschen Zusammenstellung gegeben haben. Ihre Größe wie ihre Form, was uns jedoch von nicht gerade wesentlichem Bedeutung erscheint, war eine stark variierende. Wichtiger erscheint uns der Punkt, daß ihr Epithel durchweg und vorzugsweise ein rein zylindrisches war. Wohl kann hier und da eine Wand des Schlauches aus kubischem Epithel bestehen, es ist dies auch von $\mathrm{H}$ i t z ig beobachtet worden, im allgemeinen war das Epithel stets stark zylindrischer Natur. Sowohl in der Drüse des Kontrolltieres, als auch im normalfollikulären Gewebe war das Epithel kubischen, wenn nicht platten Baues.

Auch die Anlage, wie der Bau der Zellkerne, zeigte sich in für die $\mathrm{H}$ itzig- $\mathrm{M}$ i c h a u d schen Bilder typischer Weise vorhanden. Die Zellkerne waren in den Zylinderzellen basal gelegen, in sehr reichlicher Anzahl vorhanden, so daß sie sich fast berührten oder lumenwärts vorpreßten. Die Form der Kerne war meist rund bläschenförmig. Chromatinkörner konnten wenige, hingegen meist je nach der Färbung mehr oder minder zahlreiche Kernkörperchen nachgewiesen werden. Eine Kernmembran war meist stets vorhanden. Die Kernfärbung war oft sehr intensiv vorhanden.

Neben diesen schön gebauten Kernen fanden sich aller- 
dings nur vereinzelt sehr dunkel gefärbte ,,Schaltkerne" vorhanden, die an ihrer unregelmäßigen Konfiguration zu erkennen waren. Im allgemeinen entfiel wie bei Affe 4 , ein Schalt auf IO-I2 runde Kerne.

Die Epithelschicht der follikulären Bildungen konnte sehr häufig, was uns nicht unwesentlich erscheint, von den umgebenden soliden Zellpartien nicht abgetrennt werden, sondern ging direkt in diese über.

Bei allen Versuchstieren fanden sich da und dort, mehr oder weniger zahlreich papilläre Exkreszenzen, sowohl in den Follikellumina, als auch hauptsächlich in den schlauchförmigen Gebilden vertreten. Daß es sich dabei nicht um normale Verhältnisse handelt, wie $z$. B. noch Wölfle r annimmt, glauben wir annehmen zu müssen. Denn in unsern Kontrollversuchen fehlten diese Exkreszenzen fast vollständig. Wir glauben es dabei mitWucherungen pathologischer Natur zu tun zu haben. Diese Papillen waren meist auf einer ganzen Serie von Schnitten zu treffen gewesen, sie konnten schmal oder breitstielig dem Epithelrande aufsitzen. Sozusagen stets trugen sie einen schönen Epithelsaum, der dem Gebilde entsprach in dem sie saßen. Stroma war in ihrem Innern meist keines vorhanden, sondern das Innere bestand aus Zellen. Einzelne Papillen mußten direkt als Einstülpungen des Epithelsaums bezeichnet werden, oder die Papillen waren so schmal, daß sie als Septen betrachtet werden mußten.

Sicher ist, daß diese Papillen aus dem Epithel selbst im Sinne $\mathrm{H}$ itzigs entstanden sind und sich nicht mit den exogenen Vegetationen von $W$ ölf le r identifizieren laßen, die wir bei der Hundestruma allerdings gefunden haben.

In den normalen Follikeln zeigt sich der Follikelinhalt vorhanden und schön hochrot gefärbt, in den schlauchförmigen Gebilden und den mehr unregelmäßig gebauten Bläschen fand sich ziemlich häufig ein spezieller Follikelinhalt fehlend, oder dessen Färbung war eine sehr geringe, manchmal zeigte sich nur die zentrale Partie gefärbt.

Der k n ot ige n Hyperplasie im Sinne H itzig s gehören nun zum großen Teile die Strumen der Tierversuche mit Ratten an.

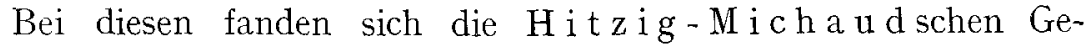
bilde unzweifelhaft scharf und deutlich hervortretend. Speziell die 
mit Aarauer Wasser erzeugten Strumen zeigten dies deutlich, teilweise schon makroskopisch, wie bei Ratte $\mathbf{I}, 2,3$ und I4, während 5 und 5 a nur histologisch die $\mathrm{H}$ it $\mathrm{z}$ i g - M i c h a u d schen Bläschen erkennen ließen, während 6 ein interesssantes Übergangsbild zu den degenerierten Strumen der Rupperswiler Ratten dar. stellt. Auch bei einzelnen dieser Versuchstiere, so bei Ratte 7, konnte deutlich ein Knötchen konstatiert werden. Diese Knötchen waren regelmäßig durch ihre intensive Blaufärbung vor dem übrigen Gewebe hervortretend.

Wie bei den Affen konnte bei den Ratten im allgemeinen auch eine wesentliche Zunahme des soliden und teilweise undifferenzierten, interacinösen Gewebes konstatiert werden. Diese soliden Partien zeigten sich weit über den ganzen Schnitt zerstreut, kamen am intensivsten jedoch in den zentralen Partien der beidseitigen Lappen vor. Solide Follikel waren vorhanden, doch nicht von besonderer Ausbreitung, die mehr strangartigen, undifferenzierten Partien zeigten sich vorherrschend. Rein follikuläre Partien, die völlig einem normalen Aufbau entsprachen, konnten auch in den strumösen Partien nachgewiesen werden, zeigten im allgemeinen, daß ein Inhalt der Follikel fehlte, oder wenn er vorhanden war, derselbe eine sehr blasse Färbung aufwies.

Das größte Interesse erweckten für uns die sicher vorhandenen, so typischen $\mathrm{Hit} \mathrm{z}$ ig - M i cha u d Bilder, die in allen Stadien sich fanden. So fanden sich diese Schläuche von 8 an der Zahl wie bei Ratte 3, bis zu den 20-40 bei Ratte I, 2 und I4. Die Schläuche waren stets zirkumskript angeordnet und traten durch ihre intensive Färbung, gegenüber den andern Partien hervor. Neben diesen größern Schlauchkomplexen konnten auch regelmäßig einzeln dastehende Bildungen in den verschiedenen Partien der Lappen nachgewiesen werden. Diese aus Schläuchen bestehenden Knötchen fanden sich regelmäBig auf einer ganzen Serie von Schnitten, und konnte dabei der wechselnde Bau der Lumina konstatiert werden.

Diese Schläuche trugen durchweg die für sie typischen Merkmale. Ihre Längen- wie ihre Breitendimensionen waren sehr wechselnd. Die Länge kann durchschnittlich bis zu roo $\mu$, die Breite bis $40, \mu$ betragen. Bei Ratte 7 fand sich ein auch diese Dimensionen bei weitem überschreitender sehr langer Schlauch.

Ebenso wie ihre Größe war ihre Form stark variierend. Lange 
schmale, fast gerade Schläuche mit einem spaltförmigen Lumen wechselten $\mathrm{ab}$ mit den kompliziertesten gewundenen Gebilden, welche sich verzweigen, verästeln und weithin lange Fortsätze senden. Daneben waren zahlreiche Übergangsformen vorhanden, die schon eine bläschenartige mehr rundliche Form angenommen hatten, deren Lumen jedoch auch noch einen sehr unregelmäßigen Aufbau aufwies, wie z. B. bei Tier 5, 6. Der Inhalt dieser Schläuche war wechselnd vorhanden, oder fehlte, in seiner Färbung konnte er ebenfalls wechseln, meist jedoch war er sehr blaß.

Die entscheidende Bedeutung kommt jedenfalls den Epithelien in diesen Bildungen zu, und hierbei ergaben sich zwischen den normalen Partien, bei den Kontrolltieren und bei den pathologischen Geweben, wie bei den Schläuchen und Bläschen tiefgreifende Unterschiede. Während das Follikelepithel normalerweise stets ein kubisches oder Plattenepithel war, so war in diesen differenten Partien die Epithelhöhe stets doppelt so hoch als breit. Wohl konnte es hier und da platt werden, dann konnten jedoch stets Kompressionserscheinungen wie bei Ratte I und 7 sicher aufgefunden werden.

Auch in den Bläschen, welche keine Schlauchform mehr hatten, fand sich dieses hohe Epithel, welches manchmal schon bei schwacher Vergrößerung nachgewiesen werden konnte. Die Konturierung des Epithels war wechselnd, scharf oder mehr undeutlich, letzteres hauptsächlich an dem gegen das Lumen zu gelegenem Rande. Der Zellleib zeigte eine intensive Färbung und häufig ein fädiges Gerüstwerk. Wie bei den Affen, jedoch hier vorzugsweise und fast regelmäßig, bestand die Epithelwand der Schläuche, meistens auch der Bläschen, aus einem mehrschichtigen Zellmantel. Auch bei den großen, schon mehr cystenähnlichen Hohlräumen, wie bei Ratte 7 , kannte eine scharfe Abgrenzung gegen das umgebende Gewebe nicht regelmäßig vorgenommen werden.

Auch die Zellkerne weisen die hervorgehobenen intensiven Unterschiede auf. Die Großzahl derselben hatte eine schöne runde Form und war basal gelegen. Sie waren etwas heller gefärbt als die unregelmäßig geformten in geringerer $Z$ ahl vorhandenen ,,Schaltkerne" (M i ch a u d s Nomenklatur). Demgemäß konnten bei den runden Formen die Nukleoli sehr deutlich und in größerer Anzahl konstatiert werden, als bei den dunkler gefärbten Schaltkernen. 
Die Zahl der runden Kerne war eine sehr reichliche, so daß die Kerne sich häufig berührten, oder nur einen geringen Abstand voneinander zeigten. Sie konnten so zahlreich werden, daß sie sich direkt lumenwärts vordrängten. Die Schaltkerne waren in wesentlich geringerer Anzahl vorhanden, und konnten hier und da auch in den soliden Partien konstatiert werden.

Auffallend zahlreich fanden sich in den Bläschen, aber auch in den schlauchförmigen Partien papilläre Erhebungen des Wandepithels vorhanden. Am ausgesprochendsten finden sich diese Papillen in einem großen Hohlraum bei Fig. I9 von Ratte I vertreten. Diese Papillen bildeten, wie Fig. 24 schematisch dartut, ein sehr zellreiches Gebilde, das stets einen Mantel von einem einschichtigen Epithelbelag trug. Die Papillen konnten sich verzweigen, und die Enden der Zweige wurden dabei bläschenförmig, so daß darin ein deutlicher Follikel nachgewiesen werden konnte. Hier und da fand sich, daß einzelne Papillenäste zusammenstießen, und auf diese Weise ein neues Lumen bildeten. Papillenähnliche Wandvorsprünge zeigten die schlauchförmigen Gebilde, die einfach aus zwei Epithelschichten bestanden, die von der Wand ausgestülpt sich aneinander legten. Diese Septen, die in verschiedener Größe, Länge und Anzahl gefunden werden konnten, wiesen deutlich darauf hin, daß der von $\mathrm{Mich}$ a u d beschriebene zweite Modus der Bläschenbildung bei den Ratten der häufigere ist. Die Schläuche werden durch Quersepta zu perlschnurförmig angeordneten Bläschen abgetrennt. Den ersten Modus, die Entstehung der Sprossung aus der Zellwand, konnten wir nicht beobachten.

Wie bei allen Anfängen der jüngern Strumen fand sich das bindegewebige Stroma nur sehr schwach vertreten, und zeigte sehr schmale und dünne Streifen in seiner Anordnung.

Schwieriger war für uns die Deutung der Bilder von Ratte $6,8,9$, II, I2, I3 und I4. Neben den leicht verstehbaren Bildern schlauchförmiger Gestalt zeigte das Gewebe, und zwar zum überwiegenden Teil, einen ganz merkwürdigen Aufbau. Die Größenzunahme dieser Drüsen war mehr eine allgemeine, diffuse. Dabei zeigten die Epithelbelege, wie auch die Kerne, eine Formveränderung, die nur als degenerierte Prozesse aufgefaßt werden konnten.

Die Epithelien bildeten keinen Wandbelag mehr, die Form der Follikel war nicht mehr rund oder oval regelmäßig, sondern 
verzerrt. Der Zusammenhang der einzelnen Epithelzellen untereinander war gelockert. Zwischen den einzelnen Zellen konnten Zwischenräume bestehen, die bis zu einer völligen Lösung des Epithelverbandes führte. Dabei lagen Stücke der Epithelwand und einzelne Epithelzellen von einer sogenannten Follikelmembran gelöst mitten im Follikellumen drin, Aber auch der Zelleib der einzelnen Epithelien nahm an dieser Lockerung teil. Er wurde ausgefasert, gelöst, Kerne und Leib konnten sich trennen, so daß im Lumen vereinzelte Kerne und kernlose Zellen sich fanden.

Aber auch die Kerne selbst zeigten wesentliche Veränderungen neben normalen, großen runden Kernen fanden sich sehr reichlich, je nach dem Grade den die Degeneration erreicht hatte, wesentlich kleinere Kerne, (kaum I $\mu$ Durchmesser) die nicht mehr eine runde Gestalt hatten, sondern mehr verklumpter, unregelmäßiger Natur waren. Diese Kerne waren ohne scharfe Membran, mit gekerbtem Rande, sehr dunkel gefärbt, ohne daß ein feiner Kernbau, z. B. Nukleolen, in ihnen hätte unterschieden werden können. Sie konnten in größern Anhäufungen sehr zahlreich vorkommen.

Als Zwischenstufe zwischen diesen mißgestalteten und den normalen runden Kernen, möchten wir diejenigen Kerngebilde aufgefaßt wissen, die wie bei Tier Io, als sogenannte halbmondförmige Kerne beobachtet wurden, bei denen ein halbmondförmiger Teil des Kernleibes eine sehr intensive Färbung trug (Fig. 27).

Je nach der stärkeren oder geringeren Ausbreitung dieser degenerierten Zellpartien zeigte das übrige Gewebe, welches aus etwas seltener vorkommenden $\mathrm{H}$ i t z i g - $\mathrm{M}$ i c h a u d schen Schläuchen, aus einem soliden indifferenzierten Gewebe oder reinen Follikeln bestand, eine mehr oder weniger intensive Ausbildung. Der feinere histologische Aufbau war dabei derselbe, wie wir ihn für Ratte I-7 beobachtet haben.

In die Augen springend war in allen Bildern stets der gelockerte Aufbau einzelner Gewebspartien. Wir glaubten zuerst, daß es sich dabei um Kunstprodukte handelte, als sich aber auf allen Schnitten dieselben Bilder und bei den verschiedensten Tieren wiederholten, da mußten wir uns überzeugen, da $B$ es sich dabei um pathologische Prozesse handelte. In all diesen Drüsen zeigte sich eine ausgesprochene Kolloidarmut. Nur in einzelnen, 
normal aussehenden Follikeln, konnte ein kolloidaler Inhalt nachgewiesen werden. In all den degenerierten Bläschen und Follikeln fehlte er vollständig, auch dies war ein auffallendes Verhalten. Das Stroma war stets nur in mäßiger Weise vertreten.

Wir glauben nun annehmen zu dürfen, daß es sich bei diesen degenerierten Drüsenpartien um ähnliche Vorgänge handelt, wie sie von $\mathrm{S}$ oph i e G etzowa u. a. für die menschliche Schilddrüse von Kretinen beschrieben worden sind.

Die wichtigsten Punkte, welche Get $\mathrm{z}$ o w a bei ihren Degenerationen als typisch beobachtete, treffen nun auch bei den von uns experimentell erzeugten Rattenstrumen zu. Als ersten Punkt wird von der Autorin hervorgehoben, daß das Kolloid in den meisten Bläschen fehle. Das Kolloid zeigte sich in den Lumina der degenerierten Follikel bei unsern Versuchsratten ebenfalls vollständig fehlend, während es in Follikeln der Kontrolltiere in durchaus guter Weise deutlich zu beobachten war.

Als zweiten Punkt weist Getzow a darauf hin, daß die Läppchen und Bläschen klein seien, auch in diesem Punkte zeigten sich bei unsern Bildern, dieselben Verhältnisse. Eine Verbreiterung des Stromas war bei unseren Strumen nicht nachzuweisen, dagegen konnte bei den Follikeln, besonders bei denen der Epithelbelag eine Auflockerung erfahren hatte eine deutliche Membrana propria, als intensiv gefärbte, scharf konturierte Linie nachgewiesen werden. Auch dieser der 3. Ge t $\mathrm{z}$ ow a sche Punkt würde zum großen Teile stimmen.

Auf die in den Läppchen eintretende lipomatöse Umwandlung, wie sie die Autorin beobachtet hat, haben wir unser Augenmerk nicht gewendet.

Die Ubereinstimmung mit dem 5. und 6. Ge t $\mathrm{z}$ ow a schen Punkte scheinen uns von wesentlicher und entscheidender Bedeutung zu sein. Daß das Epithel im höchsten Grade degeneriert war, haben wir zeigen können. Streifenweise war es losgelöst, die Zellgrenzen waren verschwommen, die Kerne fehlten. Der gegen das Lumen zu gelegene Rand war aufgezackt, die Epithelien zeigten Fortsätze und Ausläufer. Das Protoplasma war netzartig. Zell- und Kerntrümmer fanden sich recht häufig in der Mitte des Lumens oder waren voneinander getrennt.

Aber auch dieselben Kerndegenerationen, wie sie G e $t z$ o w a 
beschreibt, konnten beobachtet werden. Aufgequollene Kerne fanden sich nicht gerade in reichlicher Anzahl vorhanden, dagegen die kleinen geschrumpften und gerunzelten Kerne. Diese dunklen Kerne waren so intensiv gefärbt, daß keine Nukleoli und Chromatinkörner mehr unterschieden werden konnten, oder daß nur eine zirkumskripte halbmondförmige Partie des Randes hell geblieben war. Die feinen Unterschiede im Chromatinaufbau konnten nicht gemacht werden, da wir daraufhin keine speziellen Färbungsmethoden angewandt haben. Immerhin war der Kernaufbau in den von uns beobachteten Kernen so mannigfach, daß sicher auch diese feineren Unterschiede nachgewiesen werden können. Die von de C o u lon beobachteten Kerne, mit einer wechselnden, eckigen und zackigen Form, das letzte Stadium der Degeneration nach $\mathrm{G}$ e t $\mathrm{z}$ o w a waren sicher vorhanden.

Jedenfalls bieten die mit dem sehr starken strumigenen Rupperswiler Wasser erzeugten Strumen sehr viele Ähnlichkeit mit den Befunden der degenerierten Kretinenstrumen, wie sie von Getzow a beschrieben worden sind. Und diese Tatsache scheint uns, besonders wenn sie sich noch an einer größeren Reihe noch sicherer nachweisen ließe, von größter Wichtigkeit zu sein.

Denn die Träger dieser Strumen, die betreffenden Tiere, zeigten weder in ihrem äußern Aussehen, noch ihrem Verhalten, und was beweisend ist, auch radiographisch, keine Anzeichen dar, die auf Kretinismus schließen ließen. Die Degeneration der Schilddrüse könnte demnach nicht als Ursache des Kretinismus angesprochen werden, eine Anschauung die wir schon anderweitig verfochten und bewiesen haben. Wir stellen uns den Prozeß so vor. Die Einwirkung der strumigenen Noxe kann Kropf erzeugen, je intensiver diese Einwirkung wird, um so mehr wird die Schilddrüse davon ergriffen, sie wird dabei aber nicht nur strumös, sondern durch die sehr intensive Einwirkung kann sie zur Degeneration gebracht werden. Ist diese Einwirkung aber sehr stark, so kann neben der Beeinflussung der Schilddrüse, auch noch speziell im jugendlichen Alter, das Knochenwachstum und das Gehirn in einem nachteiligen Sinne beeinflußt werden $\mathbf{1}$ ). Dieser letztere Vor-

I) Auch das Herz, siehe Anmerkung oben, betreffs der Ätiologie des Kretinismus. 
gang läuft der Strumabildung und Schilddrüsendegeneration paralle1, beide stehen daher nicht in einem kausalen $\mathrm{Zu}$ sammenhange, sie dürfen nicht ätiologisch, nach dem sehr oft zu. falschen, post hoc ergo proptec hoc zusammengebracht werden.

Es ist selbstverständlich, daß bei den Kretinen, bei denen die intensive Wirkung der Noxe angenommen werden muB, dieser intensive Einfluß sich in einer Degeneration der Schilddrüse bemerkbar macht. Trotzdem kann in den Kretinenschilddrüsen, wie E p p i n g e r - S c h o l z, d e C o u lo n , H. B i r cher - und auch aus den Untersuchungen von Getzow a geht es ehrvor, wie wir beobachtet haben - noch normales Schilddrüsengewebe nachgewiesen werden. So fand sich auch bei unseren Ratten normales Gewebe neben dem degenerierten vorhanden, - und wenn die Tiere nicht kretinös geworden sind, so beweist dies noch nichts gegen unsere Anschauung, indem es jedenfalls schwer ist, experimentell Kretine $\mathrm{zu}$ erzeugen, da Anlage und Disposition mitwirken, und sicher eine sehr lange Einwirkung der kretinogenen Noxe notwendig ist. In zwei Beobachtungen, Ratte 6 und Hund 5, scheint allerdings eine Beeinflussung in diesem Sinne gelungen zu sein.

In bezug auf die Hundeschilddrüsen und deren strumöse Entartung sind wir speziell durch die Arbeiten von $\mathrm{Zie}$ linska, unter Langhans ausgefürt, orientiert.

Unter den normalen Hundeschilddrüsen konnte sie 4 Gruppen unterscheiden.

Zur ersten Gruppe gehören diejenigen Drüsen, bei denen zahlreiche hohle oder solide Follikel vorhanden sind. Das Epithel ist kubischer Natur. Bläschen sind nur sehr wenige vorhanden.

In der zweiten Gruppe sind ebenfalls noch zahlreiche kleine solide oder hohle Follikel vorhanden, daneben finden sich jedoch große Follikel mit einem hohen zylindrischen Epithel, deren Lumen schmal, unregelmäßig und verästelt werden kann.

In die dritte Gruppe reiht sie diejenigen Drüsen ein, bei denen kolloidhaltige Blasen ausschließlich oder vorwiegend vorhanden sind. Die Gestalt der Follikel ist wechselnd, hat Ausbuchtungen und papillenförmige Vorsprünge des Stromas. Solide Follikel fehlen. Das Epithel ist kubisch oder abgeplattet.

Zur vierten Gruppe gehört eine Drüse, welche der Kolloid- 
struma gleicht; indem sie aus kolloidhaltigen Follikeln mit verschiedenen Formen und abgeplattetem Epithel besteht.

Schon aus dieser Beschreibung geht hervor, daß der feinere histologische Aufbau der Hundeschilddrüse ein sehr wechselnder ist. Die Befunde bei unsern Kontrollhunden 4 und 6 dürften die Gruppe 3 der von Zie linska aufgestellten Systematik angehören.

In Übereinstimmung mit den Untersuchungen von $\mathrm{Z}$ i e1 i n s k a haben wir ebenfalls konstatieren können, daß die Hundestruma $\mathrm{nicht}$ a us knotige $\mathrm{n} \mathrm{Tumoren} \mathrm{besteht,} \mathrm{sondern}$ eine diffuse Vergrößerung der parnchymatösen Teile darstellt. Die Hundestruma wäre daher der diffusen allgemeinen gleichmäBigen Hypertrophie der Hitzig schen Systematik zuzuweisen. Diese gleichmäBige Hypertrophie fanden wir nicht nur bei unsern Versuchstieren, sondern auch bei den aus unserer Gegend zur Sektion gelangten mit Strumen behafteten Hunden.

Histologisch konnte $Z$ ielinska bei der Hundestruma wechselnde Bilder konstatieren, die sich dem Baue der normalen Hundeschilddrüse anschließen.

Am meisten unsern Befunden scheint das Bild der Struma eines Neufundländerhundes zu entsprechen. Der Bau war lobulär, das Gewebe kernreich. Polyedrische Zellen fanden sich reichlich in dem soliden Gewebe. Zahlreiche kleine runde, solide und hohle Follikel zeigten sich vorhanden. Zylindrische und polyedrische Zellen wechselten darin $a b$. An andern Stellen fanden sich größere Follikel und unregelmäßige Bläschen, ebenfalls schlauchähnliche Bildungen mit einem schmalen Lumen und hohem Epithel. Papilläre und septenartige Bildungen werden dabei auch beschrieben.

Ganz ähnlich sind die Bilder, die wir bei unsern Hundestrumen beobachten konnten: Die unregelmäßig gebauten größern und kleinern Bläschen waren bei den Strumen, im Vergleiche zum Kontrolltier, bei weitem am stärksten vertreten. Daneben fanden sich, ganz diffus angeordnet, schlauchförmige Bildungen. Diese großen Bläschen und Schläuche trugen durchweg ein zylindrisches Epithel mit sehr zahlreichen basal stehenden Kernen. Schaltkerne waren wenig, sozusagen keine vorhanden, eine Tatsache, die schon von $\mathrm{Z}$ i e l i n sk a für die Hundestruma konstatiert wurde. Das Epithel der Schläuche und Bläschen konnte gegen 
das umgebende Gewebe nicht scharf abgegrenzt werden. Dieses solid aussehende Gewebe, teilweise auch aus soliden Follikeln bestehend, konnte nun ebenfalls in sehr starker Ausbreitung vorkommen. Das Bindegewebe war vorhanden, doch nicht allzu stark hervortretend. Die Follikel zeigten ein kubisches Epithel. Sehr stark traten die papillären und septenartigen Bildungen in den größern Lumina hervor. Diese bestanden aus zahlreichen Epithelien und polyedrischen Zellen, hier und da konnte sich in ihnen auch ein Follikel bilden. Die Papillen zeigten da und dort einen engen Zusammenhang mit dem interacinösen Gewebe, welches auf einer Serie von Schnitten nachzuweisen war. Das interacinöse Epithel kann die Wandung durchwuchern. In diesem Falle hätten wir es daher mit einer exoge n e n Vegetation im Sinne von $W$ ölf le r zu tun.

Im Vergleich zu diesen strumösen Bildern war bei den Schnitten der Kontrolltiere der Bau ein wesentlich einfacher. Die Schläuche und Bläschen waren stark zurücktretend, ebenso die soliden Partien. Das Großteil des Bildes wurde von mehr regulär gebauten Follikeln eingenommen, Bläschen und Schläuche kamen vor, aber nur in geringer Anzahl. Der epitheliale Bau war überwiegend kubischer und nicht zylindrischer Natur, papilläre und septenartige Bildungen zeigten sich stark zurücktretend.

Wenn auch bei der diffusen allgemeinen Hyperplasie der Schilddrüse, die parenchymatöse Struma, die feineren histologischen Unterschiede gegenüber der normalen Hundeschilddrüse nicht so tiefgreifend vorhanden waren, so kann doch immerhin in vielen Punkten eine wesentliche Differenz nachgewiesen werden, die es gestattet, von einem pathologischen Vorgang zu sprechen.

Auf Grund dieser Ausführung glauben wir die Berechtigung zu haben, behaupten zu können, daß es auf experim e $\mathrm{n}$ t e 11 e $\mathrm{m}$ Wege gelingt, bei Tieren Kröpfe zu erzeugen. Diese Tatsache werden wir durch weitere Versuche, die noch im Gange sind, noch sicherer begründen und bestätigen können. Durch andere Versuchsanordnungen werden wir instand gesetzt, die über Kropf und Kretinismus noch so zahlreich unentschiedenen Fragen einer gewissen Klärung entgegen zu führen. Wie wir oben ausgeführt, handelt es sich dabei um Versuche mit verschiedenartig filtriertem Wasser, um Versuche mit Aufschwemmung des 
Filterrückstandes. Weiter sind Versuche im Gange, indem kropffreimachendes und kropferzeugendes Wasser durch verschiedene Gesteinsarten durchfiltriert wird, um auf diese Weise der kropferzeugenden Noxe näher zu kommen. Wie wir schon jetzt konstatieren können, scheint es vielleicht zu gelingen, kropferzeugendes Wasser herzustellen, wenn Wasser einer kropffreien Quelle durch Molasseschichten durchgelassen wird, und umgekehrt wird Kropfwasser frei, wenn es in geeigneter Weise durch kropffreie Schichten (Jurakalk) hindurchgelassen wird. Dieser Punkt dürfte von praktisch wichtiger Bedeutung werden. Auch mit Wasser aus der Triasformation werden Versuche ausgeführt ${ }^{1}$ ). Utber alle Resultate dieser neuen Versuchsanordnungen, die wir hier a priori festlegen wollen, soll dann s. $Z$. berichtet werden. Da wir längere Zeiträume gewinnen wollen, kann dies erst in einigen Jahren der Fall sein.

Unsere Befunde weisen mit aller Deutlichkeit und beweisender Kraft darauf hin, daß die kropferzeugende Noxe (nicht ein Organismus) an gewiss geologische Formation gebunden ist, und daß sie daraus durch das Wasser dem Organismus zugeführt wird. Sie weisen aber auch daraufhin, daß Kropf und Kretinismus enge in dem von uns oben beschriebenen Zusammenhang, also verschieden starke pa ra le ll e Folgen, desselben ursächlichen Prozesses stehen.

So reiht sich Glied an Glied zu einer festen Kette. Wohl lange wird es noch dauern, bis der physikalisch-chemische Aufbau der $\mathrm{kr}$ e tin o g e n e n Noxe restlos erkannt wird. Wenn es uns mit unsern Untersuchungen gelungen ist, ein kleines Glied in die groBe Kette zu schmieden, und etwa s für die praktische Bekämpfung der Volkskrankheit getan zu haben, so haben wir damit unsern $Z$ weck erreicht.

Es gereicht uns zum Schlusse zu großem Vergnügen, Herrn Doz. Dr. B i ng in Basel und Dr. B irkhäuser in Bern für die bei der Herstellung der Mikrophotographien gehabte Mühe zu danken.

\section{Literaturverzeichnis.}

I. B i 11 r ot h, Über fötales Drüsengewebe in Schilddrüsengeschwülsten. Müllers Archiv 1853 .

I) Anmerkung bei der Korrektur. Diese haben bis jetzt Neujahr IgIo positive Resultate gezeitigt. 
2. Virch ow, Die krankhaften Geschwülste. Bd. 3 .

3. L ü cke, Die Krankheiten der Schilddrüse Pitha-Billroth. Bd. I. 6. Lieferung.

4. W ölf le r, Über die Entwicklung und den Bau der Schilddrüse. Berlin I880.

5. Derselbe, Über die Entwicklung und den Bau des Kropfes. Berlin 1883.

6. G u t k n e h t, Die Histologie der Struma. Virchows-Archiv, Bd. 99.

7. Hitzig, Beiträge zur Histologie und Histogenese der Struma. Langenbecks Archiv, Bd. 47.

8. Zi elinska, Beiträge zur Kenntnis der normalen und strumösen Schilddrüse des Menschen und des Hundes. Virchows Archiv, Bd. I 36 .

9. M i c h a u d, Die Histogenese der Struma nodosa. Virchows Archiv, Bd. I86.

ı. Get $\mathrm{z}$ ow a, Über die Thyreoidea von Kretinen und Idioten. Virchows Archiv, Bd. I 80 .

I I. d e Coulon, Über Thyreoidea und Hypophysis der Kretinen, sowie über Thyreoidalreste bei Struma nodosa. Virchows Archiv, Bd. I47.

I2. L a $\mathrm{g}$ h a n s, Über die epithelialen Formen der malignen Struma. Virchows Archiv, Bd. 198 .

I3. Th ore 1, Pathologie der Schilddrüse. Ergebnisse von L u barsch und Ostertag. Jahrgang VII, I9O2.

14. A lexander, Das Gehörorgan đer Kretinen. Archiv für Ohrenheilkunde, Bd. 78 .

I 5. v. Eisels berg, Die Krankheiten der Schilddrüse. Deutsche Chirurgie, Lieferung 38.

16. Ew a 1d, Die Erkrankungen der Schilddrüse, Myxödem und Kretinismus. Wien u. Leipzig I909.

I7. Kolle, Über Ziele, Wege und Probleme der Erforschung des endemischen Kropfes. Korrespondenzblatt für schweiz. Ärzte, Nr. I7.

18. B é r a r d, Corps thyroïde, myxoedèmes, Thyreoïdites et Strumites. Goitres. Paris 1908 .

19. Klebs, Studien über dieVerbreitung des Kretinismus in Österreich. Prag 1877 .

20. $\mathrm{Scholz}$, Klinische und anatomische Untersuchungen über den Krretinismus. Berlin I906.

21. K o c he r, Zur Pathologie und Therapie des Kropfes. Deutsche Zeitschrift für Chirurgie. Bd. 34. I 892.

22. H. Bircher, Der endemische Kropf und scine Beziehungen zur Taubstummheit und zum Kretinismus. Basel i 883 .

23. Derselbe, Das Myxödem und die kretinische Degeneration. Volkmanns klinische Vorträge, Nr. 357 .

24. Derselbe, Fortfall und Änderung der Schilddrüsenfunktion als Krankheitsursache. Ergebnisse von Lubarsch und Ostertags. I895 und Igor.

25. E. B ir cher, Zur Pathogenese der kretinischen Degeneration. Med. Klinik, Ig08, Beiheft 6 .

26. Derselbe, Die Entwicklung und der Bau des Kretinenskelletts im Röntgenogramme. Ergänzungsband 21. Fortschritte auf dem Gebiete der Röntgenstrahlen. 